\title{
DESIGN, FABRICATION, AND IMPLEMENTATION OF A SINGLE- CELL CAPTURE CHAMBER FOR A MICROFLUIDIC IMPEDANCE SENSOR
}

\author{
A Thesis \\ presented to \\ the Faculty of California Polytechnic State University, \\ San Luis Obispo
}

\author{
In Partial Fulfillment \\ of the Requirements for the Degree \\ Master of Science in Biomedical Engineering
}

by

Joshua-Jed Doria Fadriquela

June 2009 
(C) 2009

Joshua-Jed D. Fadriquela

ALL RIGHTS RESERVED 


\section{Committee Membership}

TITLE:

Design, Fabrication, and Implementation of a

Single-Cell Capture Chamber for a Microfluidic

Impedance Sensor

AUTHOR: Joshua-Jed Doria Fadriquela

DATE SUBMITTED: $\quad$ June 2009

COMMITTEE CHAIR: Dr. David Clague, Assistant Professor of

Biomedical Engineering

COMMITTEE MEMBER: Dr. Robert Szlavik, Assistant Professor of

Biomedical Engineering

COMMITTEE MEMBER: Dr. Robert Crockett, Director of General

Engineering Program 


\section{Abstract}

Design, Fabrication, and Implementation of a Single-Cell Capture Chamber for a Microfluidic Impedance Sensor

$$
\text { Joshua-Jed D. Fadriquela }
$$

A microfluidic device was created for single-cell capture and analysis using polydimethylsiloxane (PDMS) channels and a glass substrate to develop a microfluidic single-cell impedance sensor for cell diagnostics. The device was fabricated using photolithography to create a master mold which in turn will use soft lithography to create the PDMS components for constant device production. The commercial software, COMSOL ${ }^{\mathrm{TM}}$ Multiphysics, was used to quantify the fluid dynamics in shallow micro-channels.

The device will be able to capture a cell and sequester it long enough to enable measurement of the impedance spectra that can characterize cell. The proposed device will be designed to capture a single cell and permit back-flow to flush out excess cells in the chamber. The device will be designed to use syringe pumps and the syringe-controlled channel will also be used to capture and release the cell to ensure cell control and device reusability. We hypothesize that these characteristics along with other proposed design factors will result in a unique microfluidic cell-capture device that will enable single-cell impedance sensing and characterization.

Keywords Single-cell analysis, BioMEMS, Microfluidics, COMSOL CFD 


\section{Acknowledgements}

I am greatly indebted to my thesis advisor Dr. David Clague for providing me the opportunity to take on this project. The opportunities and support you have provided for me in the past year have not only allowed me to develop myself to become a better student, but also a better person. Thank you for believing in me and allowing me to show leadership within the group. Your character and personality are also a demonstration that accomplished and respected individuals are as energetic and entertaining as their students.

I am also greatly indebted to Prof. Hans Mayer, Dr. Richard Savage, Ryan Rivers, and the Cal Poly Micro Systems Technology group, for providing me with the knowledge and resources for micro-system design and fabrication. I cannot thank you enough for the countless hours you have committed to help me complete this project and allowing me access to your technologies.

I would like to thank Dr. Robert Szlavik and Stephanie Hernandez for continuing the project by taking the design and implementing the critical features of electronics. Your work and dedication will be another milestone to achieve the final goal of the project.

I am also grateful to all my colleagues of the Cal Poly Biofluidics Research Group for allowing collaboration between projects. It was an honor to be seen as a design consultant for your projects and I wish you the best of luck in your respective theses.

I am thankful to the California Central Coast Research Partnership (C3RP) for providing funding necessary for the project. The results of this thesis would not be possible without your continuous support.

I am grateful to Dr. Lanny Griffin and Dr. Robert Crockett, chairs of the Dept. of Biomedical and General Engineering. The organization of the department has allowed me to gain knowledge in engineering and has always welcomed me with open arms.

I would like to express my sincere thanks to Dr. Michael Black and the Biotechnology Lab, who provided the cell cultures for our project. Your collaboration with the College of Engineering and the Biomedical Department will encourage the multi-disciplinary aspects of working together. 


\section{Table of Contents}

\section{Contents}

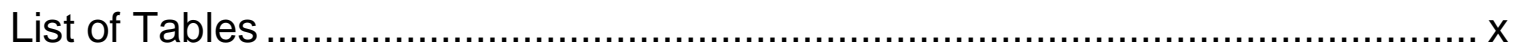

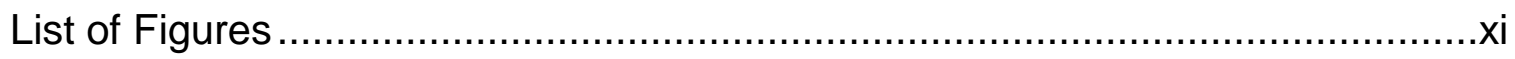

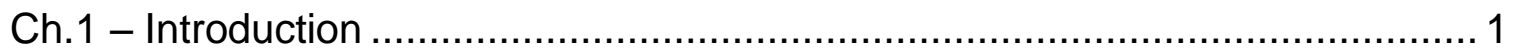

1.1 - The Microfluidic Impedance Sensor ................................................. 1

1.2 - Purpose: A Design for a PDMS Cell-Capture Chamber .......................... 5

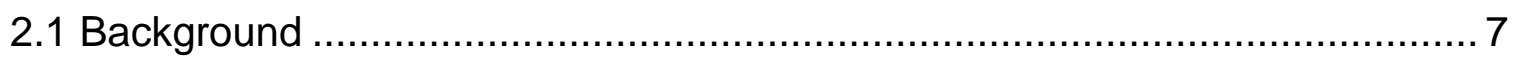

2.1 - MEMS and Microfluidics …....................................................... 7

2.2 - Biological and Biomedical Research with MEMS ............................... 8

2.3 - Microfluidic Design and Microfabrication.......................................... 10

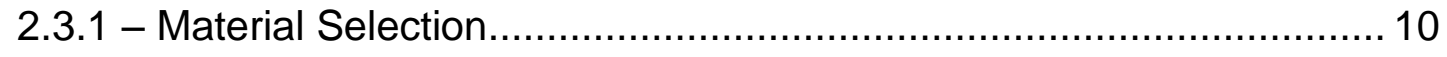

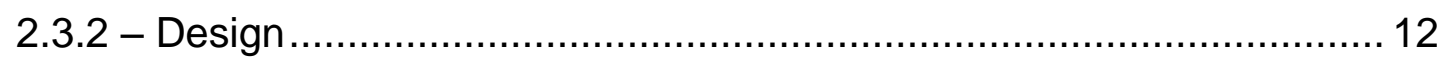

2.3.2a - Performance Objectives ..................................................... 12

2.3.2b - Functional Requirements .................................................. 12

2.3.2c - Design Rules .................................................................... 13

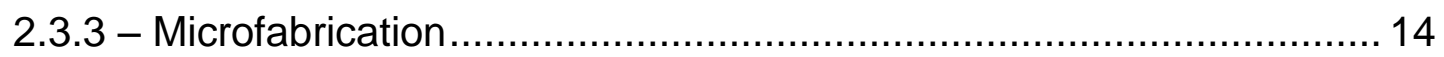

2.4 - Characterizing and Modeling Devices............................................. 19

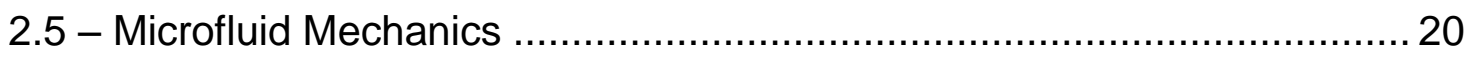

2.6 - The Cellular Impedance and Electric Double Layer .............................2 23

2.7 - Saccharomyces cerevisiae in Biological Studies ................................2 26

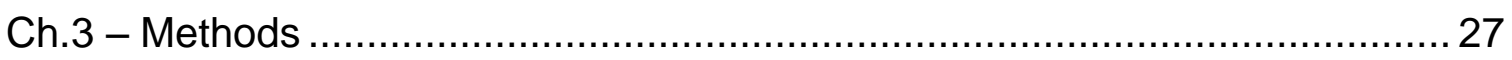


3.1 - Cell and Test Bead Experimentations

3.1.1 - Cell Growth and Harvesting .................................................. 27

3.1.2 - Count Test Dilution and Measurements ...................................... 27

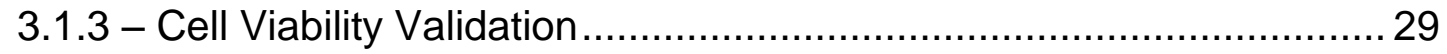

3.1.4 - Comparison and Measurement of Beads and Cells ....................... 29

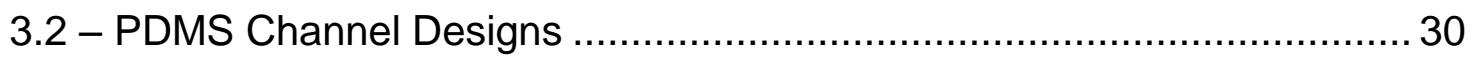

3.2.1 - Design of the PDMS Capture Chamber ......................................... 30

3.2.1a - Generation 1: Flow-through Suction System ........................... 30

3.2.1b - Generation 2: Multi-chamber Capture Prototype....................... 32

3.2.1c - Generation 3: Single-chamber Design ................................... 37

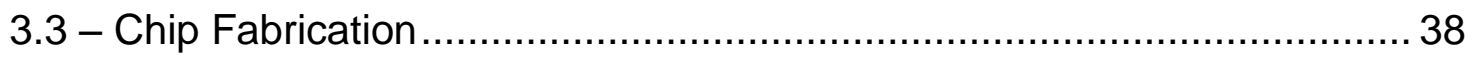

3.3.1 - SU-8 Silicon Wafer Master Mold Fabrication, Photolithography........ 38

3.3.2 - PDMS Preparation and Pouring, Soft Lithography .......................... 42

3.3.3 - Glass Bonding and Alignment ................................................. 43

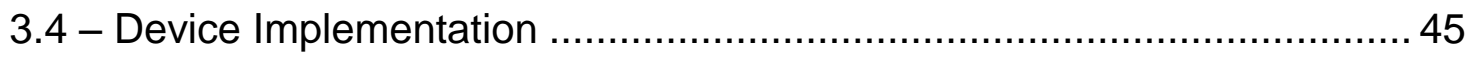

3.4.1 - Development of the Microfluidic Test Station .................................. 45

3.2.2 - Fluid Routing Circuit Package for Syringe Pump Control................. 47

3.2.3 - Breadboard Design for Fluid Fixture Alignment and Control ............. 48

3.4.2 - Computational Fluid Dynamics of Flow through Channels in

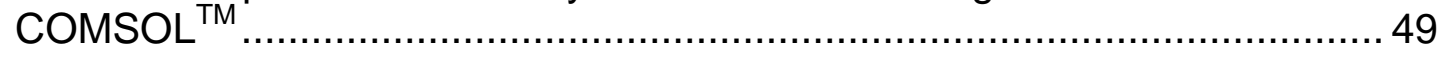

3.4.4 - Imaging and Validation of Bead and Cell Capture ...........................50

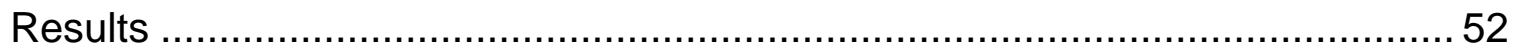

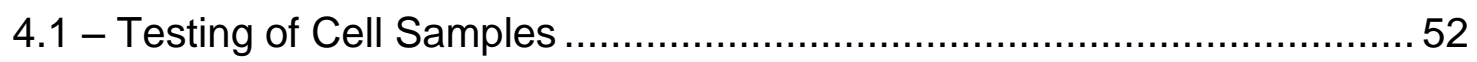

4.1.1 - Statistical Measurement of Mean Cell Diameter ............................. 52 
4.1.2 - Viability through Methylene Blue Stains ...................................... 54

4.1.3 - Dilution of Cells for Device Testing .............................................. 55

4.2 - Fabrication Results of Microfluidic Devices....................................... 57

4.2.1 - Comparisons between the CAD and Mask ................................... 57

4.2.2 - Imaging of Final Device before Testing ....................................... 58

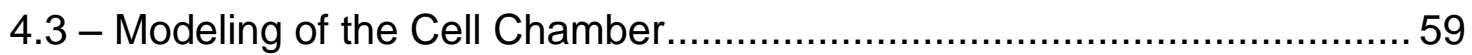

4.3.1 - Velocities and Reynolds numbers for Various Channel Widths ....... 59

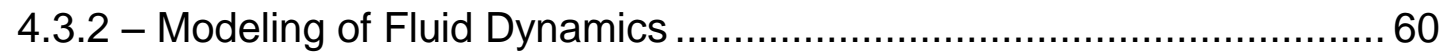

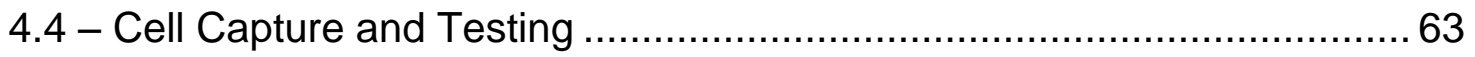

4.4.1 - Fully Integrated and Packaged Chip Assembly............................. 63

4.4.2 - Sample Introduction and Capture Protocol ................................... 64

4.4.3 - Capture of a $10 \mu \mathrm{m}$ Bead and Yeast Cells ..................................... 65

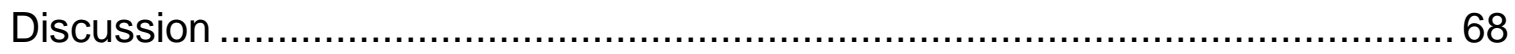

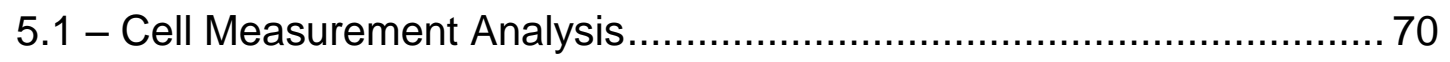

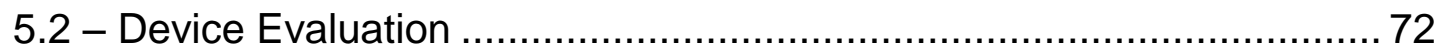

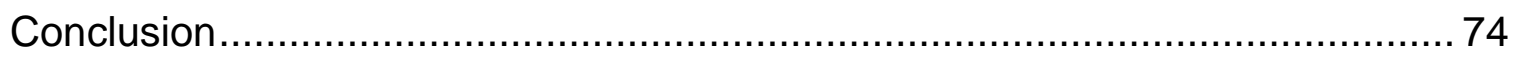

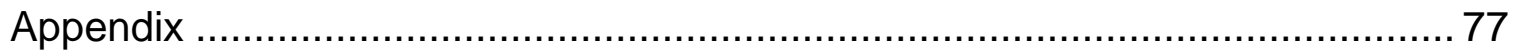

A. Design Rules for Developing Microfluidic PDMS Designs based on the Stanford Microfluidic Foundry criteria......................................................... 77

B. Fabricating an SU-8 Master Mold from a Transparency Mask - (Hans

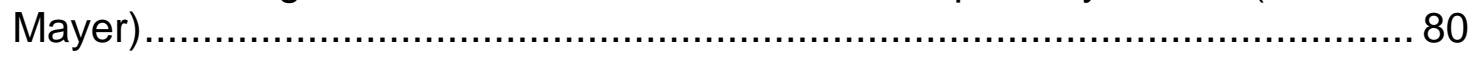

C. Preparation and Processing of PDMS for Device Fabrication.................. 82

D. Assembling a Fluid Circuit using LabSmith MicrofluidicComponents....... 91

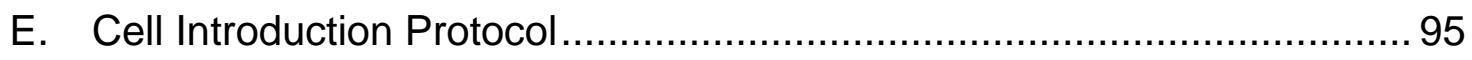




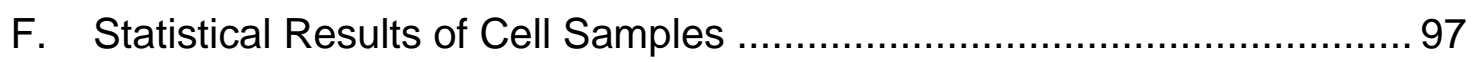

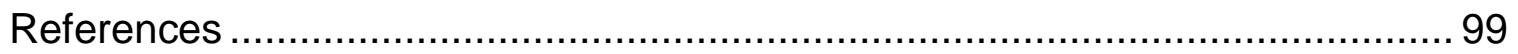




\section{List of Tables}

Table 1 - Reynolds Numbers for Flow Regimes in MEMS Devices [37] ............. 21

Table 2 - Number of Cells per Hemocytometer Grid........................................ 56 


\section{List of Figures}

Figure 1 - Impedance spectroscopy device developed by Cheung et al.

with a schematic and theorteical impedance as a function of time and

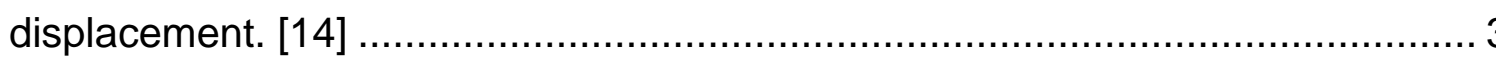

Figure 2 - Cell capture and impedance measurement device designed by

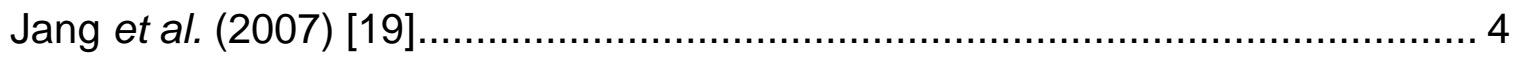

Figure 3 - A system for studying biomarkers (CP Biofluidics, Clague) ................. 9

Figure 4 - Chemical structure of Polydimethylsiloxane ................................... 11

Figure 5 - Scheme for rapid prototyping and replica molding of microfluidic

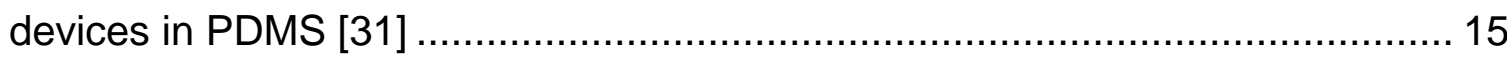

Figure 6 - Cross-sectional view of the Lithography process that

demonstrates the creation of microfluidic channels ........................................ 16

Figure 7 - Fabrication steps involved for Photolithography and Soft

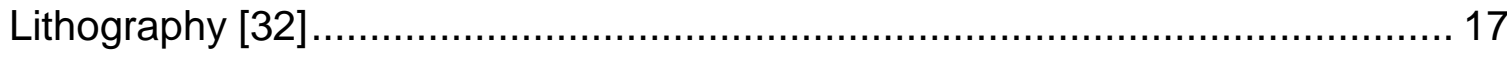

Figure 8 - Contact angle measurement of DI water on a PDMS surface

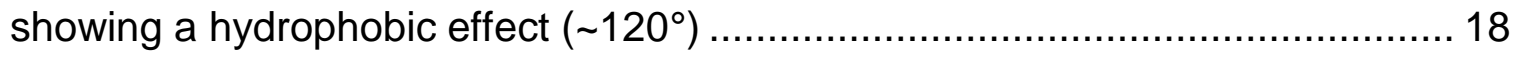

Figure 9 - Sketch for movement of sphere between parallel plane walls.

[38]

Figure 10 - Equivalent circuit of detection electrodes [18] ............................. 24

Figure 11 - Schematic of the Electric Double Layer [38]................................ 25

Figure 12 - Image of yeast cells in a hemocytometer for cell counting (left).

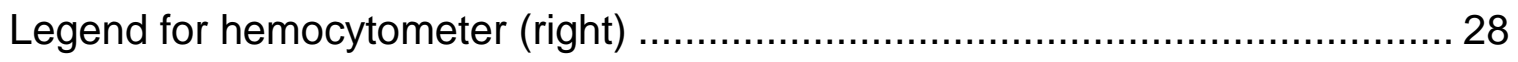




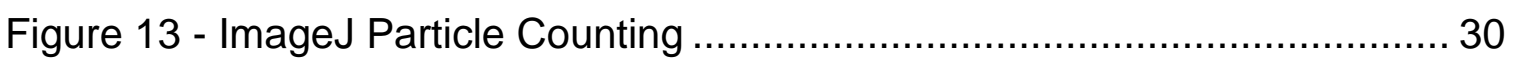

Figure 14 - Conceptual Design of the Gen1 Impedance Sensor ...................... 31

Figure 15 - Solid model of the Gen2 Multichamber Design ............................. 33

Figure 16 - Schematic of the Capture Chamber section of the design (top)

and view of the multiple control chambers (bottom) …................................... 35

Figure 17 - Cross-sectional diagram demonstrating function of multiple

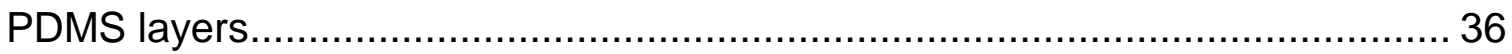

Figure 18 - Solid model of the Gen3 Single-chamber Device.......................... 38

Figure 19 - Negative Transparency Masks of the Gen2 Design (left) and

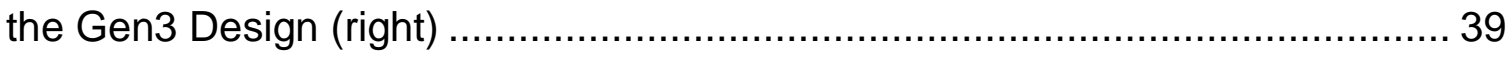

Figure 20 - A spin-coater used at the Cal Poly Microfabrication Lab ................. 40

Figure 21 - The photolithography aligner in the Cal Poly Microfabrication

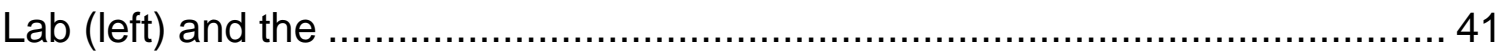

Figure 22 - Aligner Lamp Exposure Energy chart as of Spring 2009 (Dr.

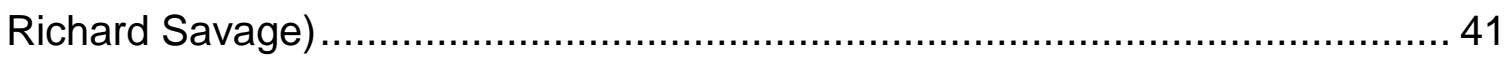

Figure 23 - A PDMS section removed from the master mold after soft

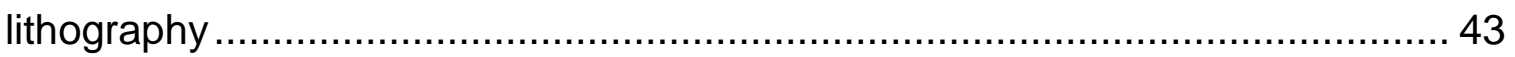

Figure 24 - Plasma-treatment machine at the Cal Poly Microfabrication

Lab

Figure 25 - Model of the Alignment mark on the PDMS surface ...................... 45

Figure 27 - The Microfluidics Test Station analyzing a Device ........................ 46

Figure 28 - Schematic of the Fluid-circuit for pumping and capture................... 47 
Figure 30 - Customized Acrylic Breadboard for mounting Fluid-Circuit fixtures.

Figure 31 - Finite Element Mesh of the Cell Capture Chamber in COMSOL 50

Figure 33 - Image of a Cell Chamber with Flow Directions. 51

Figure 34 - The $0.04 \mathrm{~mm}^{2}$ grid from the hemocytometer for image post-

processing 52

Figure 35 - Isolating Cell Shapes using Threshold Adjustments in ImageJ ........ 53

Figure 36 - Distribution of the Cell Sample displaying Average Diameter ......... 54

Figure 37 - Viability Test using a Methylene Blue staining technique .................55

Figure 38 - An oversaturation of $10 \mu \mathrm{m}$ beads in the capture chamber ............. 57

Figure 39 - Comparisons between: (left) Transparency Mask Features at 20k DPI and (right) CAD dimensions ........................................................ 58

Figure 40 - Empty Microfluidic Device Ready for Testing ............................... 59

Figure 41 - Spreadsheet for calculating velocity and Reynolds Number

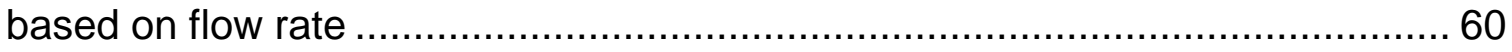

Figure 42 - Two-dimensional laminar flow velocities displaying magnitude of flow near the Chamber 61 Figure 43 - Three-dimensional cross-sectional model showing velocity of side channels and suction effects due to the channel beneath the chamber ...... 62 Figure 44 - Two-dimensional view of the magnitude of pressure within the chamber and arrows dictating the direction of fluid flow 63 Figure 45 - Fully Integrated and Packaged Chip Assembly 64 
Figure 46 - Beads Stacked Atop Chamber during Sample Introduction 65 Figure 47 - Single Bead Isolation Using Flushing Velocities from Side Channels 66

Figure 48 - Yeast Cells inside the capture chamber 67

Figure 50 - a) Small $6 \mu \mathrm{m}$ cells in the chamber; b) same $6 \mu \mathrm{m}$ cell sample in between electrodes 71

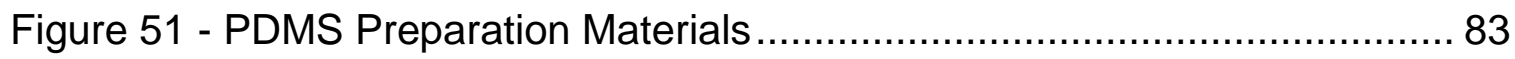

Figure 52 - SU-8 Wafer in an Aluminum Foil Dish for PDMS Pouring ............... 84

Figure 53 - Vacuum Chamber Power Generator ......................................... 86

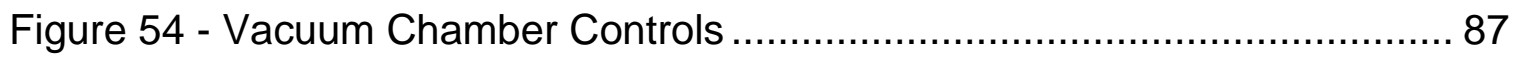

Figure 55 - Degassed Mixing Cup of PDMS in a Vacuum Chamber ................. 88

Figure 56 - Trimmed PDMS-Wafer Mold Prepped for PDMS Pouring ................ 89

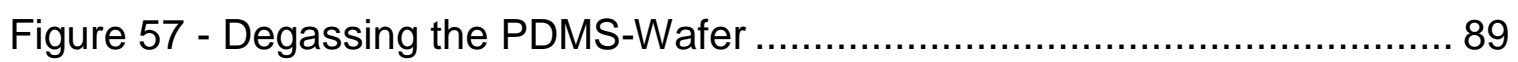




\section{Ch.1 - Introduction}

Many medical breakthroughs throughout the years revealed that much of disease characterization or quantification can be discovered at the cellular and sub-cellular levels. Cell sizes are on the order of one to ten microns in size and current diagnostic tools for disease discovery, with the exception of lateral flow assays (typically bench scale), require precise handling and are not readily accessible. With the advent of MEMS (Micro-Electro-Mechanical Systems) \& BioMEMS (Biological MEMS) technology, it is possible to develop instrumentation to enable cellular and sub-cellular level disease diagnostics.

\section{1 - The Microfluidic Impedance Sensor}

Single-cell analysis is an important tool for characterization of disease at the cellular level as well as its sub-cellular levels. Such a capability would permit numerous experimentations to quantify cell states through diagnostics, manipulations, and detection [1-8]. The emergence of microfluidics in microsystems technology has allowed engineers to create a device that can perform single-cell analysis on chip rather than macroscopically. Using biocompatible materials, Polydimethylsiloxane (PDMS), single-cell analysis can be performed; furthermore, in a microfluidic environment, electric fields can be introduced to measure cellular impedance spectra. The impedance measurement, as a function of frequency, enables one cell to be distinguished from another through quantification of frequency dependent conductivity and permittivity [9-11]. 
Several researchers have developed microfluidic based impedance sensors for flow-through analysis. Micro-features have been introduced to either route or trap cells accordingly which makes these microfluidic systems functional for analysis. Researchers have transitioned microfabrication techniques used in the silicon electronics industry and applied them to their respective microfluidic impedance sensor designs and used tools such as chemical vapor deposition (CVD), also known as sputtering, that can deposit angstrom-thin layers to device surfaces to create excitation and sensing electrodes [12]. However, these devices have two problems; one, the duration of analysis is dependent on the average velocity of the fluid, and two, the target species passes through the excitation/sensing chamber at different positions (heights), yielding different spectra based on location. Other works in microfluidic impedance sensing have described the design and fabrication to create their devices [13-18].

An example of previous work for impedance sensors has been developed by Cheung et al. (2005) for their impedance flow cytometer [14]. A series of electrodes are patterned onto the bottom layer of a flow-through system (cytometer) to detect changes between the electric field between layers through an applied frequency. The study involved flowing cells through the channels and capturing the impedance data so that a spectra can be developed for a series of samples. The study conducted by Cheung et al. (2005), as seen in Figure 1, is an excellent advancement in flow-through microfluidic impedance sensing. While a success for rapid cell assay, it is not the best system configuration for precise cell health assays in disease quantification studies. 

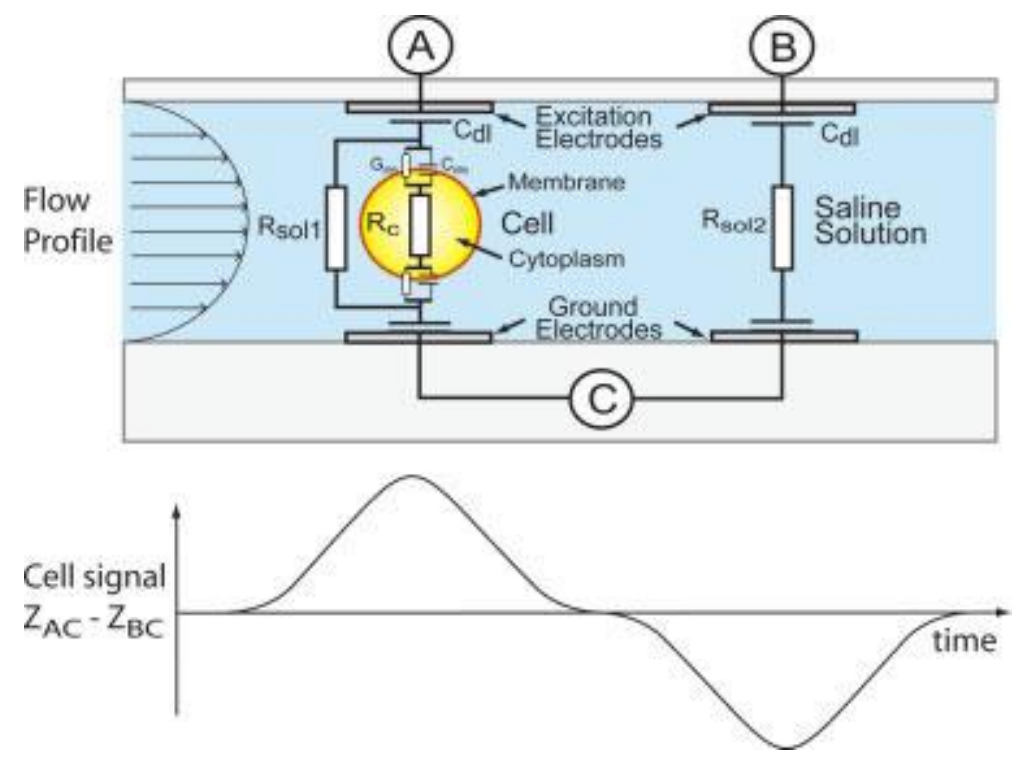

Figure 1 - Impedance spectroscopy device developed by Cheung et al. with a schematic and theorteical impedance as a function of time and displacement. [14]

First, due to the flow-through system, the cell is constantly moving through the channels and only as the cell passes through the electrodes will they sense impedance. This adds a new variable in the data since the impedance graphs produced will also be a function of not only frequency but the position of the cell with respect to the channel height; therefore, the cell position relative to the electrodes. The second difference is related to the flow pattern since the residence time of the solute in the detection region is not sufficient to sweep a desired frequency range, e.g., $10 \mathrm{~Hz}$ to $20 \mathrm{MHz}$.

A second example of a microfluidic impedance sensor is based on a publication from Jang et al. (2007) [19]. The design, also derived from flowthrough systems, allows a cell to flow through a chamber and become trapped by three non-conducting pillars downstream in the device, see Figure 2. The impedance electrodes, arranged to make a $10 \mu \mathrm{m} \times 10 \mu \mathrm{m}$ cavity, are positioned 
directly under the capture chamber and the impedance spectra for a single cell is recorded. They demonstrated the desired spectra successfully.
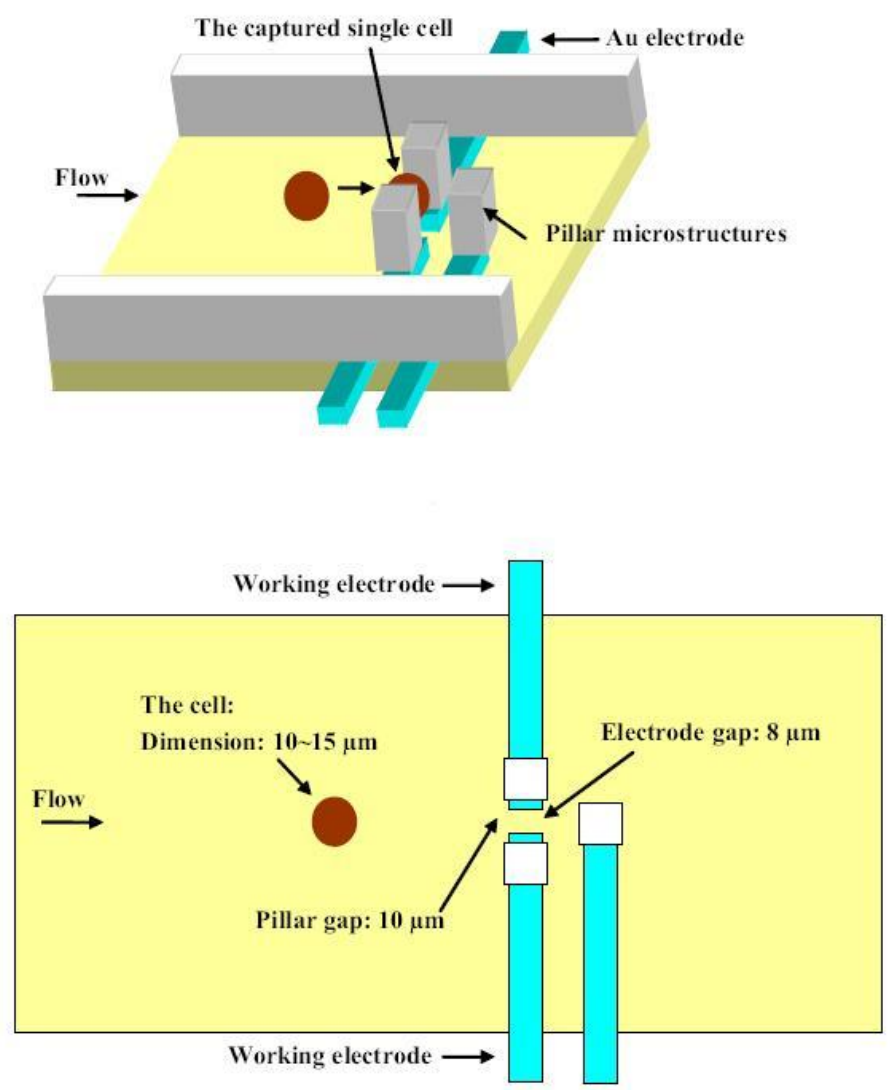

Figure 2 - Cell capture and impedance measurement device designed by Jang et al. (2007) [19]

The design in Figure 2 compared to Cheung et al. (2005) differs in the impedance as a function of position relative to the electrodes and the residence time stated previously; however, the design obviates shortcomings regarding cell capture efficiency. As stated by Jang et al. (2007), "the probability of cell capture is $10 \% "$, and therefore this design does not guarantee cell capture nor capture a specified target. Additionally, the design does not permit an obvious way of 
clearing out a captured cell for device reuse. The only way to remove the cell is to apply a flow in the opposite direction, or to manually remove the cell. Jang et al. (2007) do not mention cleaning and reusability of the device.

We propose to develop a new microfluidic impedance sensor that ensures target species capture, isolation of a single cell, and reuse. The device will be able to capture a cell and sequester it long enough to enable multiple assays including measurement of impedance spectra. The proposed device will also be designed to capture a single cell and permit back-flow to flush out excess cells in the assay chamber. The device will also be designed to use syringe pumps connecting to microchannels. The syringe-controlled channel will be used to capture and release the cell to ensure cell control and device reusability. We hypothesize that these characteristics along with other proposed design factors will result in a unique microfluidic cell-capture device that will enable single-cell impedance sensing and characterization.

\section{2 - Purpose: A Design for a PDMS Cell-Capture Chamber}

The first step in creating a microfluidic impedance sensor is to design and fabricate an actual chamber made from PDMS and to validate the design by capturing test beads and yeast. Since the design is relatively simple and based solely on geometry, the device was hand fabricated at the Cal Poly Microfabrication Clean Room and assembled on campus. The goals for this project is to (1) Design and fabricate the PDMS component of the impedance sensor using Cal Poly facilities, (2) Assemble a microfluidic test station (the MTS) 
for implementation and testing of the device, (3) Demonstrate capture through bench testing, (4) Use the final design for a companion project dealing with electrode fabrication and impedance testing. Using these goals, we fabricated a single-cell analysis chamber made from PDMS to effectively capture yeast cells and to be used as a major component for a microfluidic impedance sensor. 


\subsection{Background}

\section{1 - MEMS and Microfluidics}

Micro-electro-mechanical systems (MEMS) are the technology of small structural tools that range in the order of $10^{-6}$ of a meter, almost comparable to the diameter of a human hair (approximately $150 \mu \mathrm{m}$ or microns). MEMS technologies were derived from the microelectronic industry to develop smallscale chips like the Pentium processor or inkjet cartridges for printers [20]. Using the microfabrication techniques to make small-scale chips and integrated circuits, the field of MEMS has advanced to develop mechanically and electrically-driven tools such as pumps, membranes, sensors, valves, and cantilevers [21]. The small natures of these devices are advantageous because they are portable, implantable, can be rapidly manufactured and mass produced.

Some applications of MEMS devices can also be classified based on their target analyte. For example, developing a MEMS device based solely on using fluid as the working media can be classified as a microfluidic device [22]. Microfluidics deals with the behavior and control of fluids that are constrained in small channels at the micron scale. An advantage to this type of device is the ability to use only small sample volumes for testing (i.e. picoliters, pL); however, due to the increased importance of surface area to volume ratios at these lengthscales, unique physical factors occur when dealing with the microfluidic phenomena. 
Some of these factors include colloidal surface interactions between the microfluidic material (PDMS) or support substrate, e.g. glass, which can either be, for example, hydrophobic or hydrophilic in nature; furthermore, flow regimes for liquids based on Reynolds numbers range from laminar to Stokes flow. Taking factors such as these into account, the device can be designed and fabricated to either take advantage or suppress physical phenomena.

Additionally, microfluidic devices can also incorporate electrical components to aid in the fluid manipulation, e.g. using AC fields generated from electrodes to cause chaotic mixing [23]. An example of this can be seen in electro-osmosis, when electrolyte fluids are pumped under the influence of an applied electric field [24]. Taking these design factors into account, we will look at examples of how these devices are currently used for biologic systems.

\section{2 - Biological and Biomedical Research with MEMS}

Although MEMS technologies began and developed in the chemical, mechanical, and electronic industries, the use of MEMS devices for biological/biomedical applications has emerged as a key technology for the future [25]. This branch in MEMS applications is known as biological microelectromechanical systems (BioMEMS). Simply put, the field of BioMEMS uses MEMS devices for applications in medical and health related technologies and when a collection of devices are put together in a system to perform a complete analysis, two known terms resulted: Lab-On-A-Chip (LOC) and Micro-Total Analysis Systems ( $\mu$ TAS). 
BioMEMS have allowed development of target specific devices that aim to do biological sample preparation, electrophoresis, bio-separations, and/or biomarker identifications [21]. An effort performed by the Cal Poly Biofluidics Research Group under the supervision of Dr. David Clague, is currently being developed to operate such technologies on chip. The devices are part of a continuous system aimed for biomarker detection as seen in Figure 3.

\section{A Continuous Systems}

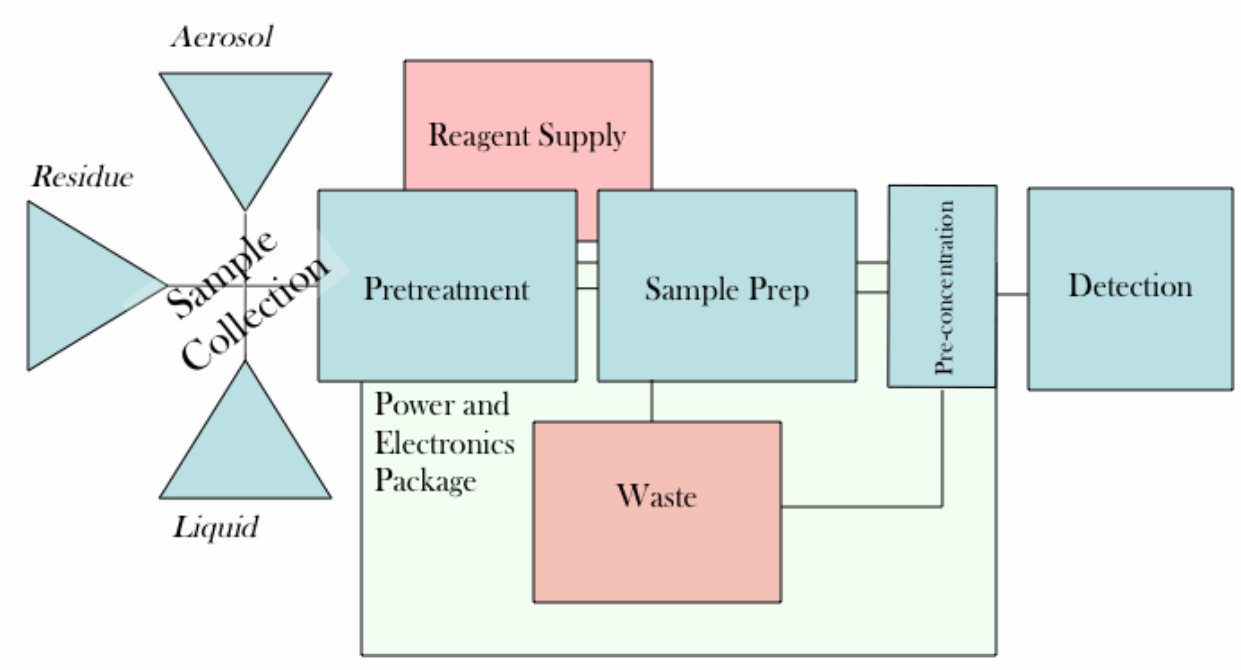

Figure 3 - A system for studying biomarkers (CP Biofluidics, Clague)

There are many advantages of BioMEMS devices when compared to other bench-scale biological lab procedures. The small nature of these microdevices consumes sample volumes in the picoliter range rather than the milliliter $(\mathrm{mL})$ range when compared to clinical samples. This also aids the user and requires little human involvement in many of the pretreatment and processing steps, since those techniques can be designed accordingly within the device [21]. 
This can also lead to consistent results which will benefit in quality and quantity as well as reduce overall cost and time needed to conduct experimentation. The downside is that surfaces can foul causing cross-contamination between samples.

\section{3 - Microfluidic Design and Microfabrication}

Production of a desired microfluidic device requires several key steps: Identification of desired function, development of conceptual designs, CAD drawing of final design, mask production, microfabrication of PDMS molds by soft lithography, bonding PDMS with substrates, and interfacing with support equipment (packaging).

\subsection{1 - Material Selection}

Three key materials for our microfluidic device are glass as a substrate, gold for sensing electrodes, and polydimethlysiloxane (PDMS) for the microfluidic chamber. The common feature between all three materials is biocompatibility which is how an organism responds to a foreign material and how the foreign material responds to the organism [26]. Since our device will constantly interact with biological media, it is important to choose biocompatible materials. Glass and gold are common non-polymer biocompatible materials in medical devices and have been used widely in microfluidics $[12,27]$. The glass substrate also benefits users due to its transparent optical property when doing observations under a microscope. Gold is a common material in microfabrication when building small-scale integrated circuits and has been widely used in the silicon 
electronics industry [12]. Therefore, gold electrodes will be used in our microfluidic device based on their electrical properties.

Polydimethylsiloxane is a silicon-based organic polymer that is actively used in microfluidics. The polymer not only acts as a structural material but offers several key advantages: 1 ) it can be cast against a suitable mold with a sub-0.1 $\mu \mathrm{m}$ fidelity, 2) it can be cured at a low temperature or quickly at a higher temperature, 3) it is permeable, 4) it has a transparent optical property, 5) it can create a covalent bond with itself and a select group of substrates through surface treatment, and 6) it is biocompatible to any cell that comes in contact. Another key feature in microfabrication is that due to its elastomeric properties, it can conform to smooth non-planar surfaces and will not damage a master mold or the PDMS when removed after soft lithography [28]. The chemical structure can be seen in Figure 4.

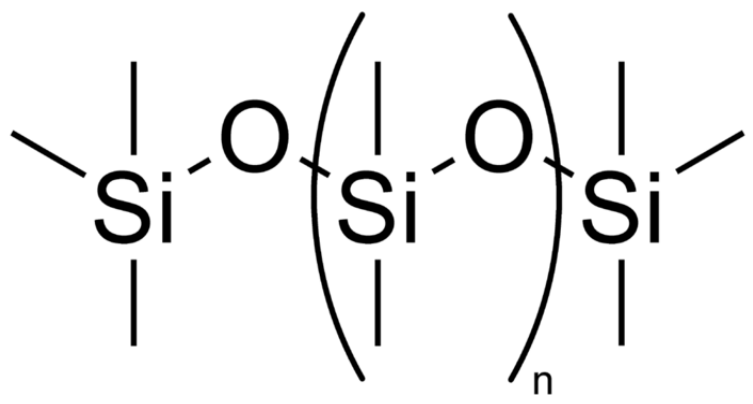

Figure 4 - Chemical structure of Polydimethylsiloxane 


\subsection{2 - Design}

\subsection{2a - Performance Objectives}

The objectives of the design are as follows: 1) allow a biological fluid sample, e.g. blood, to be introduced into the device, 2) allow a number of cells to be sequestered into a PDMS chamber, 3) trap a single cell in a designed chamber using a suction channel, 4) isolate the single cell using a flush channel to push away excess cell stacked atop the chamber, 5) perform single-cell optical and electrical analysis if appropriate, and 6) remove the isolated cell for device reuse.

\subsection{2b - Functional Requirements}

The design must perform and exhibit the following functional requirements: 1) input sample using either three of the injection methods: capillarity, vacuum suction, or mechanically driven through a push syringe pump, 2) allow cells to diffuse into the chamber by creating a hydrophilic environment in the PDMS channels through surface treatment, 3) create a pressure in the suction channel to perform suction to initiate capture using a vacuum or pull syringe pump, 4) create a set of flushing channels limited to laminar flow but with a proper fluid velocity to create a force that removes excess cells stacked atop the chamber, 5) perform an impedance spectra analysis by adding a set of electrodes to create an AC field, 6) use the suction channel and reverse the flow so the cell captured in the chamber is removed to ensure device reusability, 7) the PDMS component must not exceed 2" $\times 3$ " or at least ideal enough to fit either a 1" $\times 3$ " or 2 " $\times 3$ " glass slide, 8) micro-channels must be a minimum of 5 
$\mu \mathrm{m}$ in width, 9) micro-features (excluding channels) must be a minimum of $8 \mu \mathrm{m}$ (length or width), 10) the channel height must match at least $10 \mu \mathrm{m}, 11)$ bored holes in the PDMS must be punched with a 16 gauge needle $(1.651 \mathrm{~mm}$ OD, $1.194 \mathrm{~mm}$ ID) to interface with Tygon tubing, and 12) the minimum height-towidth aspect ratio for micro-channels must be 1:10 to prevent PDMS ceiling collapse.

\subsection{2c - Design Rules}

Microfluidic devices require standard design rules in order for a device to work in a desired fashion [29]. The practitioner must also understand the microfabrication techniques in order to determine what is possible and practical when designing a device. From repeated trial and error and physical understanding, design rules can be developed to guide new users and to prevent failures such as channel collapse and/or bonding failure. One common design rule for PDMS is when a height-to-width aspect ratio limit (1:10) must be followed to ensure that the ceiling of a micro-channel does not collapse to the supporting substrate floor when in subsequent process or in use. Following these rules, listed from the Stanford Microfluidic Foundry in Appendix A, will yield the desired results and can result in multiple uses if followed correctly.

Microfluidic design is the first step in creating a device. The user must understand what the device should do and how it will do it. General rules of design include using a CAD program such as AutoCAD to develop a transparency mask that can produce a master mold needed to create devices. Within this mask contain the device features such as channel lengths, widths, 
hole diameters, and alignment marks. These features are necessary for proper identification, alignment, and orientation of the PDMS block with the substrate. Also, the designer must understand how long, wide, and thick the PDMS block should be in order for it to be bonded to a substrate such as glass.

\subsection{3 - Microfabrication}

Microfabrication is important for a designer so that he/she can achieve the features needed for the device. Key microfabrication capabilities include the use of instruments such as a photolithography mask aligner, metallic sputtering system, and plasma-treatment depositor. Two important procedures for microfabrication, applicable for microfluidics, are photolithography and soft lithography.

Photolithography is the use of an optical image and a photosensitive film to produce a pattern on a substrate. For microfluidics, we developed a master mold that contains structures that represents their respective channel sizes and features. Using a silicon wafer as a substrate, photoresist such as SU-8 is coated on top of the wafer which will represent structures when exposed to UV light. The photoresist can be classified as either a positive or negative resist and are dependent on their sensitivity to UV light. For positive resist, the sections that are exposed to UV light are sections that aim to be removed or etched; a negative resist yields an opposite effect where the exposed sections are features that are meant to be kept while the other unexposed sections are etched away. In microfluidics, the negative photoresist used is an epoxy-based photopolymer

known as SU-8. The silicon wafer substrate coated with SU-8 is placed under a 
transparency mask which was commercially printed and plotted from a CAD file. This mask allows UV light to expose only in certain areas so the exposed structure features will be kept and unexposed SU-8 photoresist will be developed away. A photolithography mask aligner is necessary so that a cross-linking photoresist polymer lying on a silicon wafer will be exposed to the UV light penetrated through the transparency mask [30]. The rapid-prototyping process is visually described in Figure 5. Removal of the uncross-linked photoresist through a process known as wet etching (developing) will yield a wafer with photoresist in the shape of the device channels. The resulting wafer with micron-scale features, known as the "master mold", will allow users to pour PDMS on top of this mold and peel off the hardened PDMS block to be used for a final device. The master mold can then be used multiple times to create more PDMS devices.

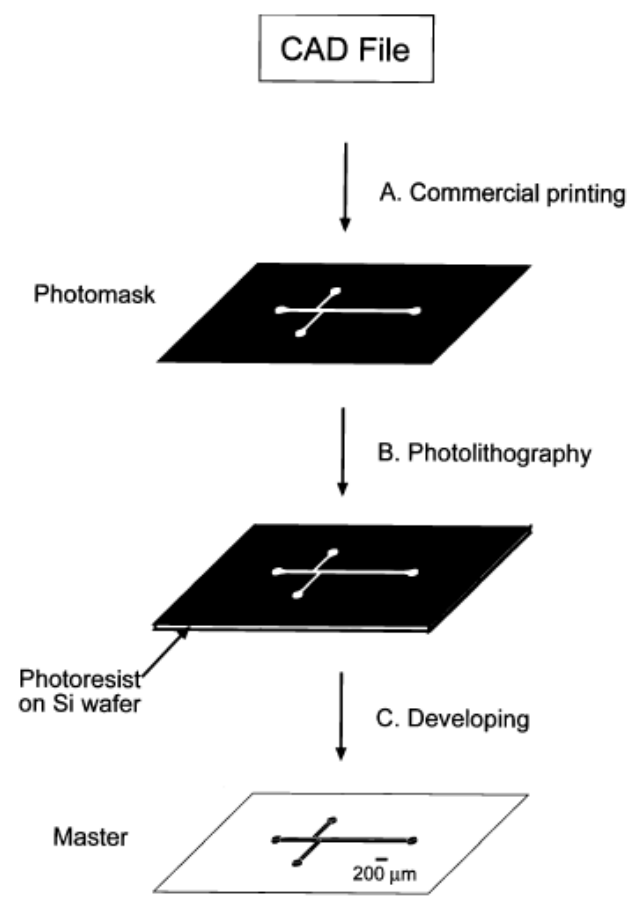

Figure 5 - Scheme for rapid prototyping and replica molding of microfluidic devices in PDMS [31] 
Soft lithography is the next step in developing a microfluidic device composed of Polydimethylsiloxane (PDMS). Soft lithography in microfluidics differs from photolithography because it is a process that replicates the structures from the master mold by pouring a viscous elastomeric material such as PDMS and removing the elastomeric block. The PDMS block will contain the microfeatures such as the channels with appropriate lengths, widths, and depths. The cross-sectional diagram in Figure 6 demonstrates how a microfluidic channel is produced by the PDMS elastomer poured over the master mold. Figure 7 shows a detailed example with steps of photolithography and soft lithography to produce the PDMS with micro-features.

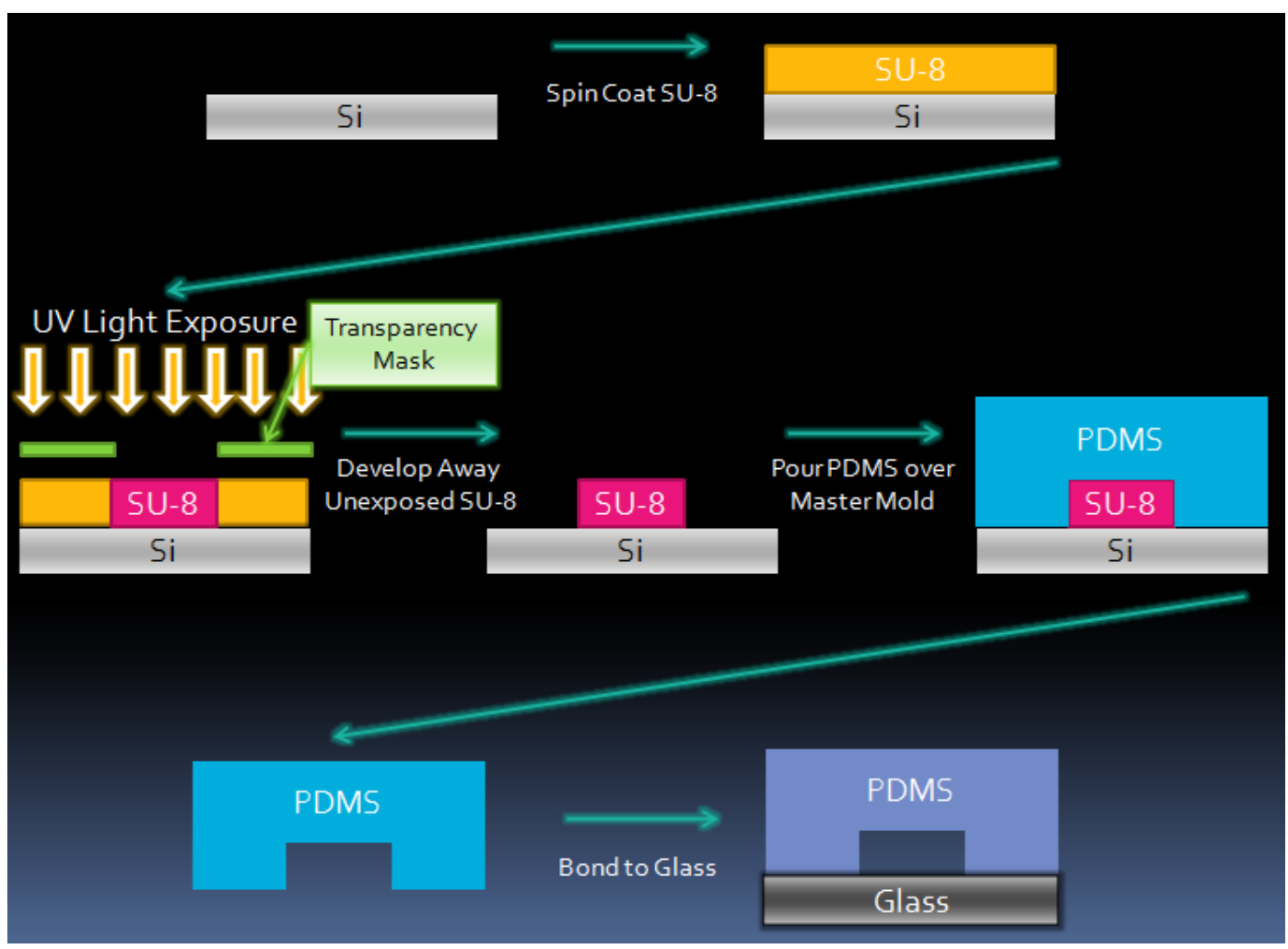

Figure 6 - Cross-sectional view of the Lithography process that demonstrates the creation of microfluidic channels 


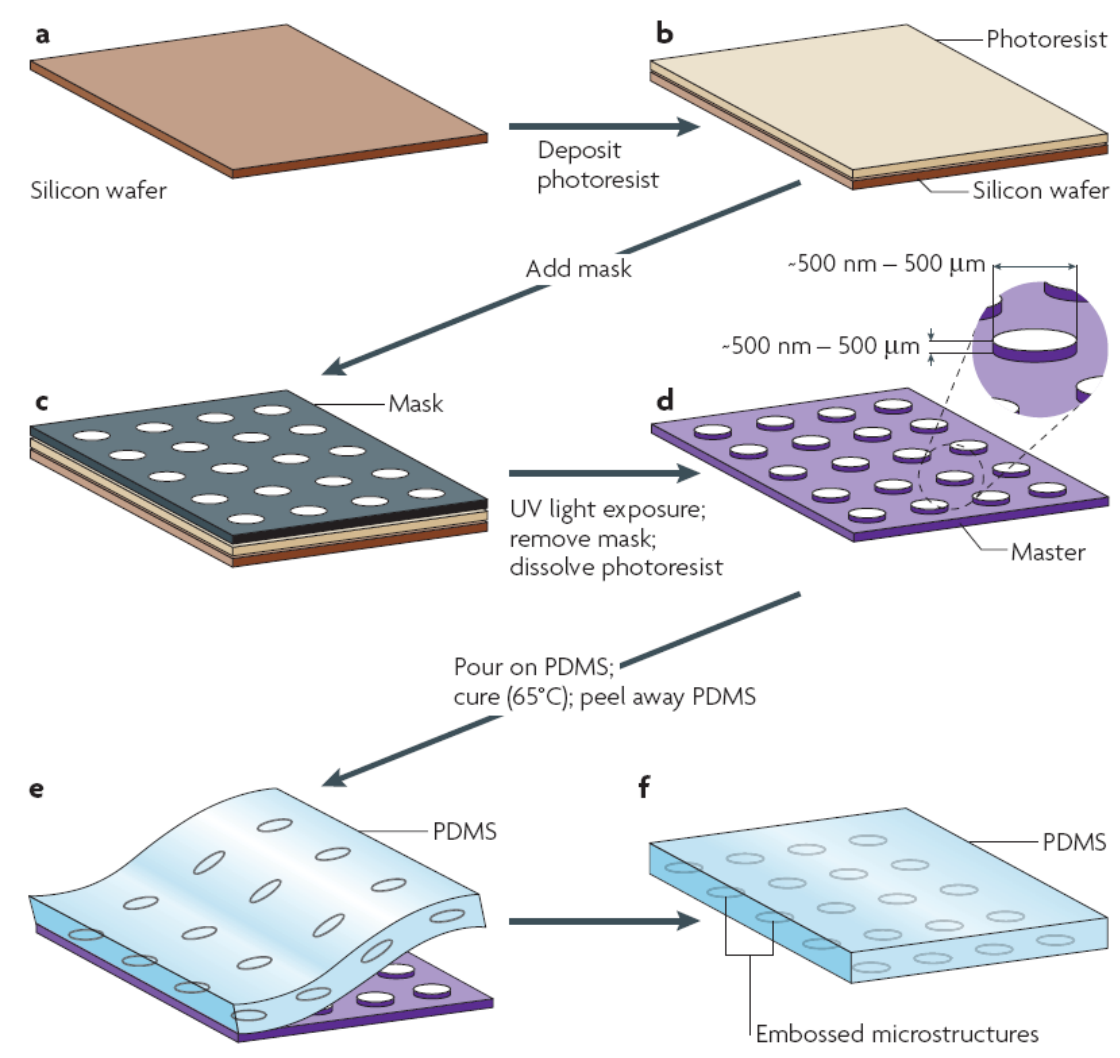

Figure 7 - Fabrication steps involved for Photolithography and Soft Lithography [32]

The PDMS block with micro-features is bonded to a substrate to form a water tight seal. Additionally, features can be introduced via the substrate, e.g. metallic layers to form electrodes. These metallic layers, typically ranging from $100 \mathrm{~nm}$ to $1 \mu \mathrm{m}$, are deposited onto a substrate based on the user's design if the thickness and dimensions are critical. The shape of the thin-layers is achieved again through another photolithographic process and transparency mask. These thin-layers will be used as the electrodes needed to induce electric fields within the device [12]. 
Plasma-bonding is necessary to bond the final PDMS block with micronscale features to the substrate to permanently seal off the device from the external environment and allow fluid to travel within the micro-channels. PDMS is normally hydrophobic at the surface and will make fluid difficult due to a contact angle of $120^{\circ}$ as demonstrated in Figure 8.

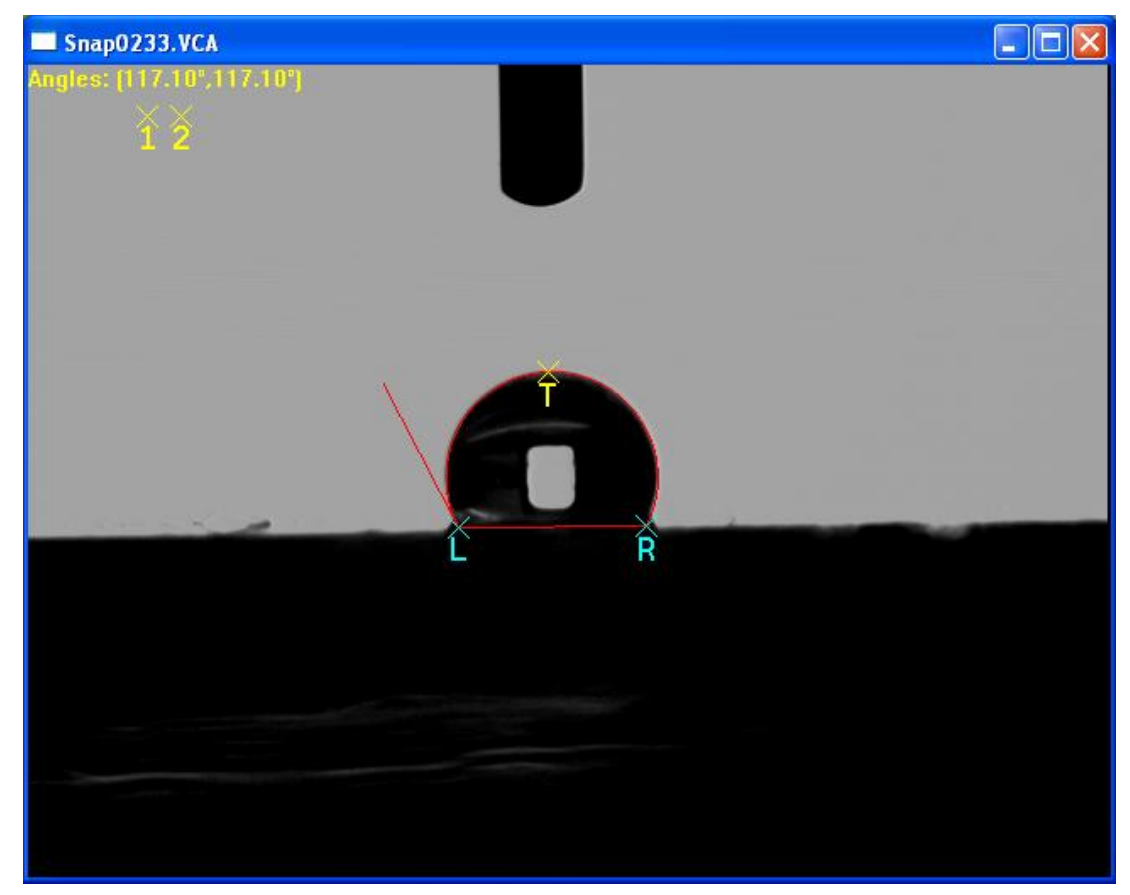

Figure 8 - Contact angle measurement of DI water on a PDMS surface showing a hydrophobic effect $\left(\sim 120^{\circ}\right)$

The PDMS surface can be hydrophilic by exposure to plasma and oxygen to generate silanol groups $(-\mathrm{SiOH})$ at its surface. Similarly, the substrate surface, e.g. glass, can be treated as well and joining the two surfaces together will cause an irreversible covalent seal with a maximum pressure of $20 \mathrm{psi}$ [32]. The plasma-treatment bonder and a methanol solution $\left(\mathrm{CH}_{3} \mathrm{OH}\right)$ will ensure the user 
that device will seal correctly and prevent leaks throughout the device.

Additionally, both the PDMS and the substrate have alignment marks so that the device is bonded square and collinear with any other contained features.

\section{4 - Characterizing and Modeling Devices}

After a microfluidic device assembly of PDMS and glass has been fabricated, testing must ensue to ensure that all the device functionality works properly. It is beneficial to the designer to model a device and numerically test the design using tools such as Finite Element Analysis (FEA) and Computational Fluid Dynamics (CFD). Tools such as COSMOSWorks ${ }^{\mathrm{TM}}$ or $\mathrm{COMSOL}^{\mathrm{TM}}$ are commonly used to understand stresses and strains induced within a device, flow velocities, and concentration mixtures within micro-channels.

The program chosen for this project was $\mathrm{COMSOL}^{\mathrm{TM}}$ (MEMS module) to understand and simulate microfluidic phenomena such as Stokes Flow and AC electric fields in a conductive media. These concepts are further explained in Chapter 2.5 - Microfluid Mechanics. COMSOL ${ }^{\mathrm{TM}}$ was used to determine the flow velocities necessary to achieve the desired results for the device as well as AC field effects in electrodes.

As mentioned, implementation of the device is necessary to show that the manufacturing procedures and simulations obtained earlier will match that of the actual device performance and characteristics. To achieve this, the device was imaged and scanned via video microscopy to validate that the features meet the design requirements. Fluid with $10 \mu \mathrm{m}$ polystyrene, fluorescent beads injected 
via syringe-pumps set at certain flow rates were measured to ensure that the flow rates match the target set on the syringe pumps and match the flow rates predicted from, say COMSOL modeling.

\section{5 - Microfluid Mechanics}

Applications for MEMS that are based on microfluidics require unique interpretation when compared to those used for macro-scale devices [33]. More specifically modeling tools used for macro-scale systems typically lack capability required for analysis and must be approximated for the micro-realm, e.g. surface forces. Surface mechanisms such as surface tension are a challenging issue when in use with liquid for transporting, sensing, and controlling within the microfluidic channel [34]. Techniques such as surface treatment to achieve a hydrophilic layer in a channel can be used to improve overall surface mechanics when interaction with fluid.

Reynolds numbers, a dimensionless value to classify a flow as laminar or turbulent, differ when dealing with microfluidics owing to the small length scales involved. These numbers are important in devices because cells from a sample travelling smoothly through the channels will be subjected to movement based on feature geometries rather than turbulence. Also pressure caused from high velocity in a small channel may cause the PDMS structures to rupture under excess stress leaving the device to become unusable. Target Reynolds numbers elucidate good starting points for deciding flow rates; however, it should be noted that mass flow rates of simple straight micro-channels were found to transition to 
turbulence at a much lower Reynolds number than channels in the macro-scale; macro $R e$ is approximately 2000 while micro $R e$ is around 1000 [35]. Table 1 describes the fluid type, flow conditions for simulations, and Reynolds numbers for laminar flow in MEMS devices [36]. Values used in $\mathrm{COMSOL}^{\mathrm{TM}}$ simulations will be compared to the table value to ensure that the flow through the device is indeed laminar.

$$
R e=\frac{\rho V D}{\mu_{d}}
$$

Table 1 - Reynolds Numbers for Flow Regimes in MEMS Devices [37]

\begin{tabular}{|ccc|}
\hline Fluid Type & Flow Regime & Reynolds Number \\
\hline Compressible Fluids (Gasses) & Laminar Flow & $\mathrm{Re}<100$ \\
\hline Incompressible Fluids (liquids) & $\begin{array}{c}\text { Transient Stokes } \\
\text { Flow }\end{array}$ & $\mathrm{Re}<<1$ \\
\hline Incompressible Fluids & Laminar Flow & $\mathrm{Re}<1000$ \\
\hline Incompressible Fluids & Transition Phase & $2000<\mathrm{Re}<4000$ \\
\hline Incompressible Fluids & Turbulent Flow & $\mathrm{Re}>4000$ \\
\hline
\end{tabular}

Finally, Stokes Law was used to estimate the viscous force experienced by a translating spherical particle in a liquid. The result yielded an equation known as the Stokes drag law,

$$
F=6 \pi \mu a U
$$

where $\mu, a$, and $U$ represent dynamic viscosity, sphere radius, and sphere relative velocity (relative to the fluid) respectively. This equation is applicable for a single sphere in an infinite volume of fluid; however given a microfluidic environment, where the domain is bounded, some correction coefficients are 
necessary to predict viscous forces in relevant scenarios [38]. Two correction coefficients related to our cases in a microfluidic environment, taken from Low Reynolds Number Hydrodynamics by Heppel \& Brenner (1965), are the "Sphere moving parallel to one or two stationary parallel walls" and "Sphere moving perpendicular to a plane wall." shown below, respectively as the Stokes flow result,

$$
\begin{gathered}
\overrightarrow{\boldsymbol{F}}=\frac{-\boldsymbol{i}_{x} 6 \pi \mu a U}{1-0.6526\left(\frac{a}{l}\right)+0.1475\left(\frac{a}{l}\right)^{3}-0.131\left(\frac{a}{l}\right)^{4}-0.0644\left(\frac{a}{l}\right)^{5}+O\left(\frac{a}{l}\right)^{6}} \\
F=6 \pi \mu a U\left[1+\frac{3}{4}\left(\frac{a}{h}\right)+\frac{9}{16}\left(\frac{a}{h}\right)^{2}+\frac{19}{64}\left(\frac{a}{h}\right)^{3}+\cdots\right]
\end{gathered}
$$

where $\mu, a, U, I, h$, and $O$ represent dynamic viscosity, sphere radius, particle speed of superficial fluid velocity, length distance to the boundary, distance of sphere midpoint from the plane, and arbitrary point fixed in particle, respectively. Figure 9 below represents the variables.

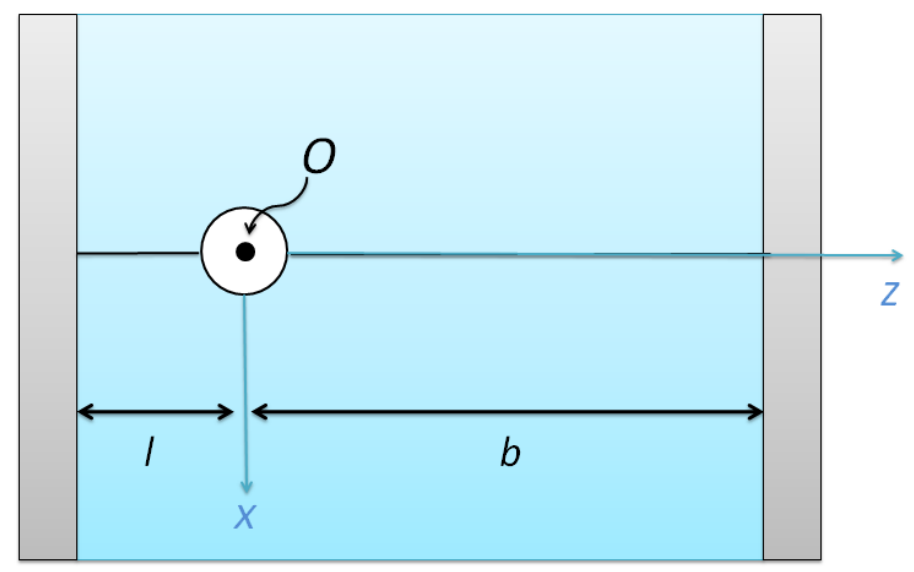

Figure 9 - Sketch for movement of sphere between parallel plane walls. [38] 
The correction coefficients are necessary to include since our spherical particles, cells and beads, interact with PDMS walls in two principle directions, parallel and perpendicular, during transport through the thin microfluidic channels.

\section{6 - The Cellular Impedance and Electric Double Layer}

Characterization of cell electrical properties, conductance, and permittivity, based on their natural impedance has been characterized for years $[39,40]$. The complex impedance (the magnitude of the Real and Imaginary vector resistances, in electrical engineering terms) has been associated with cells primarily due to a reaction in response to an induced electrical current. The voltage change exhibited when performing experiments such as these have led to understanding an equivalent circuit analogy for a cell [41]. For example, a cells membrane is analogous to a capacitor and the cytoplasm as a resistor.

Therefore, using sensing electrodes to create a circuit to measure impedance can be used to classify the nature of a cell. An equivalent circuit for detection electrodes is seen below in Figure 10. This schematic identifies key sub-circuits such as the effect of the equivalent resistance of a solution, capacitance of a cell, and electric double layer of an electrode. 


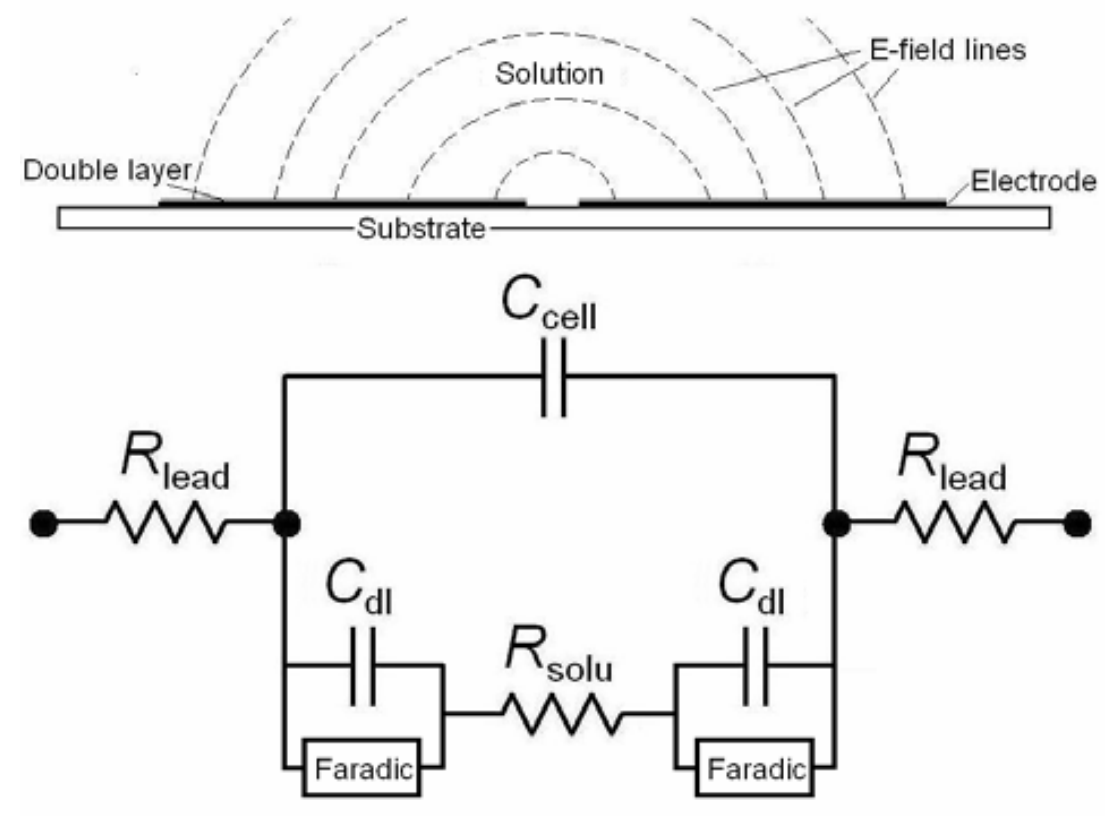

Figure 10 - Equivalent circuit of detection electrodes [18]

If an isolated cell can be positioned symmetrically over the electrodes, it will induce an electric field and the impedance is measured, along with the electric field of relative fluid. A differential measurement can then be used to subtract out any excess impedance (i.e. the surrounding fluid) so that the measurement is only for cellular impedance. In theory, a healthy cell whose membrane and cytoplasm are intact will yield the standard baseline impedance. If the cell being measured is infected with a pathogen that causes damage to either the membrane or cytoplasm, or if the cell is in a dead state whether there is permanent damage to the membrane or cytoplasm, the overall impedance will change [42]. For a dead cell, the membrane potential goes to zero and the cell cytoplasm ion concentration is that of the fluid. The resulting impedance will yield an impedance spectrum very similar to the suspending fluid. 
In performing electrical measurements on cells in fluid, other electric phenomena will occur. One of these phenomena is the electric double layer, caused from a cloud of ions forming upon charged surfaces [43]. The double layer contains groups of ions making two layers, the Stern layer and the Diffuse layer, and acts as a capacitor. The combined diffuse layer and surface charge is known as the electric double layer. Using theory of electro-mechanics, the double layer can be characterized by the Debye screening length (the length scale when the surface potential decays to the bulk fluid potential). When taking impedance measurements, the electric double layer must be taken into account. Therefore, the equivalent circuit must include the electric double layer and it can be modeled as a capacitor in series with the equivalent cell circuit model [44].

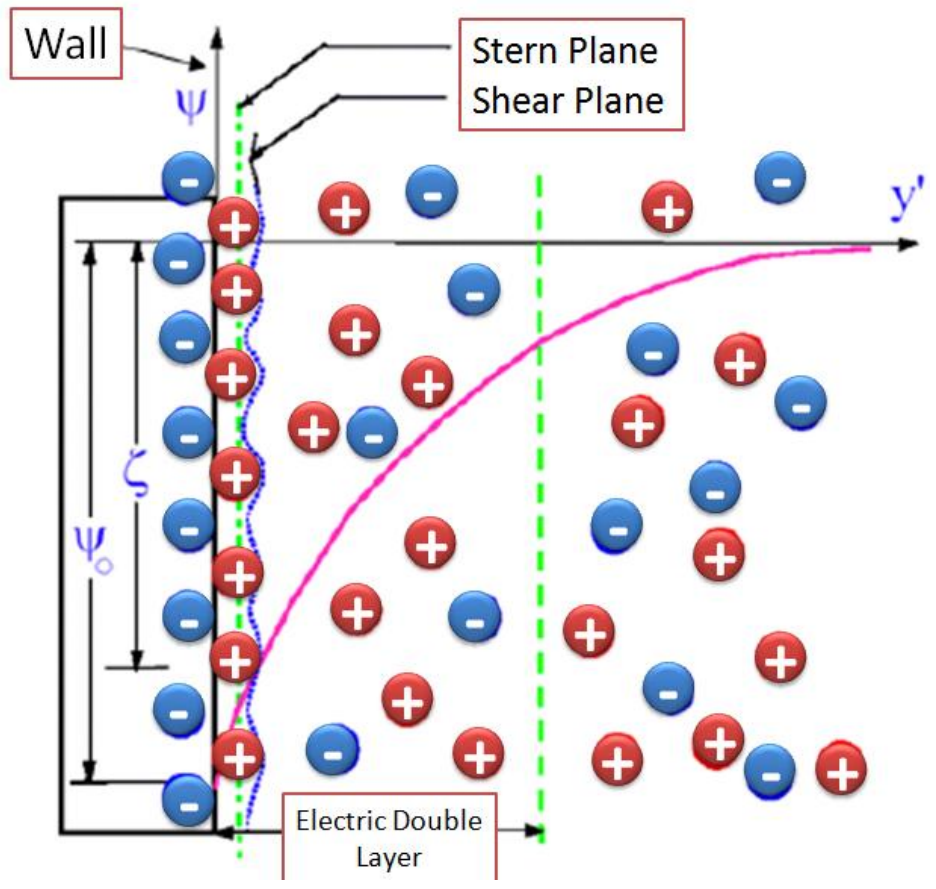

Figure 11 - Schematic of the Electric Double Layer [38] 


\section{7 - Saccharomyces cerevisiae in Biological Studies}

Yeast cells, Saccharomyces cerevisiae, are commonly used in cellular biology due to its cell cycle. The cell cycle of $S$. cerevisiae matches the life cycle of cells in humans in terms of cell division, DNA replication and recombination, and metabolism [45]. Therefore, we proposed to use S. cerevisiae for our cell experiments. The cell impedance spectra of $S$. cerevisiae should yield results comparable to those most living cells (i.e. blood, mast, and macrophages) and therefore a useful model for pathogen diagnosis [42]. Since yeast cells are normally spherical, microsphere test beads of comparable diameters were used to test the device design [46]. The test beads were Invitrogen ${ }^{\mathrm{TM}}$ FluoSpheres (SKU\# F-8834). The fluorescent polystyrene beads were of a $3.6 \mathrm{E} 6$ beads $/ \mathrm{mL}$ dilution with a $10 \mu \mathrm{m}$ diameter and a red fluorescent wavelength range of 580$605 \mathrm{~nm}$. 


\section{Ch.3 - Methods}

\section{1 - Cell and Test Bead Experimentations}

\subsection{1 - Cell Growth and Harvesting}

A culture of Saccharomyces cerevisiae was acquired through the Undergraduate Biotechnology Laboratory under lab director, Dr. Michael Black at Cal Poly San Luis Obispo, CA. A dilution of $3.6 \mathrm{E} 6$ cells $/ \mathrm{mL}$ was requested to match that of the Invitrogen ${ }^{\mathrm{TM}}$ FluoSpheres so testing of the device would be consistent for both cell and test beads. The $S$. cerevisiae culture that was requested was incubated for 24 hours before mixing with a buffer solution. $S$. cerevisiae (Y128) was grown, incubated, and removed 24 hours later. A buffer solution of sodium bicarbonate and sodium chloride was developed using $\mathrm{Ayr}^{\circledR}$ Saline packets (Ayr Saline Nasal Rinse Kit) since it is biocompatible and commercially available [47-49]. Once prepared the $\mathrm{Ayr}^{\circledR}$ Saline packets were mixed with DI water yielding a solution with a neutral $\mathrm{pH}$ of 7 and conductivity of $20 \mathrm{mS} / \mathrm{cm}$. A packet of $\mathrm{Ayr}^{\circledR}$ Saline (1.57g) was mixed with $177 \mathrm{~mL}$ of DI water and $50 \mathrm{~mL}$ of buffer solution was extracted for experimentation. A super-saturated yeast concentration of $4 \mathrm{~mL}$ was centrifuged at 3000 RPM for 3 minutes in room temperature to extract the supernatant. The pellet concentration was then mixed with $10 \mathrm{~mL}$ of buffer solution to obtain a $12 \mathrm{~mL}$ cell solution.

\subsection{2 - Count Test Dilution and Measurements}

Dilution for the cell solution was validated before performing experiments in conjunction with the microsphere test beads. Therefore measurements of the 
new cell solution were performed to estimate the concentration of yeast cells per milliliter using a Hemocytometer Counting Chamber (Hawksley \& Sons). To perform the test, $10 \mu \mathrm{L}$ of cell solution was extracted with a micropipette and injected between the counting chamber and a cover slip as seen in Figure 12 (left).
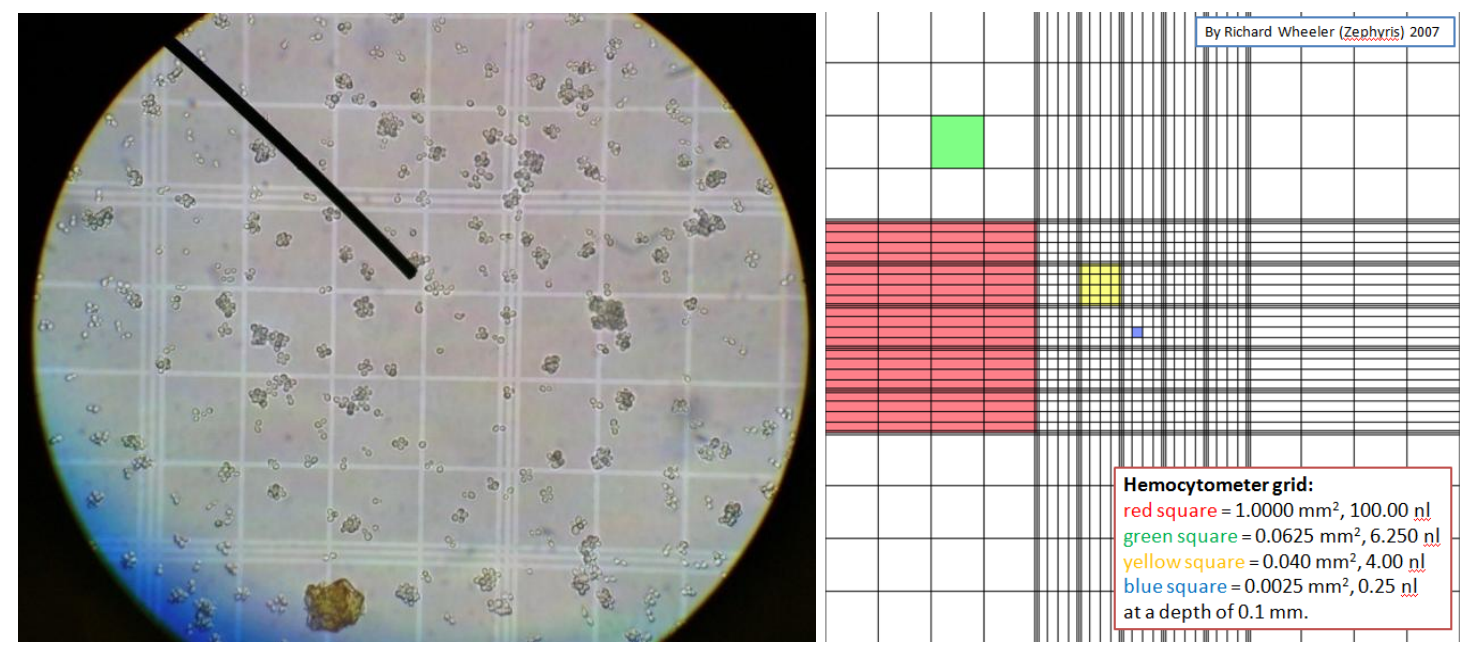

Figure 12 - Image of yeast cells in a hemocytometer for cell counting (left). Legend for hemocytometer (right)

The counting chamber was placed under a microscope for visual analysis and cells were counted between square areas. Cells between the squares were counted individually and the area to cell ratio was calculated to determine the dilution estimate. The largest square size, group square, smallest square, and depth of chamber are $1 \mathrm{~mm}^{2}, 0.04 \mathrm{~mm}^{2}, 0.025 \mathrm{~mm}^{2}$, and $0.100 \mathrm{~mm}$ respectively. Figure 12 (right) shows a legend that indicates where the squares are located in the hemocytometer. 
The dilution formula estimate is:

$$
\frac{\text { Number of cells }}{\text { Counted area }\left(\mathrm{mm}^{2}\right) * \text { Chamber depth }(\mathrm{mm}) * \text { dilution factor }}=\text { Cells per } \mu \mathrm{l}
$$

\subsection{3 - Cell Viability Validation}

To determine optically that cultured cells were viable, a stain of $1 \%$ Methylene Blue was applied to the cells. When cells are dead or when the enzymes are inactive and denatured, the cell will be in a colored state [50, 51]. A cell sample of $10 \mu \mathrm{L}$ was mixed with $10 \mu \mathrm{L}$ of $1 \%$ Methylene Blue and placed on the Hemocytometer with a cover slip. The cells were observed under the LabSmith $^{\text {Inc }}$ microscope to determine if the cell was in a viable, living state.

\subsection{4 - Comparison and Measurement of Beads and Cells}

A statistical measurement of yeast cells was used to determine the average diameter of a group of cells from different samples [52]. The goal is to obtain a cell culture with an average diameter of $10 \mu \mathrm{m}$, or be within a range of 5$12 \mu \mathrm{m}$. The resulting samples used for testing were the yeast cells from the Cal Poly Biotech Lab. A random sample of yeast cells were collected and imaged on a glass slide with a cover slip. ImageJ, a program used for the image postprocessing, isolated the image of cells from its external surroundings. The data generated from the program was extracted onto a spreadsheet that calculated the areas of individual cells. Using the formula for area of a circle, the diameter was estimated. The variances between the cell sizes from different samples were compared to determine if the results yielded an average close to $10 \mu \mathrm{m}$. 


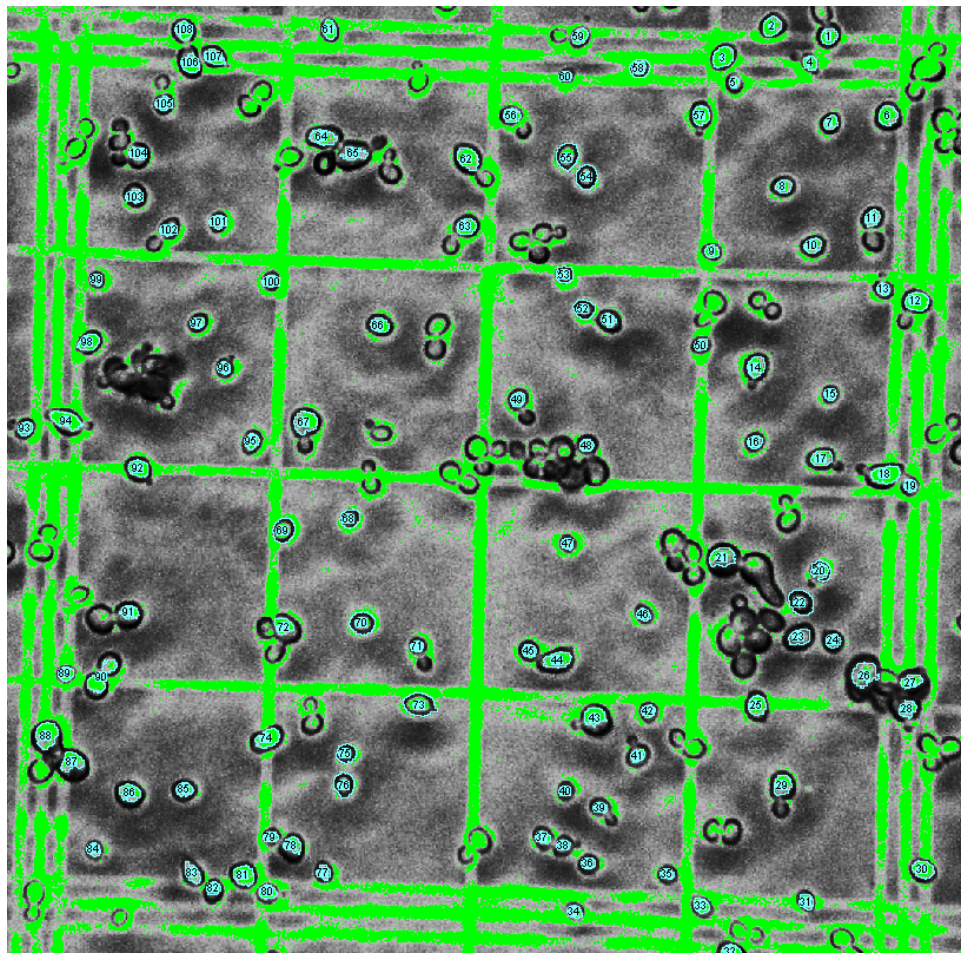

Figure 13 - ImageJ Particle Counting

\section{2 - PDMS Channel Designs}

\subsection{1 - Design of the PDMS Capture Chamber}

An initial sketch of the device features was designed and calculated according to microfluidic design rules, provided by the Stanford Microfluidics Foundry. A solid model of the design was developed in SolidWorks and also converted into an AutoCAD drawing for mask development. Three conceptual designs were theorized for the PDMS cell capture chamber.

\subsection{1a - Generation 1: Flow-through Suction System}

The following design allowed a fluid sample to flow through a straight channel with two sets of impedance electrodes above and below a walled 
obstruction, see Figure 15. The obstruction would guide cells to the top area of the channel where a suction port would capture a single cell while the bottom area was blocked off to allow only fluid to flow through a thin channel. The top chamber would measure the impedance of a captured cell and differentiate the fluid impedance measured from the bottom set of electrodes.
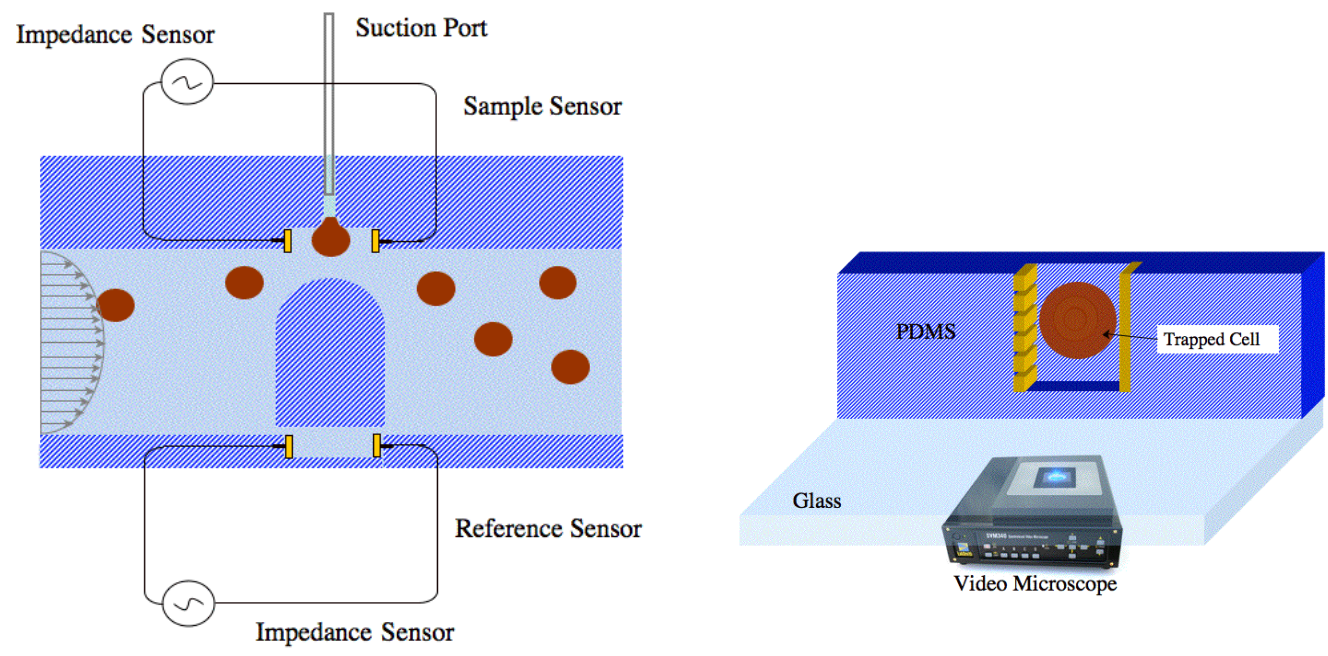

Figure 14 - Conceptual Design of the Gen1 Impedance Sensor

This device concept was intended to be fabricated and tested however this design had some fabrication issues during a design validation. First, the electrodes were meant to stand on the vertical walls of the PDMS channels so the cell could be imaged; however this would require sputtering directly onto PDMS, which is known to be problematic. The second issue dealt with the need to make the device a flow-through system, since the design involved some trial and error in trapping a yeast cell for testing. The next generation design located electrodes on the top and bottom support substrates, e.g. glass, and used a 
system with flow directly into the test chambers. These changes would make the electrode patterning and yeast cell trapping much easier and more reliable. However, there was an issue regarding the electronics integration to drive the electrodes. One electrode is meant to drive an AC field while the second is meant for sensing and data acquisition. Since two electrodes perform different tasks, they require a separate data acquisition card for each function. The data acquisition impedance workstation computer was limited to drive two sensing electrodes and the design described here required a total four sensing electrodes to be hooked up simultaneously. Given electrode patterning constraints, limited resources, and cost of data acquisition cards, it was decided that the design can be reworked accordingly to use only two sensing electrodes rather than four.

\subsection{1b - Generation 2: Multi-chamber Capture Prototype}

This particular design was meant as a sample prototype to verify if new design geometries would ensure cell capture. The design was made to allow a collection of cells to be introduced into the inlet chamber and settled into 14 different capture sites on a 2" x 3" glass slide. Figure 15 shows the solid model of the design in isometric, bottom, and side-view. 

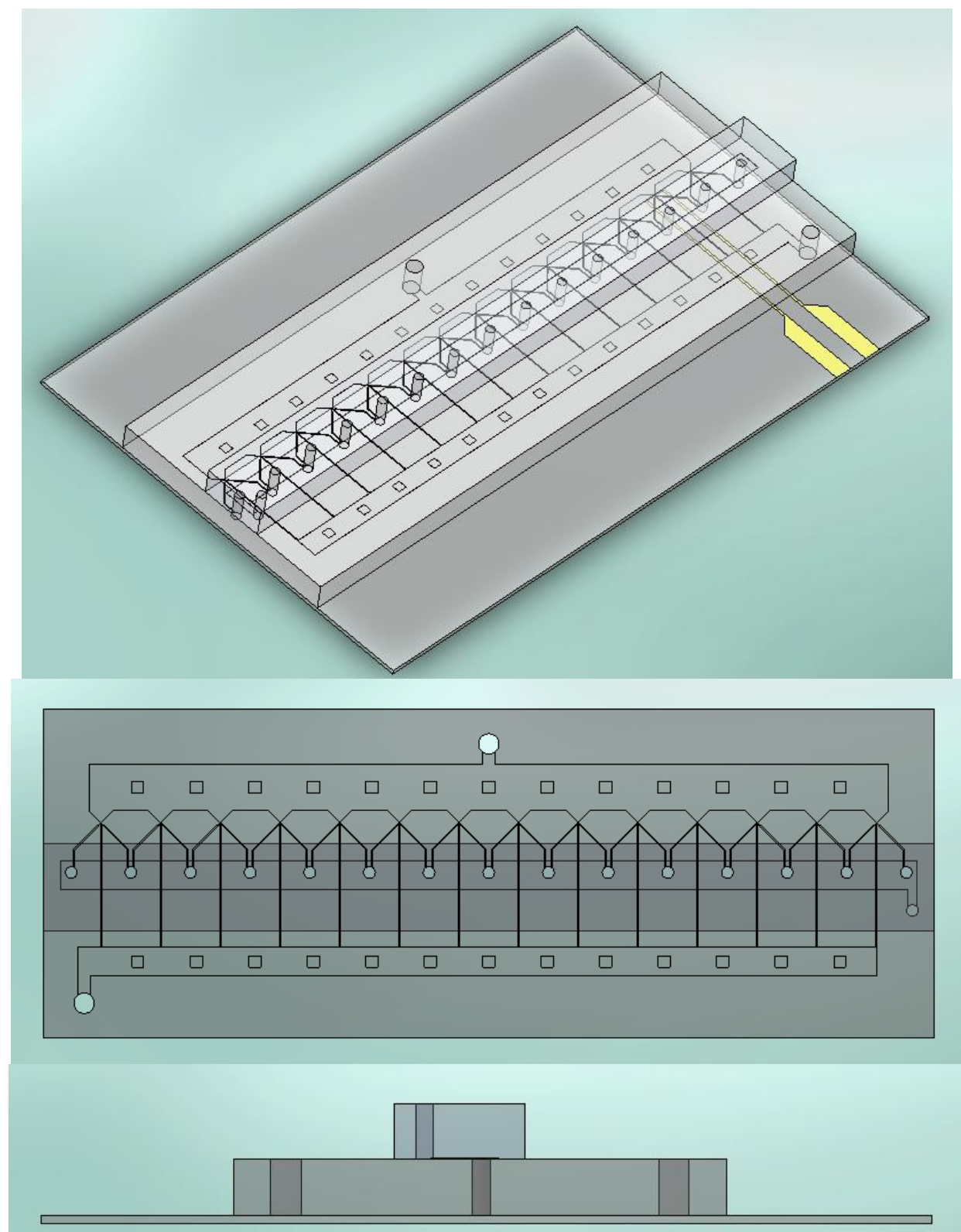

Figure 15 - Solid model of the Gen2 Multichamber Design

Since cells are on the order of one to ten microns in size, the channel height was designed to approximately $10 \mu \mathrm{m}$. Also, a suction chamber applied to each suction site was used to capture and sequester an individual cell while a pair of flush channels, controlled by a separate chamber, for back-flow lay 
diagonal to the capture site to get rid of any excess cells that may stack on the captured site. Both of these chambers are controlled through their respective syringe pump. Using volumetric flow rate equation,

$$
Q=A_{c} *\langle V>=w * h *<V>
$$

where $Q, A_{C},\langle V\rangle, w$, and $h$, represent volumetric flow rate, cross-sectional area, average velocity, width of the channel, and height of the channel, respectively, it is evident that the in order to get a high velocity with a given flow rate, the crosssectional area must be as small as possible. Since the height of the channels is fixed at $10 \mu \mathrm{m}$, the only variable we can change is the width of a channel. Therefore the suction and flush channels were designed as small as possible ( 5 $\mu \mathrm{m}$ ) to get a high velocity. Figure 16 (top) shows the schematic from the solid model that demonstrates the location of each functionalized channels. 


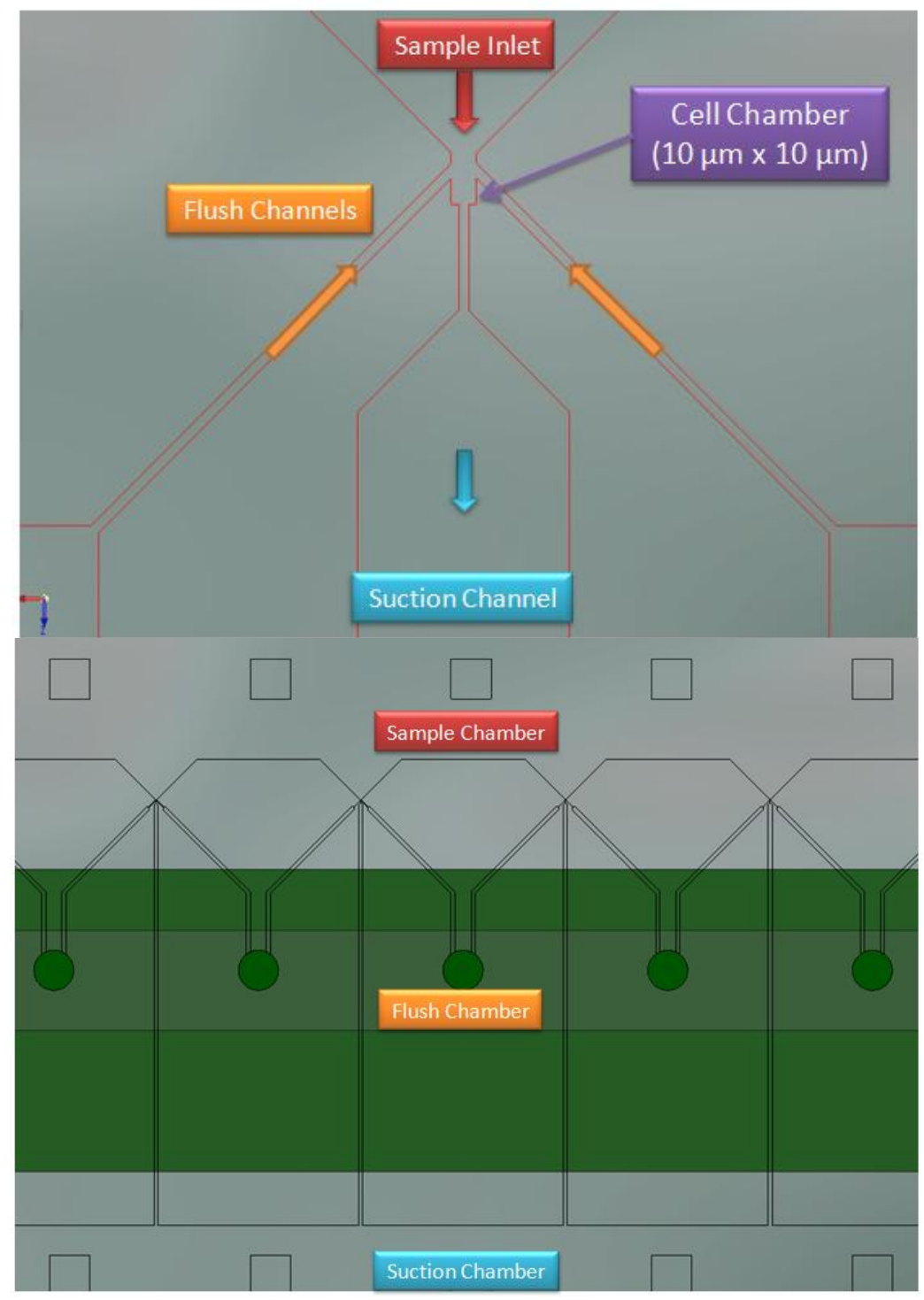

Figure 16 - Schematic of the Capture Chamber section of the design (top) and view of the multiple control chambers (bottom)

Since the design has multiple capture sites, it was recommended that each thin-channel was controlled concurrently with other channels by a respective chamber. Figure 16 (bottom) also shows the location of the chambers for this design. However, a design challenge with the flush chamber is that crosscircuiting would occur with the thin-suction channel. This means that the flush 
chamber cannot lie within the same plane as the thin suction channel or both will lose their intended functionality. This problem was addressed by creating a second PDMS layer to control flush and bonding it on top of the first PDMS chamber that contained punched holes at the flush channels. A diagram to describe how cross-circuiting was prevented is seen below in Figure 17.

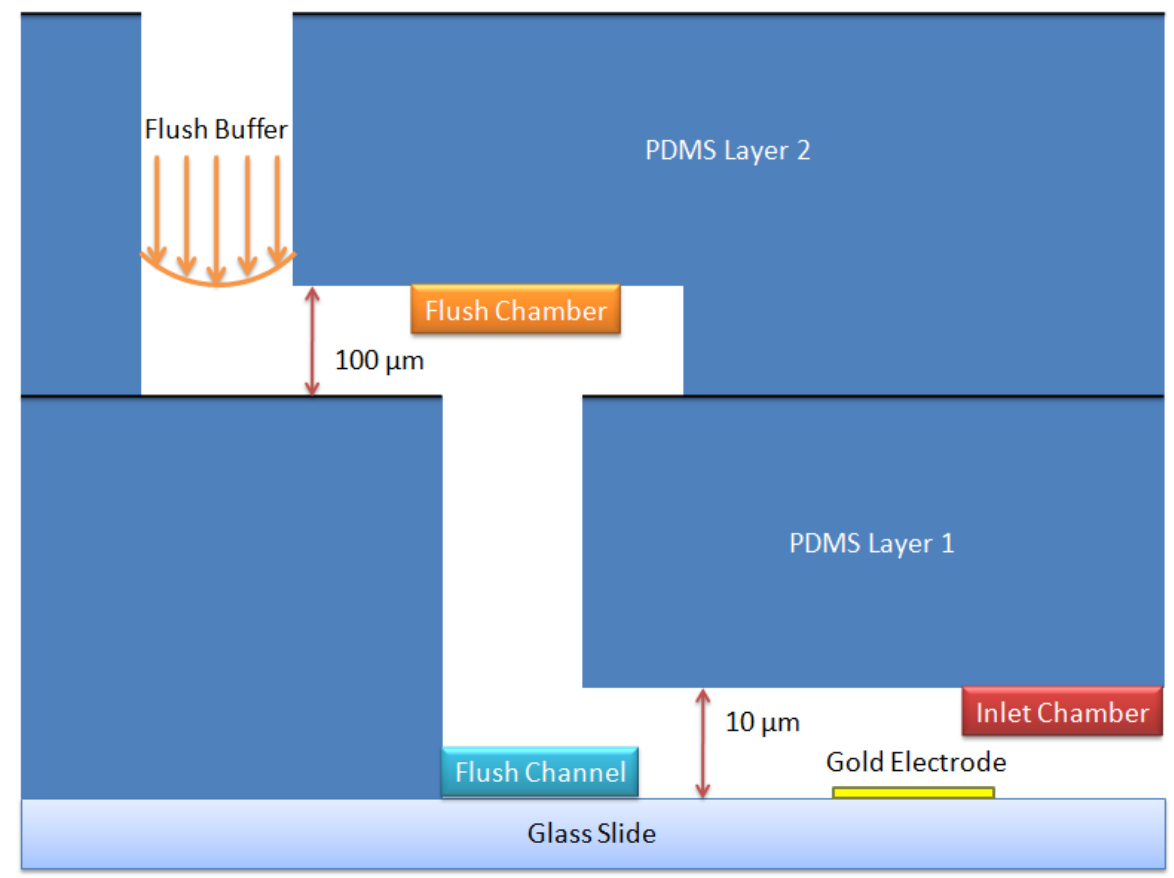

Figure 17 - Cross-sectional diagram demonstrating function of multiple PDMS layers

The design was meant only as a prototype to determine if cell capture was achievable, simultaneously in multiple channels. Electrodes were meant to run across all chambers and run statistical impedance as a proof for concept; however, manufacturing errors on the electrode fabrication proved to be problematic and overly time consuming. Another inconvenience was the need to develop the second PDMS layer to control the flush channels that prevented 
cross-circuiting since it added another step in PDMS developing and bonding. Regardless of these issues, it was shown that this design enabled reliable cell capture. The goal of the project was twofold: First, to trap an individual, viable yeast cell, and second to collect impedance spectra. Therefore the design was simplified to a single capture chamber with impedance electrodes.

\subsection{1c - Generation 3: Single-chamber Design}

Leveraging the successful design for cell capture from the Gen2 device, the same channel design was employed but for only a single-chamber capture site fitted on a 1" x 3" glass slide. Some changes when compared to the Gen2 device is the widening of the capture chamber for an overall tolerance of $12 \mu \mathrm{m}$ rather than $10 \mu \mathrm{m}$; thus allowing manufacturing errors to occur which may change during fabrication. The device only required a single layer of PDMS because cross-circuiting did not occur with the flush channels since chambers were no longer used. Alignment marks were placed on the device to allow precise alignment when cutting PDMS blocks or bonding with a similar alignment mark on an electrode. A solid model of this design is seen below in Figure 18. 


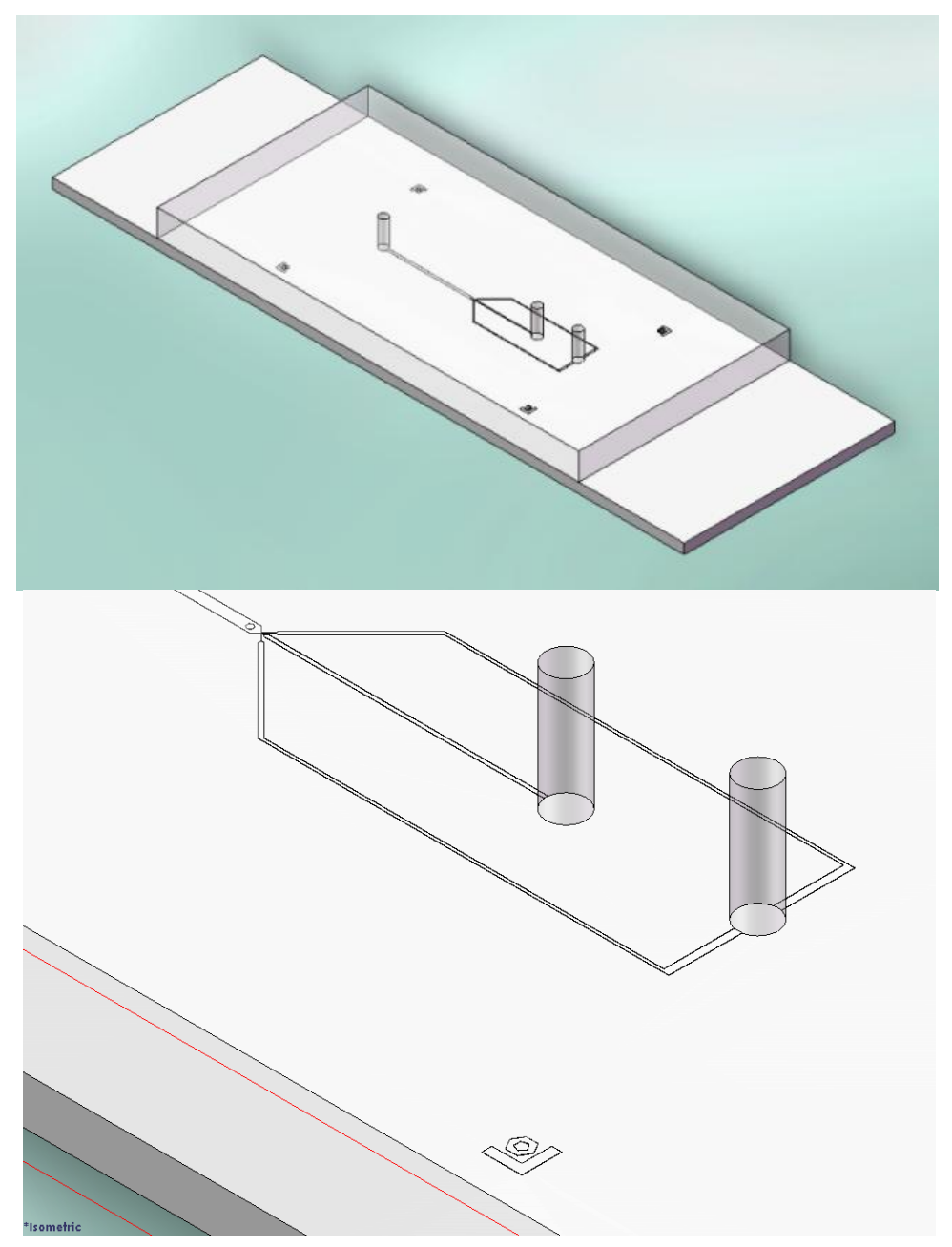

Figure 18 - Solid model of the Gen3 Single-chamber Device

\section{3 - Chip Fabrication}

\subsection{1 - SU-8 Silicon Wafer Master Mold Fabrication, Photolithography}

SU-8 is a negative photoresist polymer that cross-links when exposed to UV light. Development of a master mold is required as it will contain the features necessary so a PDMS pour will result in the desired channel geometry and heights. A transparency mask was designed in AutoCAD and submitted to a photo-plotting service company, CAD/Art Services, Inc. The negative transparency mask measured to 6" x 6" with a resolution of 20000 DPI and the 
emulsion (represented as the dark pigment) furthest from the front view, as seen in Figure 19.
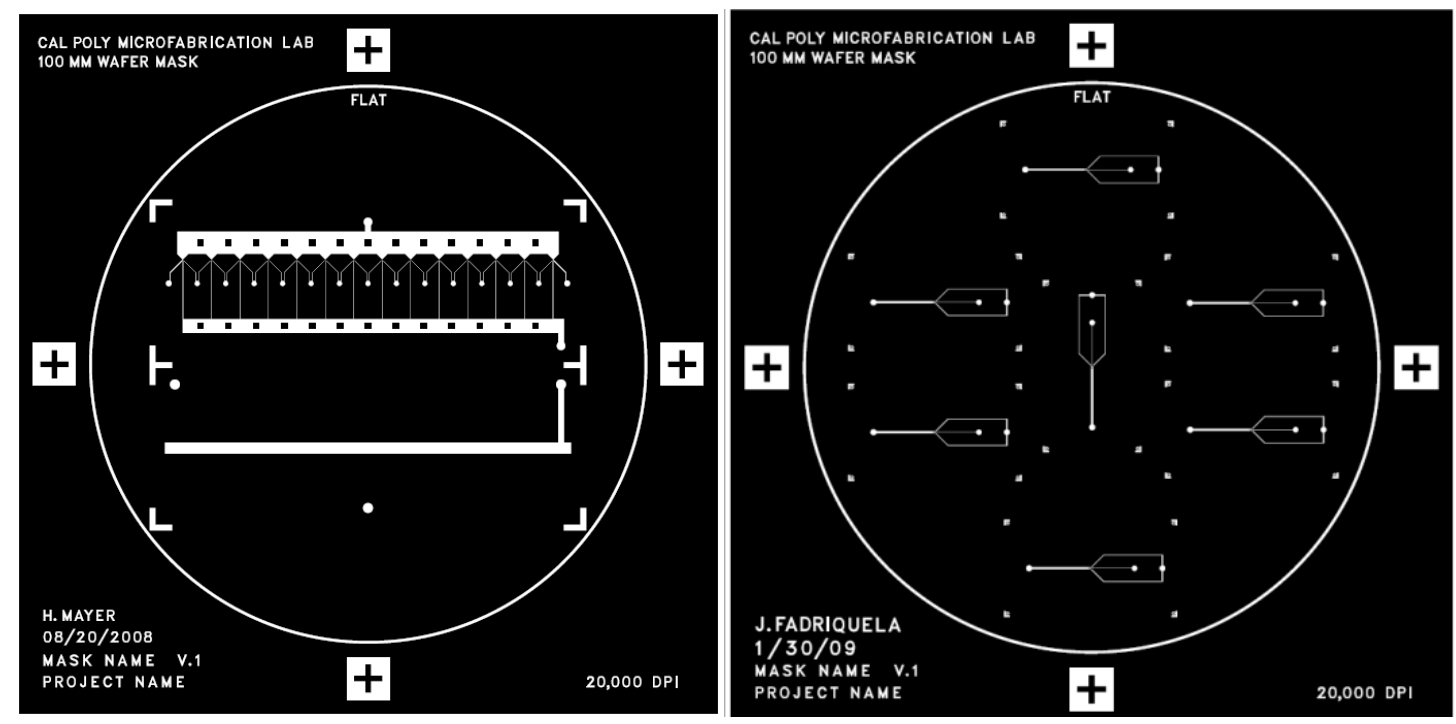

Figure 19 - Negative Transparency Masks of the Gen2 Design (left) and the Gen3 Design (right)

After obtaining the mask, a pair of $100 \mathrm{~mm}$ silicon wafers is prepped for fabrication by quenching it in Piranha (Sulfuric Acid 98\% \& Hydrogen Peroxide $30 \%$ at 9:1) for 15 minutes to clean the silicon wafer surface and quenched in DI (De-ionized) water. Then the wafers were rinsed in BOE solution ( $\mathrm{HF}$ acid/ $/ \mathrm{H}_{2} \mathrm{O}$, Transene) for 5 minutes and quenched in DI water to etch any oxide layer. The wafers were dried with $\mathrm{N}_{2}$ and baked to dehydrate at $205^{\circ} \mathrm{C}$ for 10 minutes then allowed to cool for 5 minutes at room temperature.

The wafers were coated with SU-8 through a spin-coater (Laurel Technologies, WS-400) which rotates a wafer at certain angular velocities to spread any resist at a desired height based on the spin-coat settings. $4 \mathrm{~mL}$ of SU-8 2007 (\#07110769, MicroChem) is placed concentric on top of the wafer and 
subjected to a spread cycle of $20 \mathrm{sec}, 400 \mathrm{RPM}$, and $86 \mathrm{RPM} / \mathrm{s}$ to spread the resist. A spin cycle of $35 \mathrm{sec}, 1500 \mathrm{RPM}$, and $602 \mathrm{RPM} / \mathrm{s}$ is applied to the wafer to a level that matches the height of the desired channels. Figure 20, shows the spin-coater from the Cal Poly Microfabrication Lab.

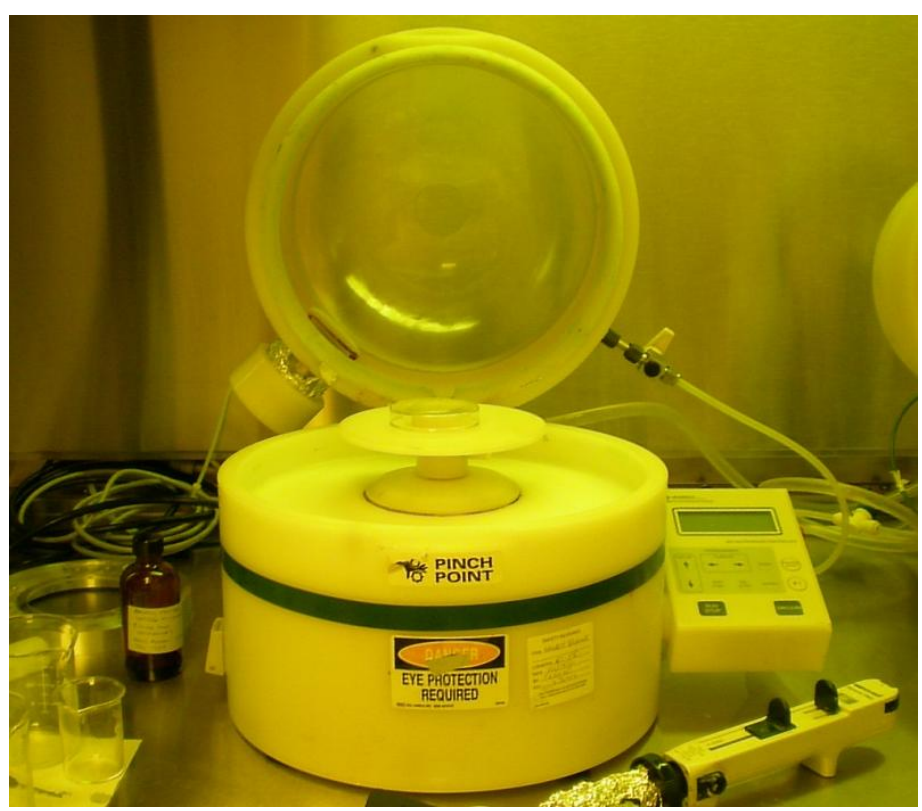

Figure 20 - A spin-coater used at the Cal Poly Microfabrication Lab

The SU-8 coating requires a soft bake on the wafer before exposure in the photolithography mask aligner. The SU-8 wafer was placed on a hot plate at $85^{\circ} \mathrm{C}$ for 3 minutes. The wafer was then allowed to cool down at room temperature for 4 minutes.

Photolithography will occur using the photolithography mask aligner (Canon PLA - 501FA) in the Cal Poly Microfabrication Lab (Figure 21) to perform exposure on the SU-8 resist. The SU-8 coated wafer was placed below the transparency mask obtained from CAD/Art Services and aligned accordingly 
using template cross-marks. A $365 \mathrm{~nm}$ glass-transparency filter was also used to filter the UV-light at the desired wave-length and two glass covers were placed above and below the wafer, mask, and filter assembly. The aligner was set to "Manual Expose" and exposed the wafer assembly to UV light for $100 \mathrm{sec}$ at 125 $\mathrm{mJ} / \mathrm{cm}^{2}$ for a $10 \mu \mathrm{m}$ height to cure the exposed areas. Figure 22 shows the Energy-Time relationship used to program the aligner, characterized by Dr. Richard Savage, director of the Microfabrication Lab

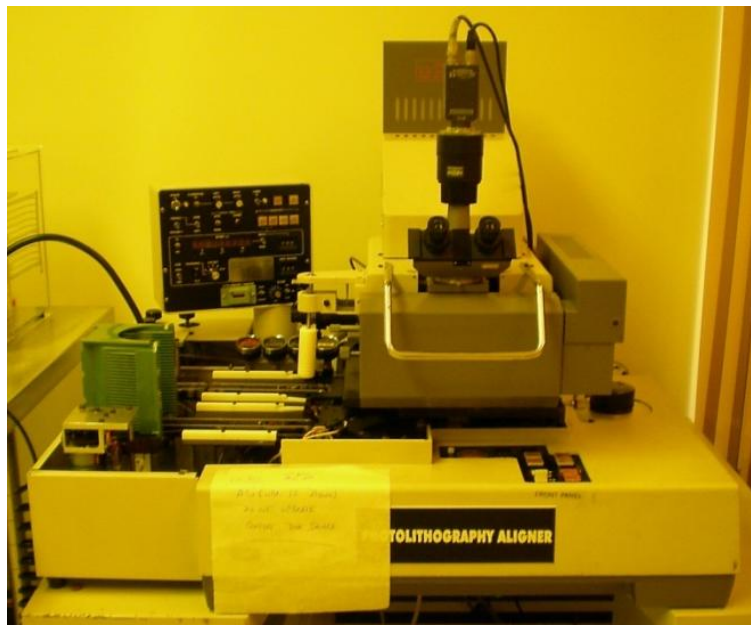

Figure 21 - The photolithography aligner in the Cal Poly Microfabrication Lab (left) and the

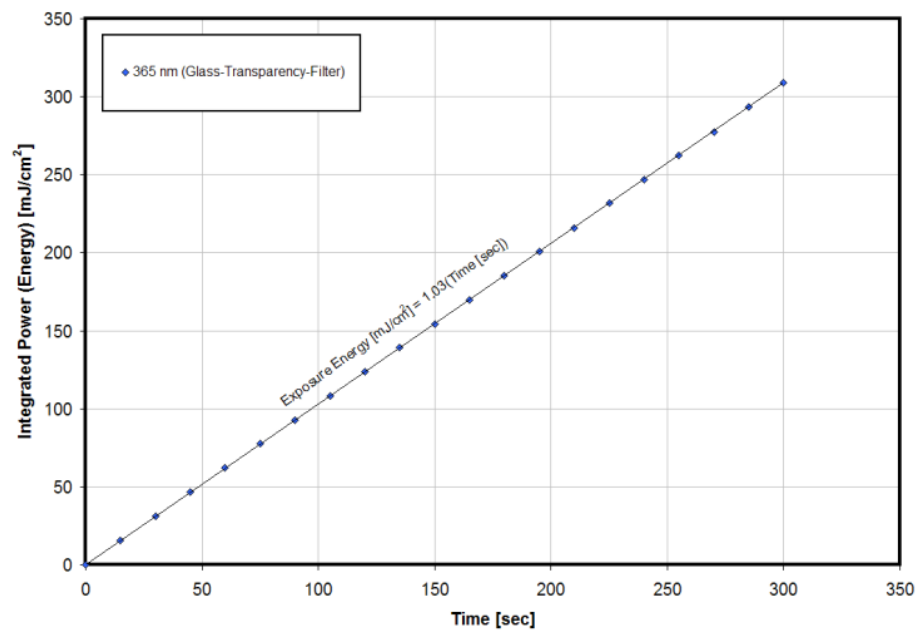

Figure 22 - Aligner Lamp Exposure Energy chart as of Spring 2009 (Dr. Richard Savage) 
After exposure, the pattern was not visible so the wafer was subjected to a post-exposure bake. The SU-8 wafer was placed on a hot plate at $85^{\circ} \mathrm{C}$ for 5 minutes. The pattern became visible 2 minutes into the bake. The SU-8 wafer was allowed to cool at room temperature for 10 minutes.

The uncross-linked parts of SU-8 are etched using a developer solution, propylene glycol monomethyl ether acetate (SU-8 Developer, MicroChem). The SU-8 wafer was placed in the solution bath at room temperature and swiveled for 3 minutes, leaving only the SU-8 features that were exposed in the aligner.

The final product is the master mold containing the hardened SU-8 features and the silicon wafer that can be used for creating PDMS blocks. Observing the master mold under a microscope revealed small cracks in the SU8 , therefore a hard bake of the master mold was performed by placing the master mold on a hot plate at $207^{\circ} \mathrm{C}$ for 15 minutes. Detailed steps of this photolithography process, written by Hans Mayer, are provided in Appendix B.

\subsection{2 - PDMS Preparation and Pouring, Soft Lithography}

PDMS is prepared by mixing the curing agent and base (Sylgard 184, Dow Corning) at a 1:10 ratio. The mixture of the curing agent is a function of desired PDMS stiffness; more curing agent increases the number of cross-links which yields a higher PDMS modulus. Upon mixture, the PDMS was degassed in a vacuum chamber at $-95 \mathrm{kPa}$ for 20 minutes to remove bubbles. Once the PDMS was clear and bubble-free, the mixture poured directly onto the master mold at a PDMS depth of $1 / 4$ ". The PDMS takes about 24 hours to completely 
harden at room temperature, but the cure was accelerated to one hour at $65^{\circ} \mathrm{C}$ in a heating oven. The PDMS was then trimmed away from the master mold by using a scalpel and peeling off the separate devices, demonstrated in Figure 23. Detailed steps of the soft lithography process, written by Josh Fadriquela, are provided in Appendix C.

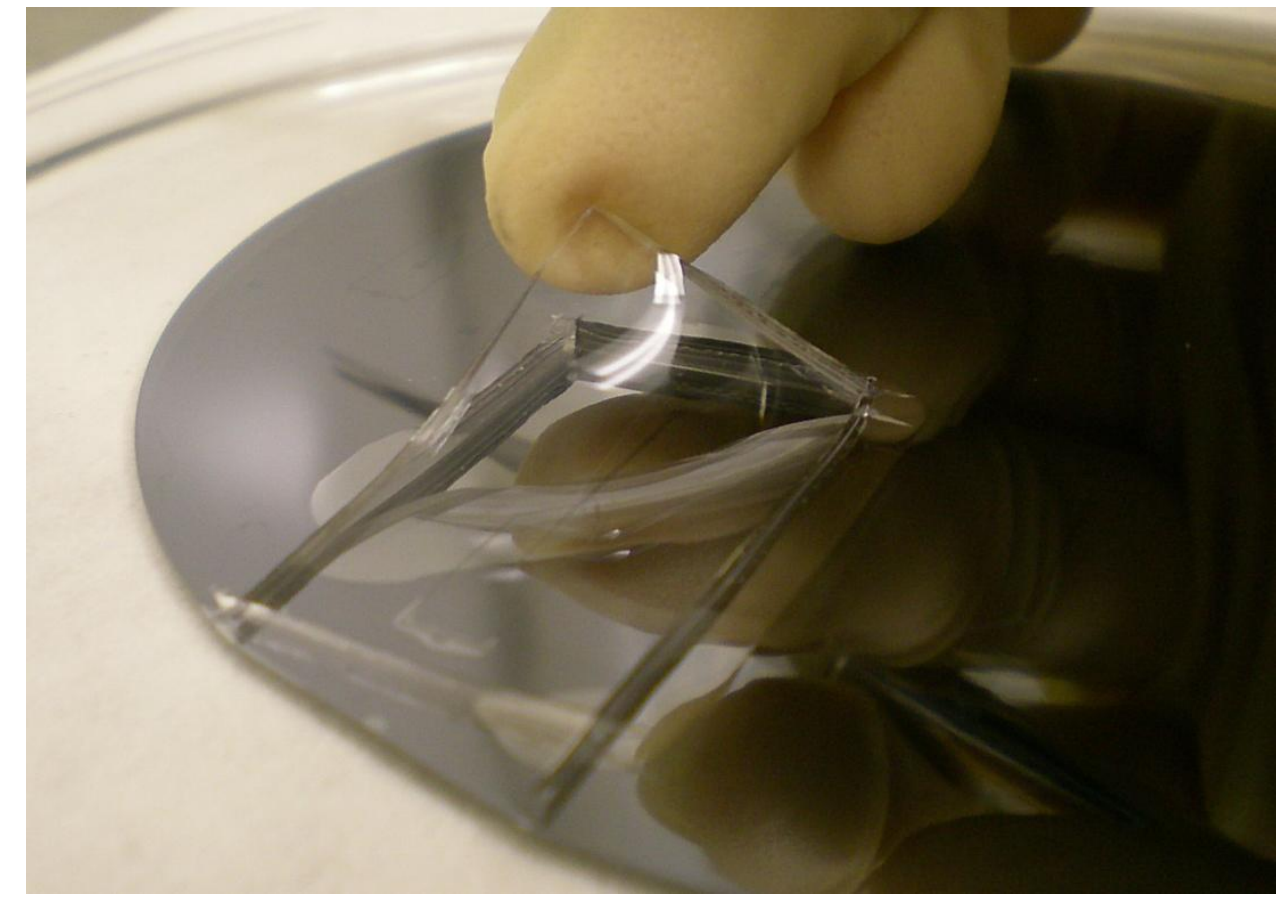

Figure 23 - A PDMS section removed from the master mold after soft lithography

\subsection{3 - Glass Bonding and Alignment}

The PDMS block in the aforementioned text combines all of the microfluidic channels and micro-features; however, the PDMS block must be bonded with a planar support that forms a water-tight seal and permits optical viewing. A standard 2" x 3" or 1" x 3" laboratory glass slide was used. A plasmatreatment machine (Duradyne, Tri-star Technolgies) from the Cal Poly 
Microfabrication Lab was used to create argon plasma to treat the surfaces, the PDMS and glass slide, to a hydrophilic nature and allowed a strong bond to inject fluid into the device. The plasma-treatment machine was set to $70 \%$ of 25 watts ( 17.5 watts) and deposited onto the surfaces at an approximate rate of 1 inch/sec. The plasma-treatment machine is seen below in Figure 24 .

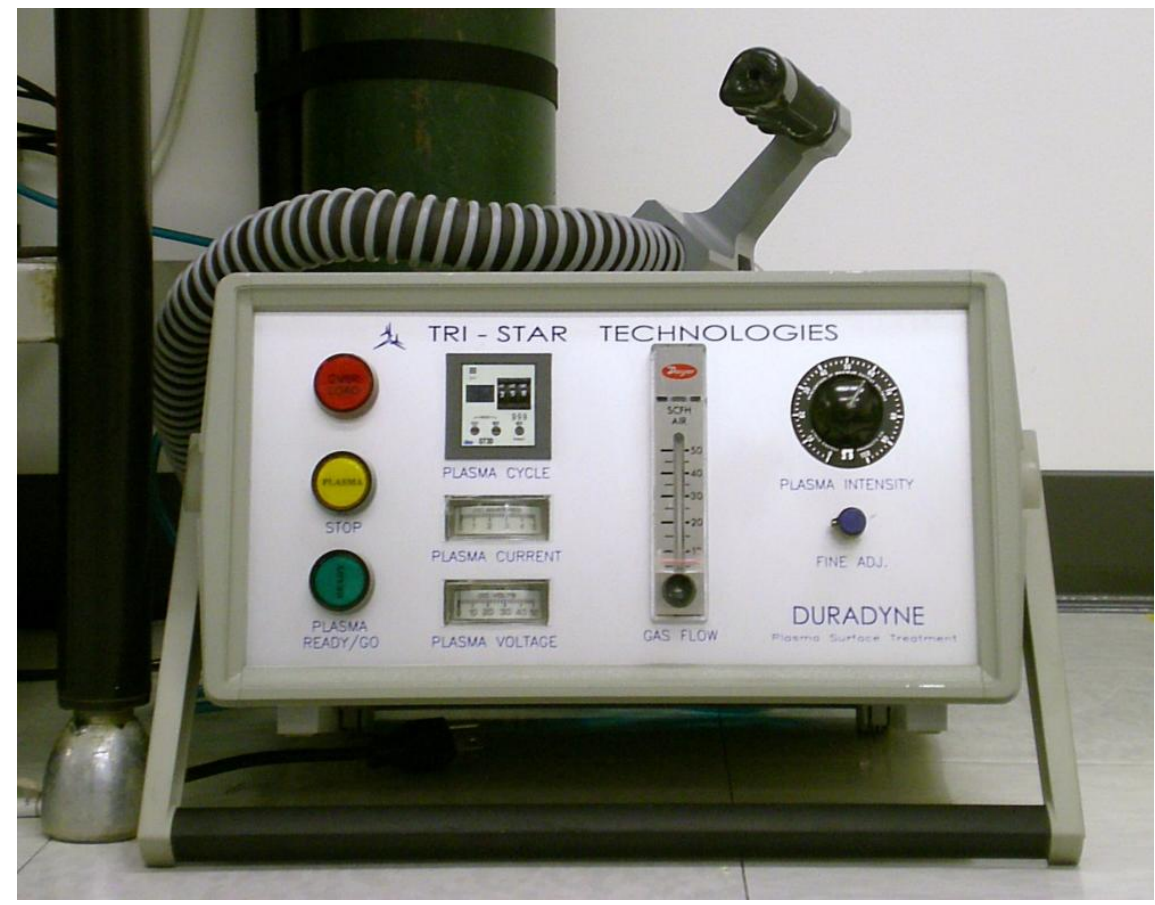

Figure 24 - Plasma-treatment machine at the Cal Poly Microfabrication Lab

Alignment marks were placed onto the glass slide by drawing a rectangle of $30 \mathrm{~mm} \times 17 \mathrm{~mm}$ from a precision marker and aligned with the alignment marks on the PDMS surface, seen in Figure 25. After plasma-treatment, the glass slide was coated with a methanol solution to create a liquid float barrier that temporarily prevents (for 5 minutes) the PDMS and glass substrate from permanently bonding. Using a microscope set at 20X, the marks were aligned 
together by careful positioning. The bonding process is finalized by putting back into an oven for an hour at $65^{\circ} \mathrm{C}$ and left alone 24 hours before testing with fluid.

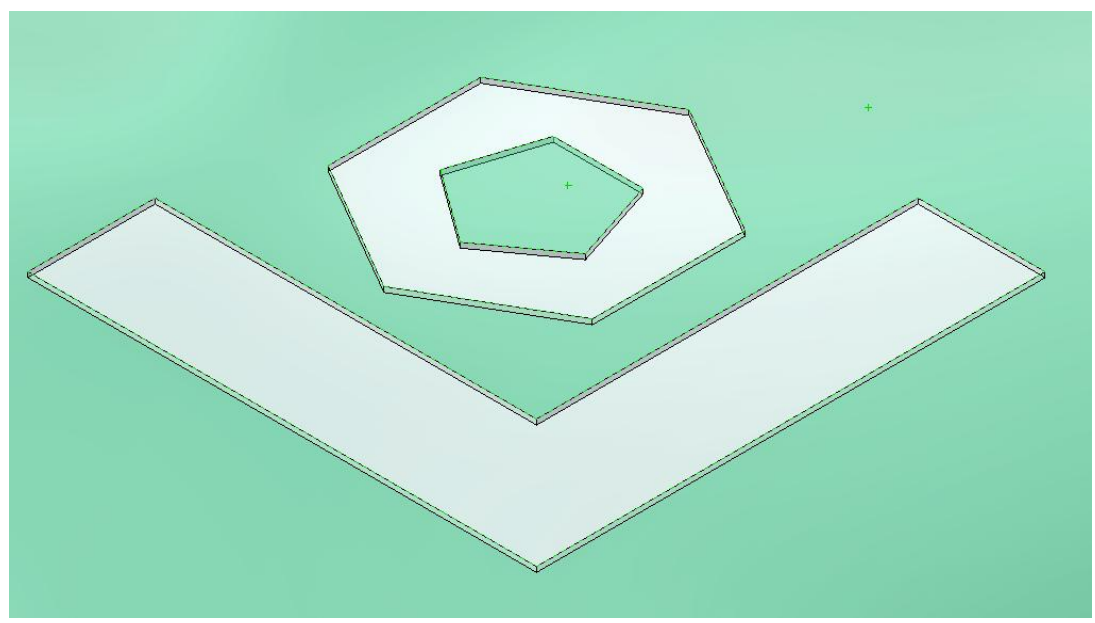

Figure 25 - Model of the Alignment mark on the PDMS surface

\section{4 - Device Implementation}

\subsection{1 - Development of the Microfluidic Test Station}

In order to properly observe the microscopic effects within the microfluidic device and control the experimentation procedures, a test station was assembled for imaging, analysis, and control of microfluidic devices. The test station is composed of 3 syringe pumps, National Instruments: Data Acquisition (NI-DAQ) cards, video-recording computers, and an inverted video microscope (LabSmith SVM340). The video microscope and NI cards have vendor supplied software for user interface. Additionally, the test station electronics were driven by LabVIEW; therefore, a computer with sufficient RAM and ROM was integrated into the system. The computer is embedded with software such as LabVIEW, ImageJ, and video microscope software provided by LabSmith. 
The specific equipment included the following parts. An inverted microscope, LabSmith SVM340, developed specifically for microfluidic purposes was attached to a Dell XPS computer to record and image devices under test. A total of three push-pull Harvard Apparatus Plus 11 Syringe Pumps were placed near the microscope to connect directly to the microfluidic device using the LabSmith Microfluidic Kit piece parts. Details on interfacing the LabSmith Microfluidic Kit with a microfluidic device is seen in Appendix D. NI-DAQ Cards (NI PCI-5124 \& 5421) were integrated with the Dell computers to provide the Waveform Generator and Digitizer, respectively. The DAQ cards were controlled through a LabVIEW Virtual Instrument program for driving and sensing the device electrodes. A picture of the Microfluidic Test Station is displayed in Figure 27.

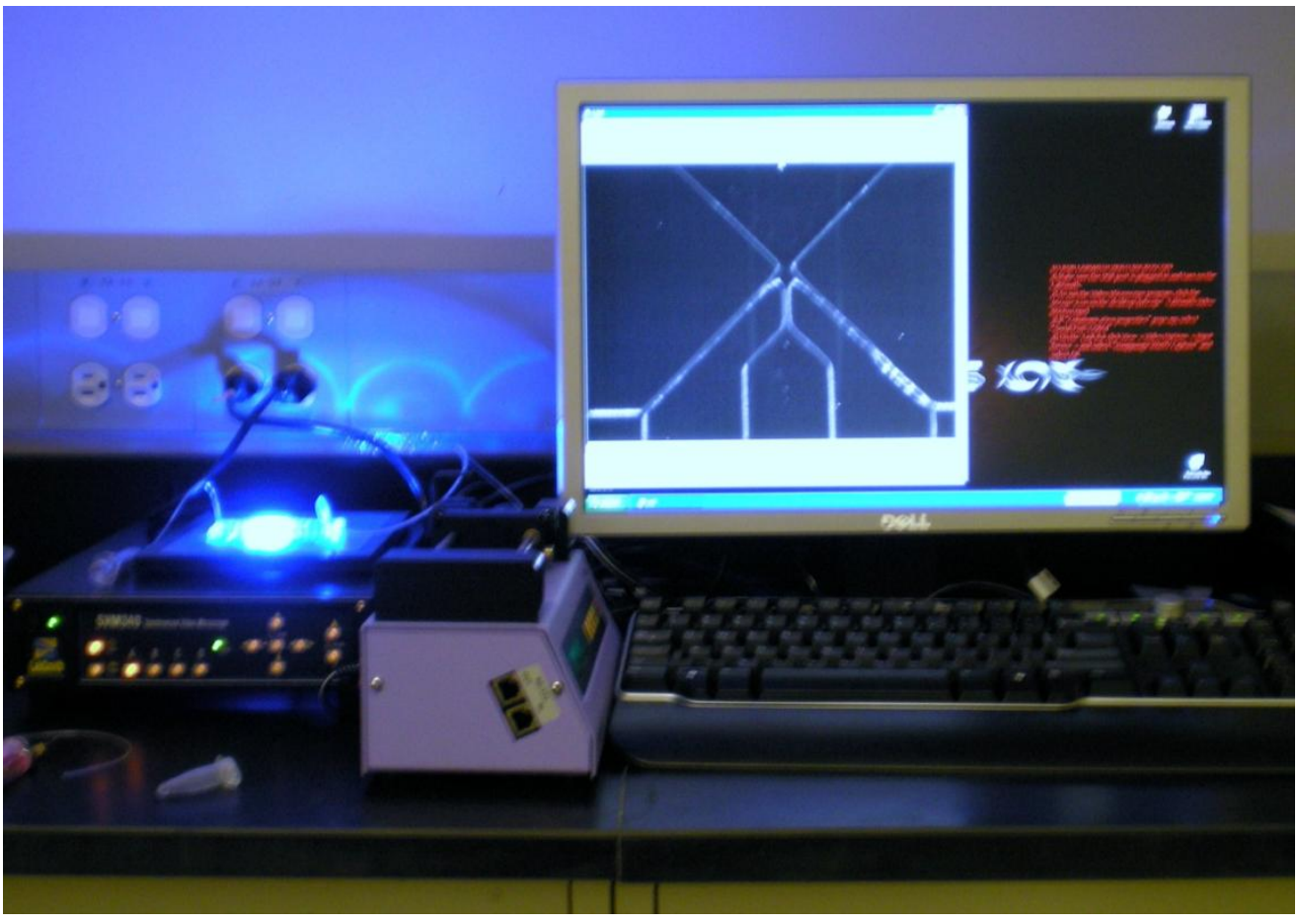

Figure 26 - The Microfluidics Test Station analyzing a Device 


\subsection{2 - Fluid Routing Circuit Package for Syringe Pump Control}

In order to perform experiments with the device, a working fluid routing circuit was prototyped and integrated with the microfluidic chip. The goal is to create an interface between the PDMS chip and external laboratory equipment, such as syringe pumps and electronics. Fixtures such as luer-lock adapters, Tvalves, and bonding ports for the inlet/outlet holes must be integrated to the device so the user has full control of the system. A schematic of the circuit system is shown in Figure 28.

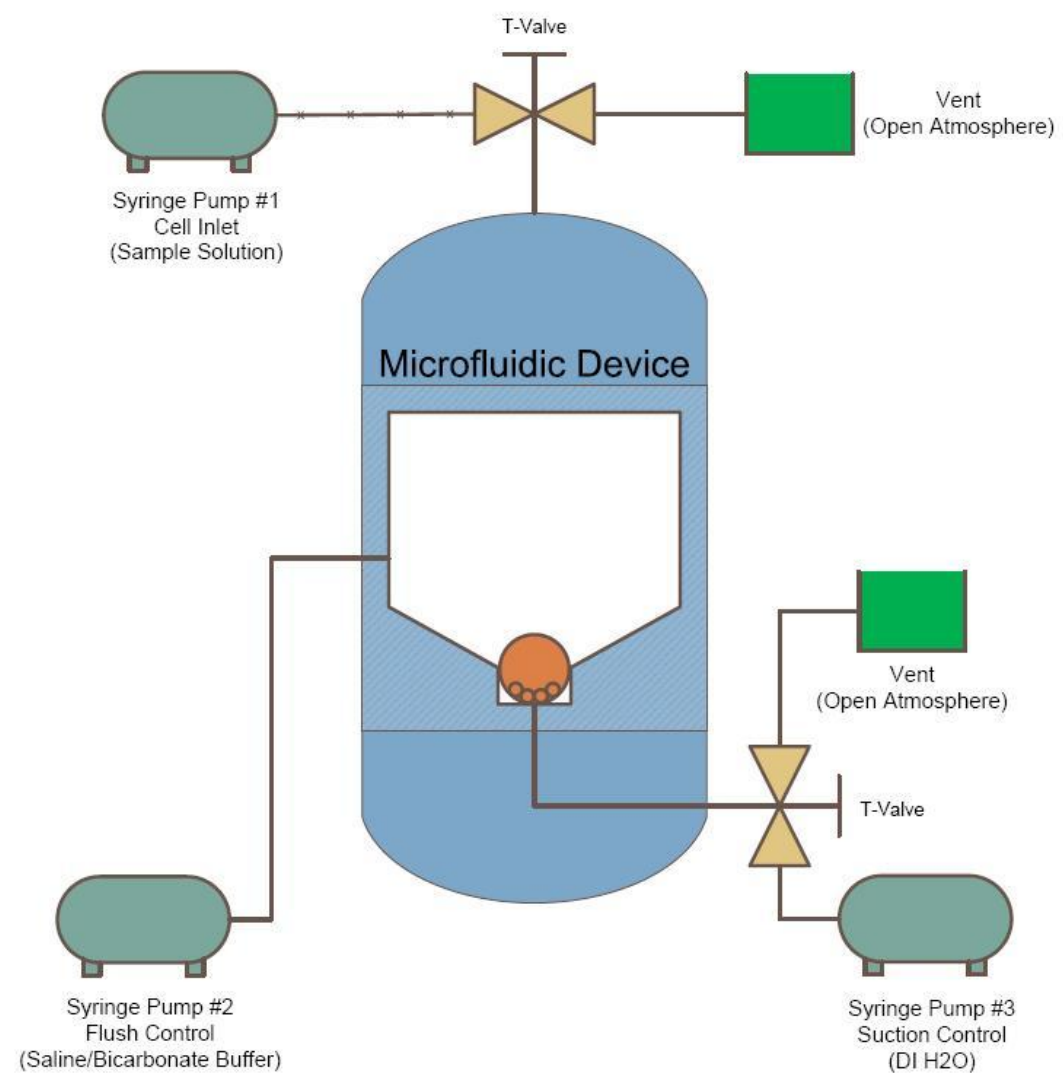

Figure 27 - Schematic of the Fluid-circuit for pumping and capture 
Luer-lock adapters are attached to the syringes so the fluid can transport to a capillary tube with a $150 \mu \mathrm{m}$ internal diameter (ID), eliminating the need of syringe needles coupled with Tygon tubing. T-Valves are used to route fluid from one direction to another. The T-valve has many uses such as routing fluid directly into the device or as open vent to allow air in the device to escape to the atmosphere. Bonding ports are specialized inputs bonded directly atop of a punched hole in the device so that the capillary tube will be sealed off and fluid can travel directly into the device. The ports are either attached via epoxy, silicone, or PDMS. The following parts were all provided from LabSmith's Microfluidic Component Kit.

\subsection{3 - Breadboard Design for Fluid Fixture Alignment and Control}

An acrylic breadboard was provided with the LabSmith Microfluidic Component Kit. The breadboard contains a grid of holes meant for affixing components such as the T-Valve or 4-way cross connectors. This will allow parts to be controlled directly onto the board that fixes onto a device. One flaw of the board is that the focal distance of the microscope is not long enough to view a device when placed on top of the breadboard. As a result, it was proposed to trim the board to fit both a 1" $\times 3$ " and 2" $\times 3$ " glass slide. The board was placed into a laser cutting machine and rectangles matching the respective dimensions were etched directly onto the acrylic. Figure 30 represents the acrylic breadboard affixing a microfluidic chip. 


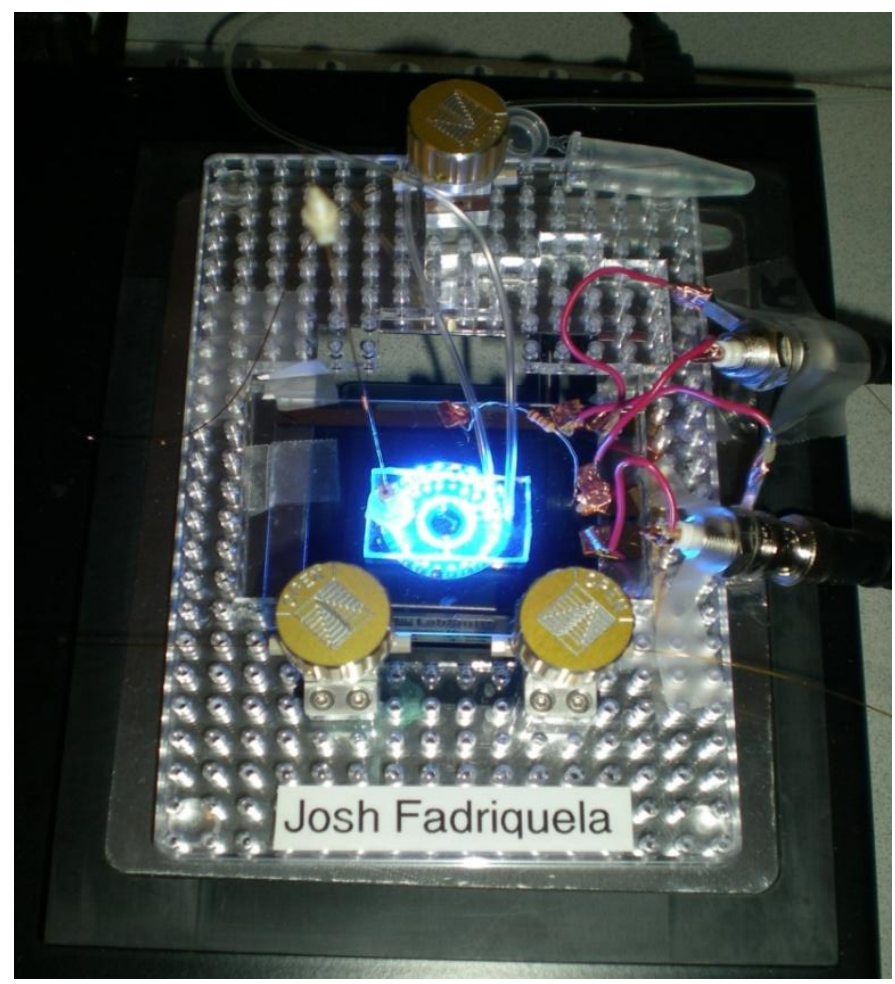

Figure 28 - Customized Acrylic Breadboard for mounting Fluid-Circuit fixtures

\subsection{2 - Computational Fluid Dynamics of Flow through Channels in} COMSOL $^{\mathrm{TM}}$

$\mathrm{COMSOL}^{\mathrm{TM}}$ was used to determine proper flow rates within the microchannels. The images and data generated from $\mathrm{COMSOL}^{\mathrm{TM}}$ gives a good visual description as well as quantitative data of the flow rates and was used to quantify if the flow rate is strong enough to induce a force to move particles away from or to trap within the chamber. Using the dimensions from the CAD model, a single chamber was imported into $\mathrm{COMSOL}^{\mathrm{TM}}$ and subjected to analysis for three different micro-flow cases: 1) General Laminar Flow, 2) Incompressible NavierStokes, and 3) Stokes Flow. An analysis of this model was performed for both 
two-dimensional (2D) and three-dimensional (3D) flow domains and data was generated to analyze velocity profiles, pressure fields, and Reynolds Numbers.

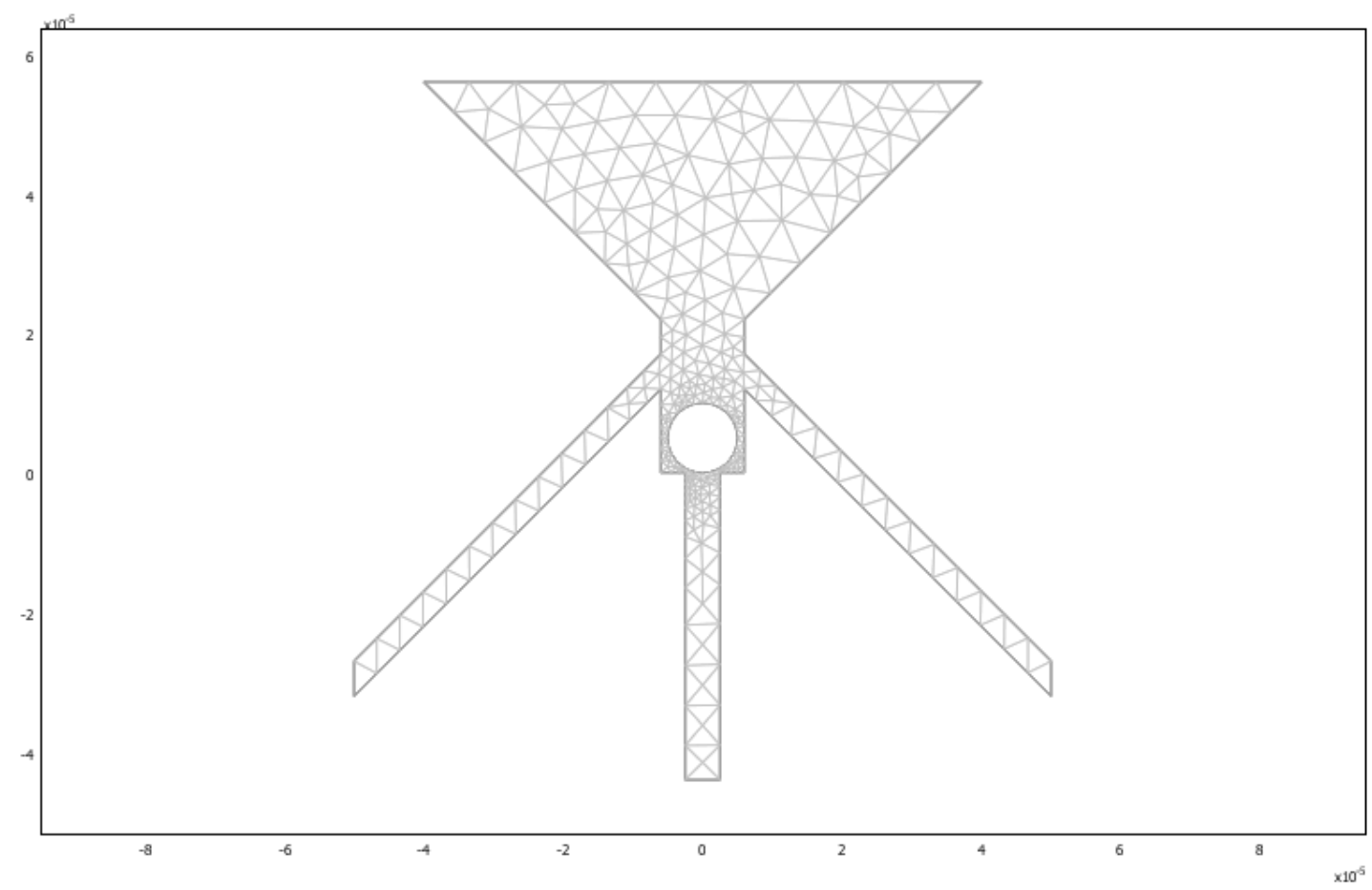

Figure 29 - Finite Element Mesh of the Cell Capture Chamber in COMSOL

\subsection{4 - Imaging and Validation of Bead and Cell Capture}

The design of the cell capture chamber was tested for capture efficacy using $10 \mu \mathrm{m}$ polystyrene beads. Using the average fluid velocity values from the aforementioned section, a bead is expected to be fixed within the capture chamber by suction pressure and the excess beads that are stacked atop of the chamber are pushed away through the flushing channels with a yield $100 \%$. To perform validation experiments, the device was integrated with the LabSmith 
Microfluidic Components to connect the syringe pumps and valves to control the flow for the sample and buffer.

A $100 \mu \mathrm{L}$ sample with a dilution of $1: 10$ of concentrated beads and buffer solution was injected at a rate $1 \mu \mathrm{L} /$ min into the inlet port of the device. When a bead is present in the chamber along with other cells stacked atop, a negative flow suction of $1 \mu \mathrm{L} / \mathrm{min}$ is applied to the suction channel. To remove the excess cells, a flow rate of $1.5 \mu \mathrm{L} / \mathrm{min}$ was applied for both flush channels so that each bead experiences an average fluid velocity of $0.5 \mathrm{~m} / \mathrm{s}$. When the analysis chamber is occupied by an isolated bead, the chamber is imaged and the bead (or cell) is ready for any optical or electrical analysis. Detailed steps for the cell introduction protocol are provided in Appendix E.

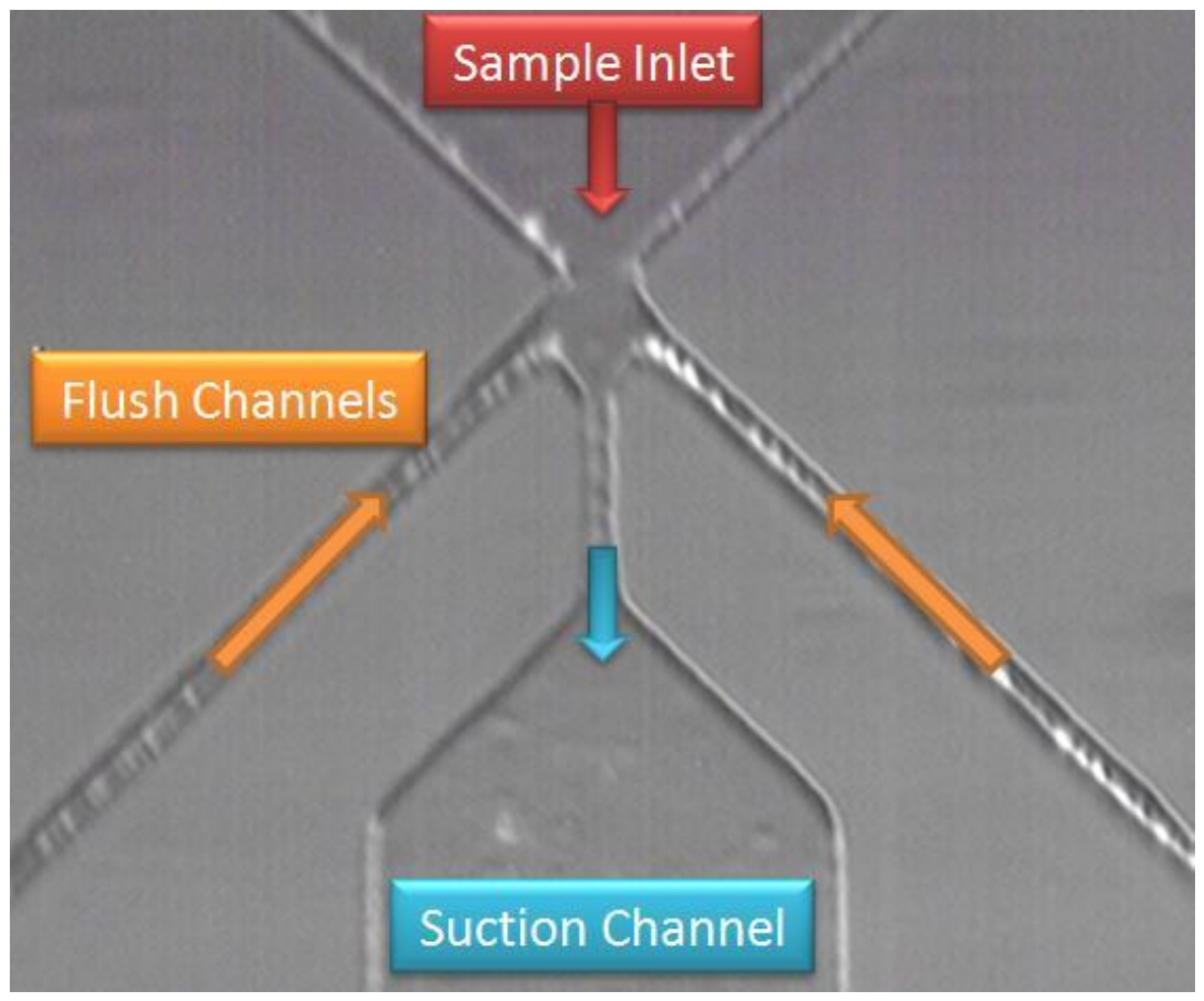

Figure 30 - Image of a Cell Chamber with Flow Directions 


\section{Results}

\section{1 - Testing of Cell Samples}

\subsection{1 - Statistical Measurement of Mean Cell Diameter}

Using the hemocytometer procedures described in the methods sections for imaging and cell counting, the images of yeast cells in the hemocytometer grid were used to determine the average cell diameter through an image postprocessing program, ImageJ. The hemocytometer image was cropped to contain the $0.04 \mathrm{~mm}^{2}$ grid as seen in Figure 34 and scaled appropriately based on the given grid dimensions and pixel-to-micron ratio.

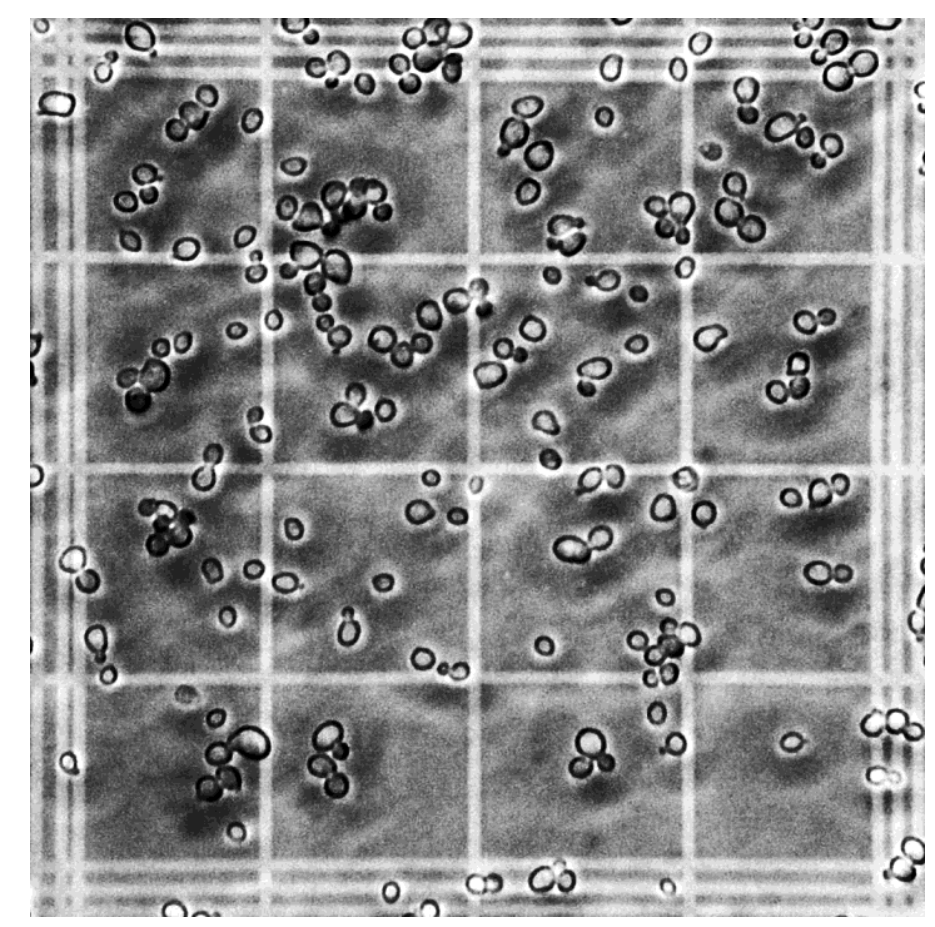

Figure 31 - The $0.04 \mathrm{~mm}^{2}$ grid from the hemocytometer for image post-processing 
An 8-bit gray-scale version of the image was used and the contrast settings of the image were adjusted to ensure that the outlines of the cells were dark enough for subtraction from the background. Using the "Image Threshold and Analyze Particles" plug-in embedded in ImageJ, the threshold of the image yielded a green environment as shown in Figure 35, where the cell can be outlined and added to a list of measurements called the "Region of Interests" (ROI). The menu-driven Image J ROI command allowed a measurement of the area for each individual outlined trace.

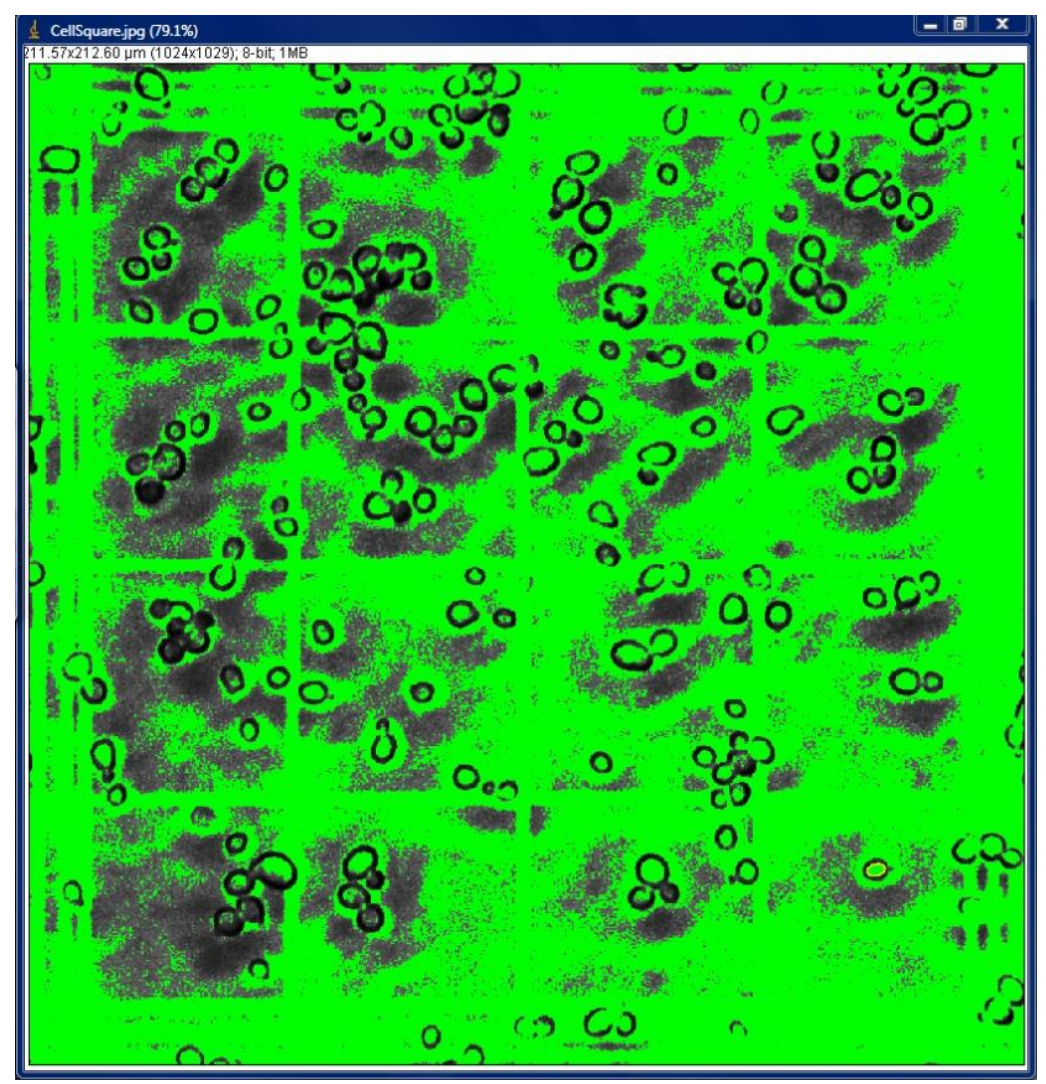

Figure 32 - Isolating Cell Shapes using Threshold Adjustments in ImageJ 
A spreadsheet was generated containing $70 \mathrm{ROI}$ measurements for each individual cell and the diameter was calculated using the equation for Area of a Circle as a function of diameter. The measurements were plotted onto a histogram to fit a normal distribution and revealed the mean, standard deviation, and number of samples taken as seen in Figure 36. Details of the statistical results (e.g. Normality, Variance, ANOVA) can be seen in Appendix F.

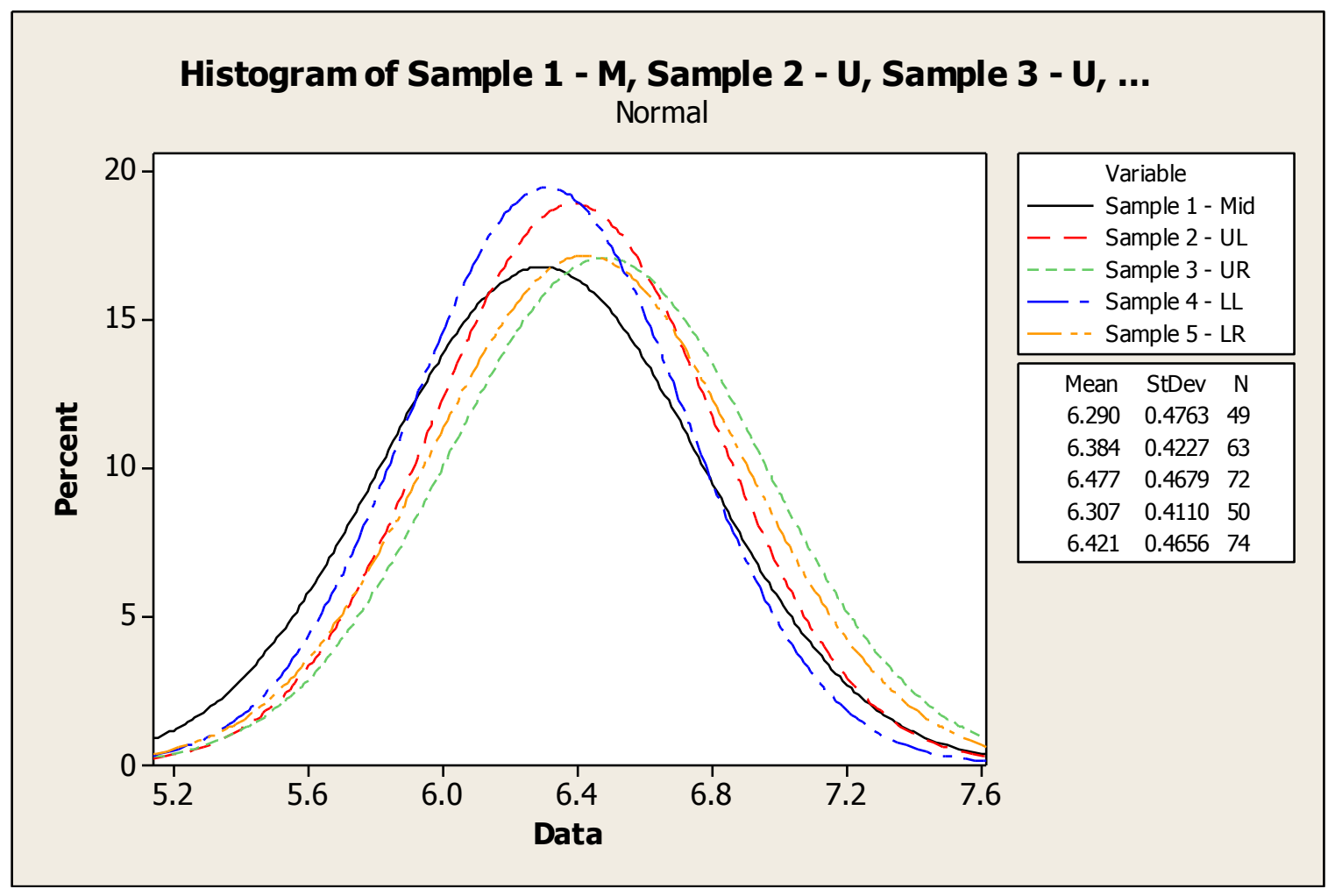

Figure 33 - Distribution of the Cell Sample displaying Average Diameter

\subsection{2 - Viability through Methylene Blue Stains}

Using the methlyene blue procedures stated in the methods, the mixture of $10 \mu \mathrm{L}$ of cell solution with $10 \mu \mathrm{L}$ of $1 \%$ Methylene blue was injected into the 
hemocytometer. This allows counting the number of viable cells and number of inactive or dead cells. The majority of cells that were viable were opaque while the inactive/dead cells turned dark blue. An example of this is shown in Figure 37.

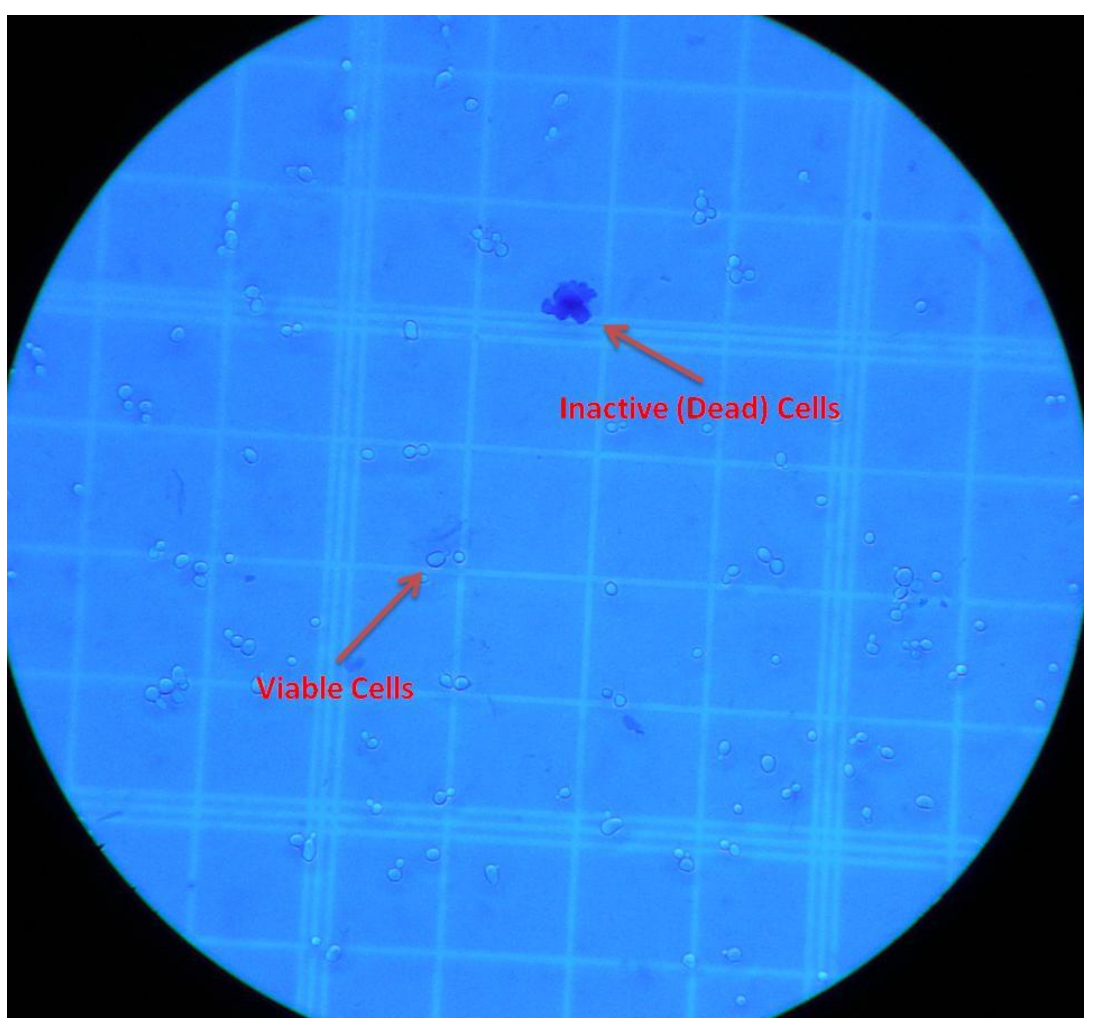

Figure 34 - Viability Test using a Methylene Blue staining technique

\subsection{3 - Dilution of Cells for Device Testing}

The hemocytometer allows users to estimate the cell dilution by counting individual particles and calculating the approximate concentration of particles per volume of fluid. Recalling the dilution formula, the concentration of the cells per $\mu \mathrm{L}$ of sample was calculated using the hemocytometer: 


$$
\frac{\text { Number of cells }}{\text { Counted area }\left(\mathrm{mm}^{2}\right) * \text { Chamber depth }(\mathrm{mm}) * \text { dilution factor }}=\text { Cells per } \mu \mathrm{L}
$$

Analyzing five of the highlighted square regions and counting the number of cells per chamber square was used to determine the average number of cells in a single grid. The estimated amounts are shown in Table 2 below:

Table 2 - Number of Cells per Hemocytometer Grid

\begin{tabular}{|lllllll|}
$\begin{array}{l}\text { Chamber } \\
\text { Square }\end{array}$ & Top-Left & $\begin{array}{l}\text { Bottom- } \\
\text { Left }\end{array}$ & Middle & $\begin{array}{l}\text { Bottom- } \\
\text { Right }\end{array}$ & Top-Right & Average \\
\hline $\begin{array}{l}\text { Number } \\
\text { of Cells }\end{array}$ & 300 & 263 & 271 & 290 & 253 & 275 \\
\hline
\end{tabular}

Using these counts and the dilution equations it was determined that the concentration of the cell solution was $13.75 \mathrm{E} 6$ cells $/ \mathrm{mL}$. Comparing this number density to the concentration of the Invitrogen Fluorosphere number density (3.6E6 beads $/ \mathrm{mL}$ ), it was determined that the saturated cell solution required further dilution. After systematic dilutions of the cell solution and cell counting, it was determined that the saturated cell sample must have a 1:4 dilution factor to match bead concentration of $3.6 \mathrm{E} 6$ cells $/ \mathrm{mL}$.

Given that the bead and cell samples have similar concentrations of 3.6E6 particles $/ \mathrm{mL}$, experiments with live cells can be compared with results from Invitrogen Fluorospheres. It was found that using the supplier number density of beads resulted in oversaturation of the test chamber and fouled the system, see Figure 38. To enable single bead (and single cell) capture, a final dilution was 
required. Using a series of trials, it was determined that the best dilution was a 1:10 ratio of cell sample solution to the sodium chloride and sodium bicarbonate buffer solution. Specifically, collecting $0.1 \mathrm{~mL}$ of cell solution and $1.0 \mathrm{~mL}$ of buffer solution yielded the best dilution for device testing.

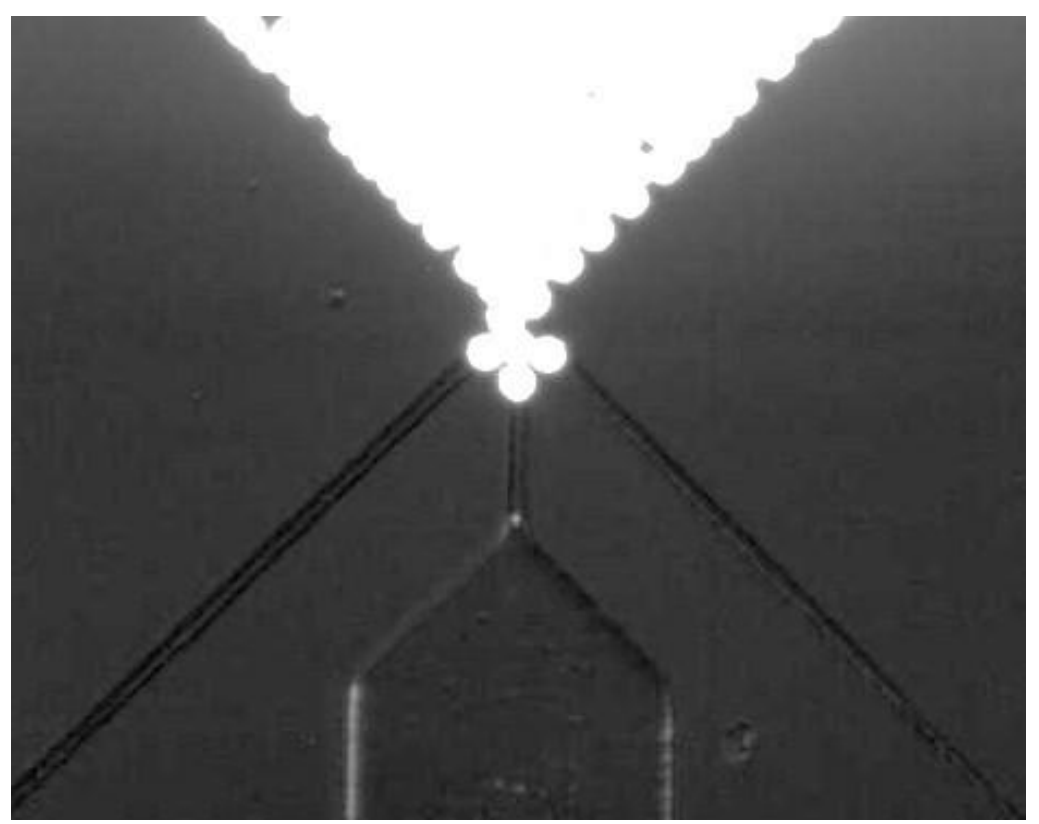

Figure 35 - An oversaturation of $10 \mu \mathrm{m}$ beads in the capture chamber

\section{2 - Fabrication Results of Microfluidic Devices}

\subsection{1 - Comparisons between the CAD and Mask}

The photo-plotted transparency mask from CAD/Art Services was limited to 20000 DPI (dots-per-inch); therefore, desired feature sizes on the mask that are less than $8 \mu \mathrm{m}$ tend not to precisely match CAD drawing features. Precise CAD drawing-to-mask matching can be achieved using expensive chrome masks (i.e. $\$ 10 \mathrm{~K}$ chrome mask). As a consequence, some of the features of the 
microfluidic design that were below $8 \mu \mathrm{m}$, notably the $3.5 \mu \mathrm{m}$ bottom layers that the bead or cell rests on, exhibited notable differences when compared to the CAD drawing as seen in Figure 39; however, the differences did not affect device performance. In practice, the actual device features can even be considered an advantage since the realized shapes comfortably fits a $10 \mu \mathrm{m}$ particle. The $5 \mu \mathrm{m}$ wide channels that control the flushing and suction actions of the device proved not to be an issue since fluid was able to flow through and therefore was proposed that the limit of $8 \mu \mathrm{m}$ or greater applied only to device features rather than channel widths.

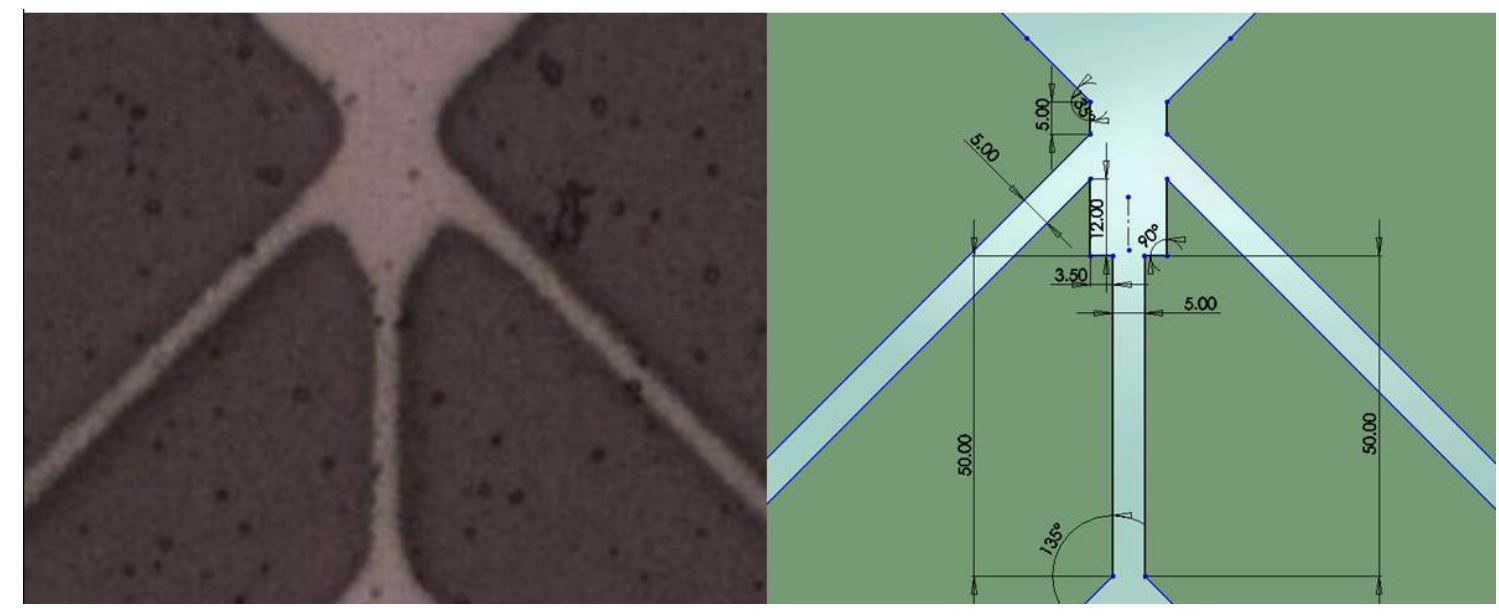

Figure 36 - Comparisons between: (left) Transparency Mask Features at 20k DPI and (right) CAD dimensions

\subsection{2 - Imaging of Final Device before Testing}

After bonding of the PDMS layer to a glass slide, the device was ready for testing. To ensure proper device function, the fluid chamber entrances and exits were imaged during operation with pure fluid. The device needed to be imaged to 
determine if features came out correctly during fabrication and that the holes were bored out properly allowing fluid to enter/exit the device. Figure 40 shows an image of a device, PDMS bonded to glass, prior to testing to ensure that channels are not closed off, ceilings aren't collapsed, and that the device is free of any debris within channels.

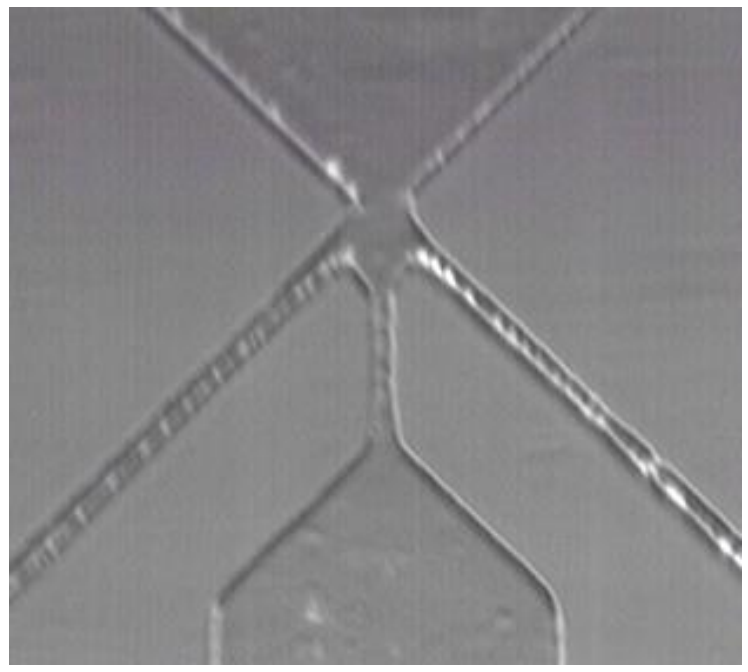

Figure 37 - Empty Microfluidic Device Ready for Testing

\section{3 - Modeling of the Cell Chamber}

\subsection{1 - Velocities and Reynolds numbers for Various Channel Widths}

Based on Volumetric Flow Rates, average fluid velocities and Reynolds numbers were determined for various channel widths. To accomplish this, an excel spreadsheet was developed to perform simultaneous calculations. A screenshot of the spreadsheet can be seen below in Figure 41 . To use the spreadsheet, the user enters the volumetric flow rate in units of $\mu \mathrm{L} / \mathrm{min}$ in the blue cell and the orange values on the right yield the average velocity and 
Reynolds Number for the different channels widths that are common in the device (see Figure 39). The spreadsheet shown in Figure 41 assumes the case for applying a flow rate of $1.5 \mu \mathrm{L} / \mathrm{min}$. It should be noted that PDMS deforms under pressure and that the calculated velocities and Reynolds numbers do not take into account back pressure or structural changes.

\begin{tabular}{|c|c|c|c|c|c|c|c|}
\hline \multicolumn{2}{|c|}{ Flow Rates } & & & & & & \\
\hline \multicolumn{8}{|l|}{ constants } \\
\hline rho, $\mathrm{kg} / \mathrm{m}^{\wedge} 3$ & thickness, $\mathrm{m}$ & viscosity, $\mathrm{Pa}^{*} \mathrm{~s}$ & & & & & \\
\hline 1000 & $1.00 \mathrm{E}-05$ & 0.001 & & & & & \\
\hline \multirow{7}{*}{ Q, uL/min } & $Q, u^{\wedge} \mathbf{3} / \mathrm{min}$ & width, um & width, $m$ & CSA, um^2 & $\mathrm{V}, \mathrm{um} / \mathrm{s}$ & $\mathrm{V}, \mathrm{m} / \mathrm{s}$ & $\mathbf{R e}$ \\
\hline & $1.50 E+09$ & 5 & $5.00 \mathrm{E}-06$ & 50 & 500,000 & 0.500 & 3.3 \\
\hline & $Q, u^{\wedge} 3 / s$ & 6 & $6.00 \mathrm{E}-06$ & 60 & 416,667 & 0.417 & 3.125 \\
\hline & $2.50 E+07$ & 7 & 7.00E-06 & 70 & 357,143 & 0.357 & 2.9 \\
\hline & $Q, m^{\wedge} 3 / s$ & 8 & $8.00 \mathrm{E}-06$ & 80 & 312,500 & 0.313 & 2.8 \\
\hline & $2.50 \mathrm{E}-11$ & 15 & $1.50 \mathrm{E}-05$ & 150 & 166,667 & 0.167 & 2.0 \\
\hline & & 300 & $3.00 \mathrm{E}-04$ & 3000 & 8,333 & 0.008 & 0.16 \\
\hline
\end{tabular}

Figure 38 - Spreadsheet for calculating velocity and Reynolds Number based on flow rate

\subsection{2 - Modeling of Fluid Dynamics}

The COMSOL models yields quantitative and qualitative descriptions of velocity magnitudes in the flush and suction channels and in the assay and device supply chambers. Since the parameters for effective single-cell capture differ, e.g. pressure within the chamber, type of cell captured, and degree of excess cell stacking in the capture chamber, the respective velocity values may 
differ accordingly. However, in all cases it is possible to determine a velocity ratio that can perform the effects as shown in Figure 42.

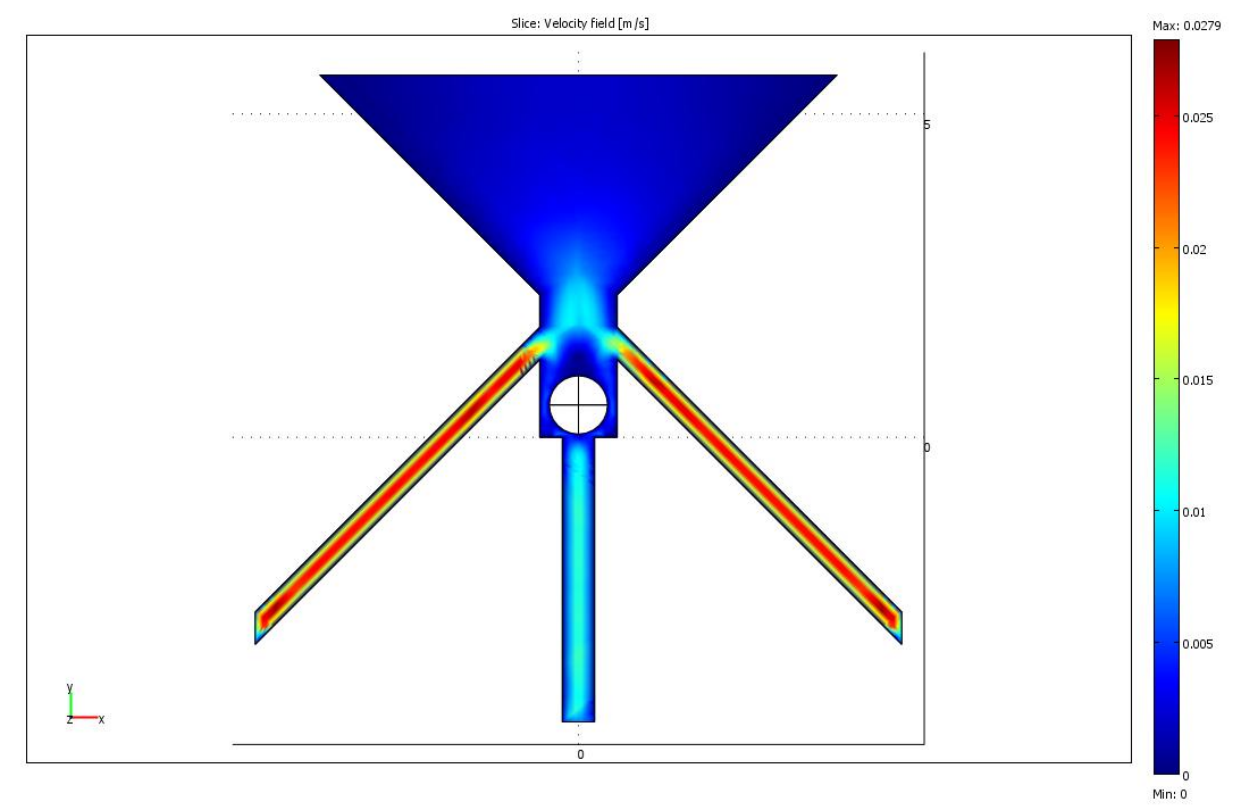

Figure 39 - Two-dimensional laminar flow velocities displaying magnitude of flow near the Chamber

The model predicts no change in single-cell capture as long as the ratio between suction velocity and flush velocity is held constant; the one caveat being as long as applied pressure and velocities are not large enough to induce mechanical lysis. It was found that a velocity ratio of $2: 3$, the negative suction velocity to the flush velocity, for a single channel was optimal. To ensure that the $2 \mathrm{D}$ model was correct with the shallow channel approximation $\left(\mathrm{COMSOL}^{\mathrm{TM}}\right.$ MEMS), a 3D model was constructed from the SolidWorks model. A threedimension analysis showing the cross-sections can be seen in Figure 43. This analysis confirmed the predicted velocity ratio and elucidated important effects of the bottom edge of a sphere due to the suction chamber. 


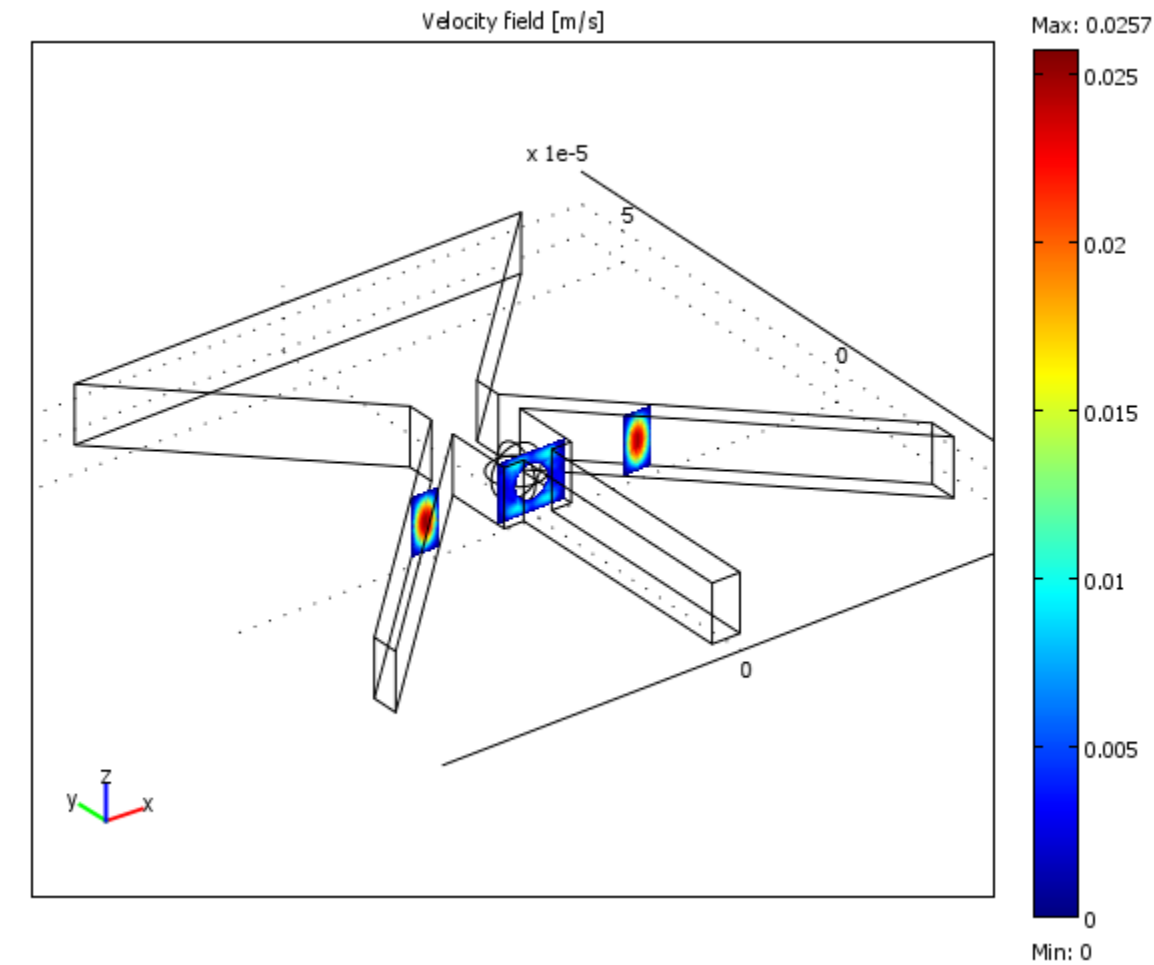

Figure 40 - Three-dimensional cross-sectional model showing velocity of side channels and suction effects due to the channel beneath the chamber

To enable evaluation of mechanical forces on captured cells, the $\mathrm{COMSOL}^{\mathrm{TM}}$ model was used to evaluate the induced pressure fields and directionality as seen in Figure 44. This result illustrates pressure distribution during operation and fluid flow in the case of an ideal cell capture. 


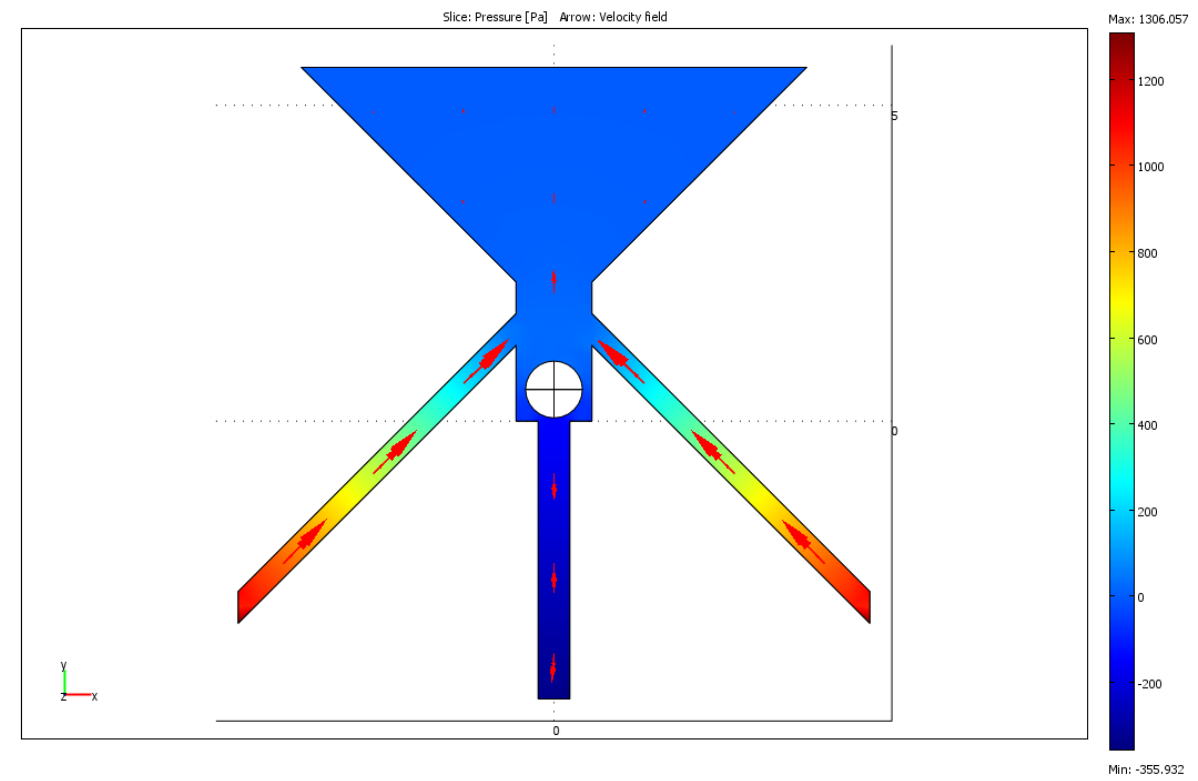

Figure 41 - Two-dimensional view of the magnitude of pressure within the chamber and arrows dictating the direction of fluid flow

\section{4 - Cell Capture and Testing}

\subsection{1 - Fully Integrated and Packaged Chip Assembly}

Using LabSmith Microfluidic Component Tools, Small Parts Tygon tubing, and various electronic connections provided by the companion project, a fully integrated and packaged chip assembly was produced and can be seen in Figure 45. 


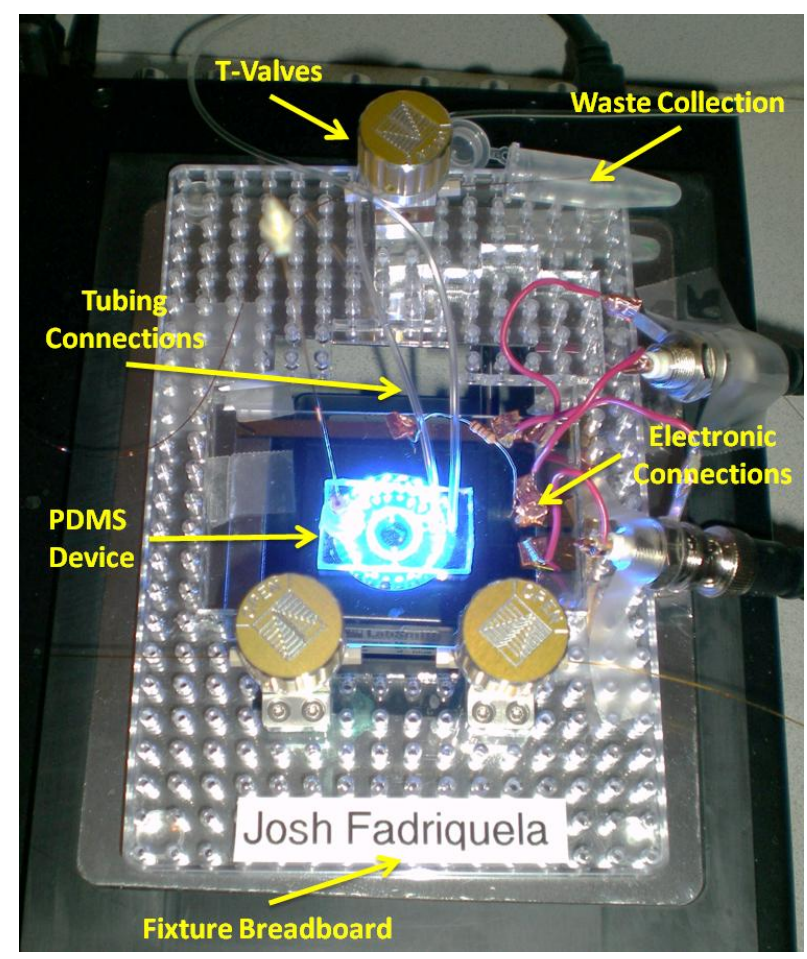

Figure 42 - Fully Integrated and Packaged Chip Assembly

\subsection{2 - Sample Introduction and Capture Protocol}

It was determined that consistent methods needed to be applied for sample introduction and capture protocols to ensure repeatability and target particle capture. Before introduction of the sample solution, the T-valve for controlling sample flow, see Figure 45 above, was set to route the solution to the waste chamber, and the device was filled with buffer at a rate of $5 \mu \mathrm{L} / \mathrm{min}$. When the device was filled with buffer, the T-valve was turned to allow the sample solution to enter the device. Through experimentation, it was determined that the sample should be introduced at a slow flow rate so that target particles do not oversaturate the chamber too rapidly; therefore, a flow rate of $1 \mu \mathrm{L} /$ min was used 
while the T-valve controlling the suction channel was allowed open to vent out excess fluid inside the device.

When target particles stack automatically in the chamber, such as the example in Figure 46, the sample solution syringe pump was turned off and the T-valve is turned to the opposite direction which will vent and let excess fluid escape to waste. To ensure that the particle in the chamber does escape, the suction channel maintains suction to hold the particle in place and the flushing channels are activated to push out the excess particles leaving a single target particle in the assay chamber. After single-cell analysis, the chamber can be cleaned by reversing the suction channel to a positive velocity which will push out the cell in the chamber and to the waste.

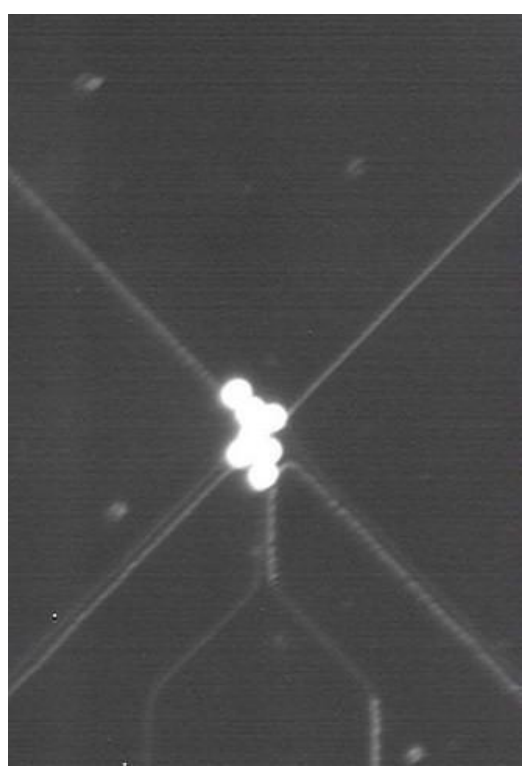

Figure 43 - Beads Stacked Atop Chamber during Sample Introduction

\subsection{3 - Capture of a $10 \mu \mathrm{m}$ Bead and Yeast Cells}


The efficacy of the design was determined by the successful capture of a single $10 \mu \mathrm{m}$ target particle in the chamber. An image was taken to show the capture sequence for $10 \mu \mathrm{m}$ polystyrene beads and can be seen below in Figure 47.

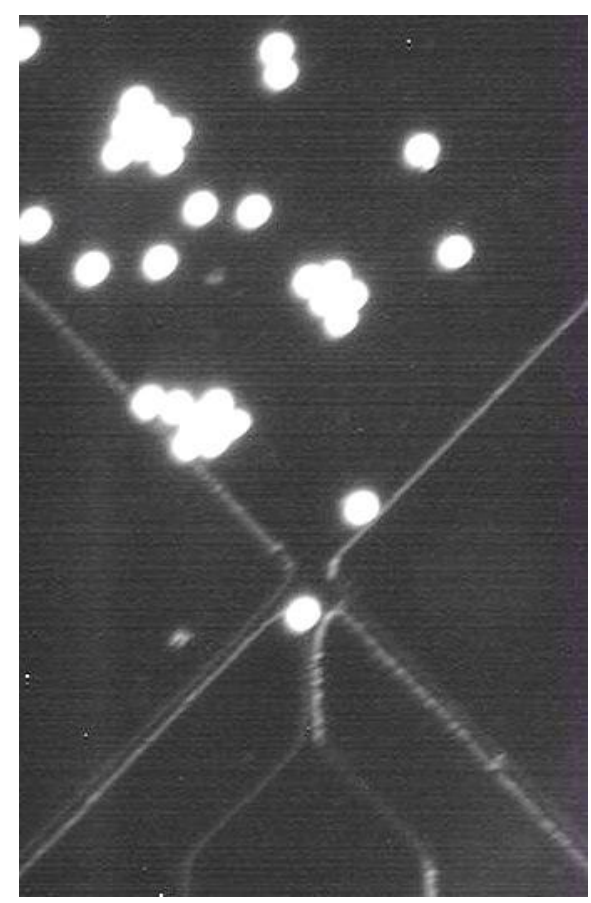

Figure 44 - Single Bead Isolation Using Flushing Velocities from Side Channels

With all the protocols worked out and a successful demonstration, the device assembly was evaluated using a comparable solution of yeast cells, see Section 4.1.3. The cell capture assay can be seen in Figure 48. 


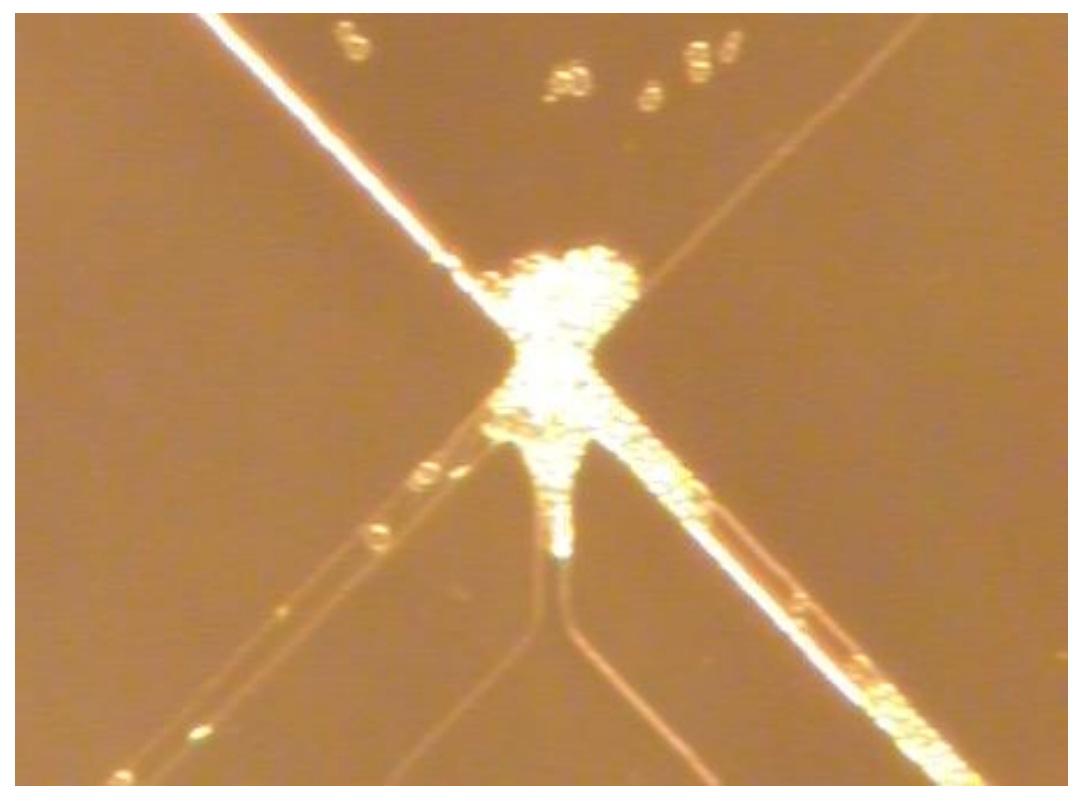

Figure 45 - Yeast Cells inside the capture chamber 


\section{Discussion}

Impedance sensing is a known approach for cell diagnostics [53].

Typically, samples under test require pretreatment to a certain dilution and physical filtration employing bench-scale instruments to isolate individual cells.

The use of microfluidic devices to make a lab-on-a-chip system is an alternative to using standard laboratory instrumentation. Owing to the ease of device design, fabrication, and integration, such devices can afford rapid prototyping and proofof-concept at low cost. An additional advantage to making this device is that it can be combined with other microfluidic devices to make a system;

consequently, the impedance sensor described in this thesis can be used as a sensing technology in combination with other sample preparation devices [54].

It follows that the overall goal of the Cal Poly Biofluidics Research Group is to develop microfluidic devices aimed at developing disease biomarker biosensing systems. The individual devices include those for electrophoresis, dielectrophoresis, and mixing chambers. Current projects done by this group are in the development stage and will eventually be integrated with a microfluidic impedance sensor.

One such example, funded by DARPA, that is currently in progress is the development of a portable diagnostic tool for point-of-care use for deployed military personnel [55]. If in the event, this point-of-care system could in principle enable minimally invasive, rapid detection to protect personnel and guide battlefield decisions. A collection of microfluidic devices can be packaged as a portable 
hand-held system and operated entirely on a microfluidic scale. Use of such a hand-held system would only require the user to inject a small volume of sample fluid into the device using, say, chromatographic injection.

Once introduced into the system, the sample physicochemical properties are adjusted to enable down-stream sample preparation. Real samples are complex and require various levels or degrees of preparation (purification) prior to detection; therefore, the sample will go into a device aimed at pre-sample treatment such as a mixing chamber to obtain the proper dilution needed for the impedance sensor. The impedance sensor can determine what condition that sample is in through comparison of the impedance database. The resulting impedance spectra for target particles, molecules to cells, can be compared with a database of "normal" spectra. Finally, when the sample condition has been determined, the fluid will route to a filtration device to separate samples accordingly based on the device either by isoelectric focusing, dielectrophoresis, or isotachophoresis [24, 56-58]. The Biofluidics Group aims to assemble these devices together to create a design prototype for further development.

Through testing and analysis of a functional prototype of the microfluidic impedance sensor, we determined that the PDMS cell-capture chamber had successfully fulfilled the project goals. First, the channel designs were developed through the aid of Biomedical, Material, and Mechanical Engineering faculty and research groups. Also, the device was fabricated and assembled entirely in the university clean room without the aid of outsourcing to a foundry. Second, a test station was assembled to analyze the device and was used to develop cell 
isolation and device re-use protocols. Using the equipment, parts, and tools for microfluidics gave us the ability to rapidly test multiple devices and develop standard operating procedures for microfluidic testing and analysis. Third, the device has successfully shown capture of both test beads and cells. The experimentation resulted in protocols to demonstrate capture using different analytes as well as understand the fluid mechanics in a micro-channel. Finally, the PDMS component was used for a companion project associated with producing an electric field within the chamber area of the microfluidic device and to collect an impedance spectrum. This was accomplished by bonding the PDMS component and aligning it with a glass substrate with patterned electrodes.

These accomplishments and procedures have led to future experimental research and of generation of impedance spectra.

\section{1 - Cell Measurement Analysis}

Based on the measurements of the yeast cell samples, we were able to create a cell concentration that matches of the stocked concentration of fluorescent test beads from Invitrogen at 3.6E6 particles $/ \mathrm{mL}$. Using the images to do cell counting in a hemocytometer, the image post-processing program was also able to measure the physical dimensions of cells. The statistics had determined that the average diameter was $6.4 \mu \mathrm{m}$.

Ideally, we expected that the average diameter for the yeast samples to be $10 \mu \mathrm{m}$. We desired this size because the smallest feature size possible when dealing with $20000 \mathrm{DPI}$ transparent photo-plotted masks for microfabrication is limited to $8 \mu \mathrm{m}$. Though the average diameter is significantly different from 10 
$\mu \mathrm{m}$, it was determined that experimentation still worked well with the measured samples. First, though the suction channel had a designed width of $5 \mu \mathrm{m}$, fabrication variables can change this dimension by $\pm 2 \mu \mathrm{m}$ (refer to Fabrication Methods Section 3.3). When a single cell less than $5 \mu$ m enters the capture chamber, it will be transported via suction to the waste, allowing a larger cell to be positioned in the assay chamber. Second, it was observed that when cells were sitting in the chamber and the negative suction velocity was turned off, small cells were prevented from exiting. In Figure 50, we can see how the smaller cells can still be captured in the chamber.

a)

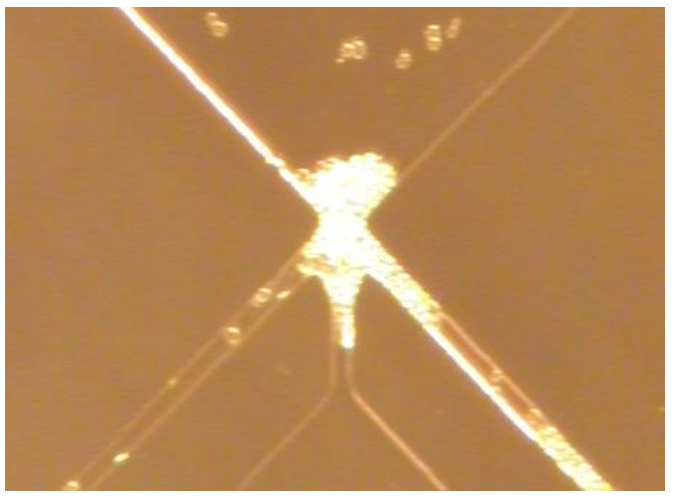

b)

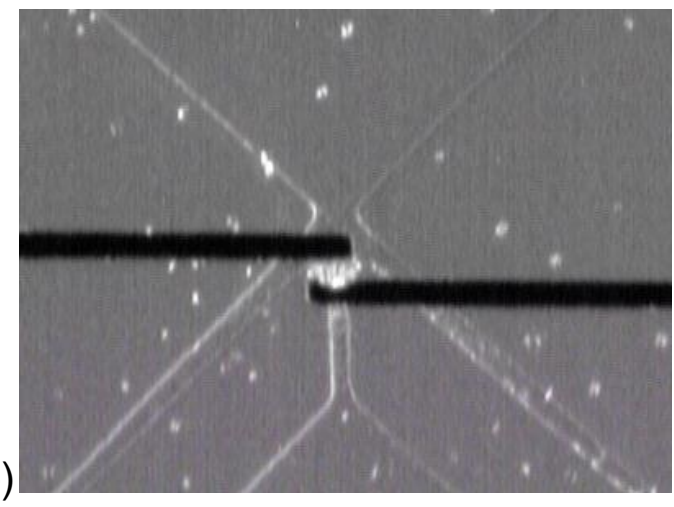

Figure 46 - a) Small $6 \mu \mathrm{m}$ cells in the chamber; b) same $6 \mu \mathrm{m}$ cell sample in between electrodes

Based on these findings, it was determined that testing with the current cell sample with an average of $6.4 \mu \mathrm{m}$ would give us satisfactory results for cell capture testing. The bead capture of $10 \mu \mathrm{m}$ clearly demonstrated that a cell sample with an average of $10 \mu \mathrm{m}$ can also be captured. It is possible to acquire a sample such Blastomyces dermatitidis or HeLa cells but due to the convenience, 
low-cost, and minimal biological hazards of growing a Saccharomyces cerevisiae culture, yeast cells were used in the experimentation.

\section{2 - Device Evaluation}

The device, manufactured using a PDMS component bonded with a glass slide, proved successful experimental evidence, ease of use, and reproducibility of test results. The evaluation was based on three goals: 1) introduction of fluid into micro-channels by a mechanically-controlled syringe pump, 2) movement of particles using theoretical first order estimates and numerical simulation, and 3) isolation of a single or small collection of particles in the cell chamber.

The introduction of fluid by syringe-pumps is critical for introducing sample fluid and controlling velocity in the suction and flush channels. Based on the calculated values from the volumetric flow rate and Reynolds numbers, the values were compared to both the COMSOL simulations and the experimental measurements. Fluid velocities predicted by the COMSOL simulation were in good agreement with experimental velocity values.

The velocity ratio of the suction and flush channels was quantified through the finite-element modeling of the fluid dynamics in $\mathrm{COMSOL}^{\mathrm{TM}}$. Owing to the complex geometries and boundary conditions of the chamber, a computational modeling process must be used rather than hand calculations. The visual intensity of fluid flowing in the channels by a high velocity gave us a unique description of how the fluid should interact with obstructions, such as excess particles, near the capture chamber. The $\mathrm{COMSOL}^{\mathrm{TM}}$ results yielded consistent and similar plots for velocity parameters. Using the results, the velocities were 
converted to volumetric flow rate through the mass continuity equation, $Q=$ $A_{c}{ }^{*}<V>$. The predicted velocity ratio $2: 3$ was shown to be correct and at this ratio the fluid performed the desired particle manipulation. While each cell line would require unique suction and flush velocities to achieve single cell isolation, the ratio to achieve successful isolation was consistently $2: 3$.

Following this channel velocity characterization study, it was observed that a single particle (10 $\mu \mathrm{m}$ test bead) had effectively been isolated and centered into the channel chamber. It was also demonstrated that a collection of small yeast cells (approximately $6 \mu \mathrm{m}$ ) can be captured in the chamber as well. This is the most critical functional requirement for the device to perform single-cell impedance experiments. A demonstration of this process was duplicated in different trials as well as with other duplicate devices made from the same master mold. Therefore, it was determined that the PDMS component design had accomplished the functional requirements and was a candidate for assembling the final device, a microfluidic impedance sensor with integrated electrodes. 


\section{Conclusion}

The microfluidic impedance sensor is an important biomedical device that can generate a catalog of impedance spectra for cellular and sub-cellular disease diagnostics. This project of developing the impedance sensor constitutes a new paradigm for disease detection and quantification and is interdisciplinary in nature. The design, fabrication, and implementation of the PDMS component with a substrate such as glass with patterned electrodes were critical steps to develop a functional microfluidic impedance sensor.

The next step for the microfluidic impedance sensor is to integrate the assembled device with patterned electrodes and an electronics work station. A companion project performed by Stephanie Hernandez deals with the electronics aspect of the microfluidic impedance sensor and features an impedance comparison of fluid, live yeast, dead yeast, and a polystyrene bead. Using a data acquisition program operating under National Instrument's LabVIEW, the operator captures a single-cell using the methods described in this project and performs a frequency sweep from $1 \mathrm{kHz}$ to $40 \mathrm{MHz}$ at voltage amplitudes of 0.1 Volts. The goal is to create a catalog of impedance spectra and compare the data generated from experimental testing to those in literature [10,13-18].

Upon completion of the experimental testing and validation with literature values, the final task of the project is to package the device to be portable and user-friendly. It is possible to achieve this by integrating the device with an LCD, microelectronics, and batteries such as the Metrika assay device [53]. Currently, 
the device described in this thesis is a proof-of-concept and requires external power-driven sources such as syringe pumps and a computer; however, there exists some possible solutions for a packaged, portable point-of-care system for our microfluidic device. Alternatives of syringe pumps to drive fluid in channels can be replaced by either electrostatic actuation or membrane valve diaphragm pumps. A computer can be replaced by using a USB-operated data-acquisition card that can attach to a portable laptop or possibly a cell phone, PDA, or smart phone with a programmable operating system such as Java, $\mathrm{C}++_{+}$, or the iPhone using Xcode. Current university projects that deal with microfluidic packaging are in progress through both the Biofluidics Research Group and the Micro Systems Technology Group.

The Gen3 single-chamber design has shown great promise and produced results necessary for proof-of-concept; however, there are plenty of opportunities for improvements to create a fully packaged device. One possible recommendation is to develop a way to sort cells based on diameter prior to entering the chamber so that the desired cell size will be captured. This can be accomplished using physical filtration and dielectrophoresis (DEP). Another recommendation is to develop a filter channel prior to the capture chamber that separates particulates from cells and prevents channel clogging.

The completion of the PDMS single-cell capture chamber is the first step in developing a portable microfluidic impedance sensor. Design and fabrication for microfluidics involves understanding scaling physical phenomena at the micro-scale as well as microfabrication. The device was built entirely in the Cal 
Poly University Clean Room and therefore projects of this scope and impact can be performed at Cal Poly San Luis Obispo. Additionally, all master molds can be re-used in the future to produce PDMS devices for future research and development. 


\title{
Appendix
}

\section{A. Design Rules for Developing Microfluidic PDMS Designs}

\author{
based on the Stanford Microfluidic Foundry criteria
}

\section{Mask Design Rules}

Masks for generating the molds for soft lithography are commonly designed using AutoCAD and then printed onto transparencies films. The following are design rules you should follow when preparing your microfluidic circuit before submitting it to Stanford Microfluidics Foundry. Also, be sure your design follows the Basic Design Rules.

\section{Mask Specifications}

a) Start by using the mask template provided. This template corresponds to a 4" diameter silicon mold size (recommended size).

b) AutoCAD files should be submitted to the foundry in .dwg format using the version AutoCAD 2000, 2004, or 2007.

c) Ensure that AutoCAD is set to the correct internal units before beginning your design. Under the menu Format -> Units, ensure the following settings:

Length Type: Decimal, Length Precision: 0.0000 Drag-and-drop Scale: Microns

d) Masks can be printed at two approximate resolutions, which results in two different minimum feature sizes possible:

20 000dpi => recommended minimum feature size $15 \mu \mathrm{m}$

40 000dpi $=>$ recommended minimum feature size $8 \mu \mathrm{m}$

e) Each mold (i.e. control and flow) is drawn in a separate AutoCAD layer. If you are creating hybrid molds where you have multiple photoresist heights on a single mold, each photoresist height must be drawn in a separate layer .

f) The AutoCAD file which you submit to the foundry must have all layers in one single file. The layers should be drawn and overlapping as corresponding to your design (you should not separate out individual layers in different areas of the workspace).

\section{General Layout}

a) Try to fit in as many devices as possible onto a single mold. However, ensure there is enough space between chips for adequate bonding and to enable the PDMS to be cut into individual chips (see Basic Design Rules). b) Leave a ring of approximately $0.5 \mathrm{~cm}$ free around the mold perimeter. This area should be void of any design or critical chip area since photoresist uniformity is least reliable around the perimeter of a wafer. 
C) Each layer should have lines or right angle corners indicating where the PDMS should be cut around the perimeter for the devices. Make these cut lines approximately $50 \mu \mathrm{m}$ wide.

d) Masks are printed on 8.5" $\times 11$ " transparency sheets. Therefore, a total of four molds in four quadrants can fit on each sheet. If you have several chip versions which do not fit onto one mold, design a second mold in another quadrant.

\section{Labeling}

a) All layers should have text labels clearly identifying:

\section{Your Name}

\section{Date}

Mold Name

Layer Name (for mulit-height molds, there will be multiple layer names for each mold)

Project Name Version Number

All these labels should be within the perimeter of each mold. The height of the characters in the labels should preferably be such that the letter "L" is at least $650 \mu \mathrm{m}$ high, if space is available.

b) Polyline-based text can be created by copying and pasting (and scaling appropriately) individual characters from either one of these files:

alphabet.dwg (AutoCad 2004 format), or alphabet.dxf (AutoCAD R12 format). You can also use the linetext AutoLisp application to draw text (instructions on how to use the application are in the linetext-readme.txt file included with the application).

c) If you have several chips of different designs on one mold, label each chip by a different name or number, i.e. Chip1, Chip2, etc.

\section{Feature Specifications}

a) All features should be composed of closed polylines or regions.

b) No hatched or filled in features should be created.

c) All polylines or regions that form a single pattern must overlap to avoid any gap between them in the printed mask (i.e. an unintentional gap of $2 \mu \mathrm{m}$ could cause a catastrophic blockage in your fluidic channel)

d) Any pattern corresponding to a thick layer of PDMS that is peeled off the mold for subsequent alignment and bonding onto a patterned thin layer will be scaled up by $1.5 \%$ to compensate for the shrinkage of the PDMS after peeling. However, this will be done by the foundry - do not do this scaling yourself.

\section{Alignment Marks}

\section{- Alignment Marks for Multi-Height Molds}


i) Sets of alignment marks for aligning between multiple layers of photoresist on a single mold should be spaced apart by approximately $6.5 \mathrm{~cm}$ on a 4 inch wafer.

ii) Alignment marks for layers which are composed of positive photoresist should be created using positive_alignment_marks.dwg. Alignment marks for layers which are composed of negative photoresist should be created using negative_alignment_marks.dwg. The positive alignment marks should be centered in the negative alignment marks.

- Alignment Marks for PDMS-PDMS Alignment

Several alignment marks should be placed around the device area. 


\section{B. Fabricating an SU-8 Master Mold from a Transparency}

$$
\text { Mask - (Hans Mayer) }
$$

\section{SOFT LITHOGRAPHY PROCESS NOTES}

THURSDAY, SEPT. 42008

HANS MAYER

$70^{\circ} \mathrm{F}, 56 \%$

TARGET THICKNESS: $10 \mu \mathrm{m}$

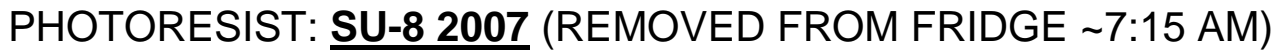

LOT \#07110769, EXP 12/1/2008

SUBSTRATE MAT'L \& SIZE: 4" SILICON WAFER - USED

MASK TYPE: 20,000 DPI TRANSPARENCY - CAD ART SERVICES

(PROVIDED)

\section{STEPS}

1) SUBSTRATE PRE-TREAT (CLEANING)

(PIRANHA HOT PLATE ON AT 8 AM, HOT PLATE SET TO $175^{\circ} \mathrm{C}$ )

START PIRANHA @ 9:20AM

PIRANHA FOR $\sim 15 \mathrm{MIN}=>$ DI QUENCH

BOE FOR $\sim 5 \mathrm{MIN}=>$ DI QUENCH $=>$ DI RINSE

DRY W/ N2

DEHYDRATE BAKE @ 205ㅇ FOR 10 MIN

ALLOW TO COOL FOR 5 MIN

2) COAT (SPIN COAT PHOTORESIST)

FOIL COATED?

PROGRAM DESTINATION: I

SPREAD CYCLE: 20 SEC, 400 RPM, 86 RPM/SEC

SPIN CYCLE: 35 SEC, 1500 RPM, 602 RPM/SEC

(SAME AS TEST WAFER FROM EARLY JULY)

3) SOFT BAKE

RECOMMENDED: $95^{\circ} \mathrm{C}$ FOR 2-3 MIN

TRY FOR $85^{\circ} \mathrm{C}$ FOR 3-4 MIN

NOTES: A FEW DEFECTS (PIN HOLES)

VERY SLIGHT STREAKING PATTERN VISIBLE

COOL DOWN: 4 MIN 
(ON WIPE)

4) EXPOSURE (ALIGNER LAMP TURNED ON AT 8:50 AM) USED AT:

FOR MANUAL EXPOSURE: PRESS 'STOP’ THEN 'UNIFORMITY'

EXPOSE FOR 100 SEC ( $1 \mathrm{MIN}, 40$ SEC) (USE FILTER!)

PATTERN NOT VISIBLE AFTER EXPOSURE

5) POST EXPOSURE BAKE

RECOMMENDED: $95^{\circ} \mathrm{C}$ FOR 3-4 MIN

TRY FOR $85^{\circ} \mathrm{C}$ FOR 4-5 MIN

SEE PATTERN? 1:40 IT IS BARELY VISIBLE COOL DOWN: $10 \mathrm{MIN}$

(ON WIPE)

6) DEVELOP

RECOMMENDED TIME: 2-3 MIN. START WITH THIS

3 MINS - DEVELOPER WASH

NOTES: SMALL CRACKS

HARD BAKE

15 MIN @ 207º 


\section{Preparation and Processing of PDMS for Device}

\section{Fabrication}

Polydimethylsiloxane (PDMS) is the main component of the microfluidic device since it contains the necessary features and channel walls. The PDMS is poured over a master mold that contains extruded SU-8 features and is peeled off upon hardening, leaving the necessary components of the device. In order to create devices from the master mold, the PDMS must be prepared and processed accordingly to achieve the best results of stiffness, opacity, and shape. The following procedures are the steps necessary to create the PDMS component of a microfluidic device from a fabricated SU-8 mold wafer.

NOTE: PDMS preparation can be a messy process, it is recommended to wear two-layers of gloves and dispose of the first layer when the PDMS mixing procedure is completed.

Materials and Equipment:

- Sylgard 184: Curing Agent and Base

- SU-8 Master Mold Silicon Wafer

- 2 Plastic Syringes (10 mL and $3 \mathrm{~mL}$ )

- Stir Bar

- Scalpel

- Mixing Cup

- Aluminum Foil 
- Vacuum Chamber (Cal Poly Microfabrication Lab)

- Heating oven within a $65^{\circ} \mathrm{C}$ range

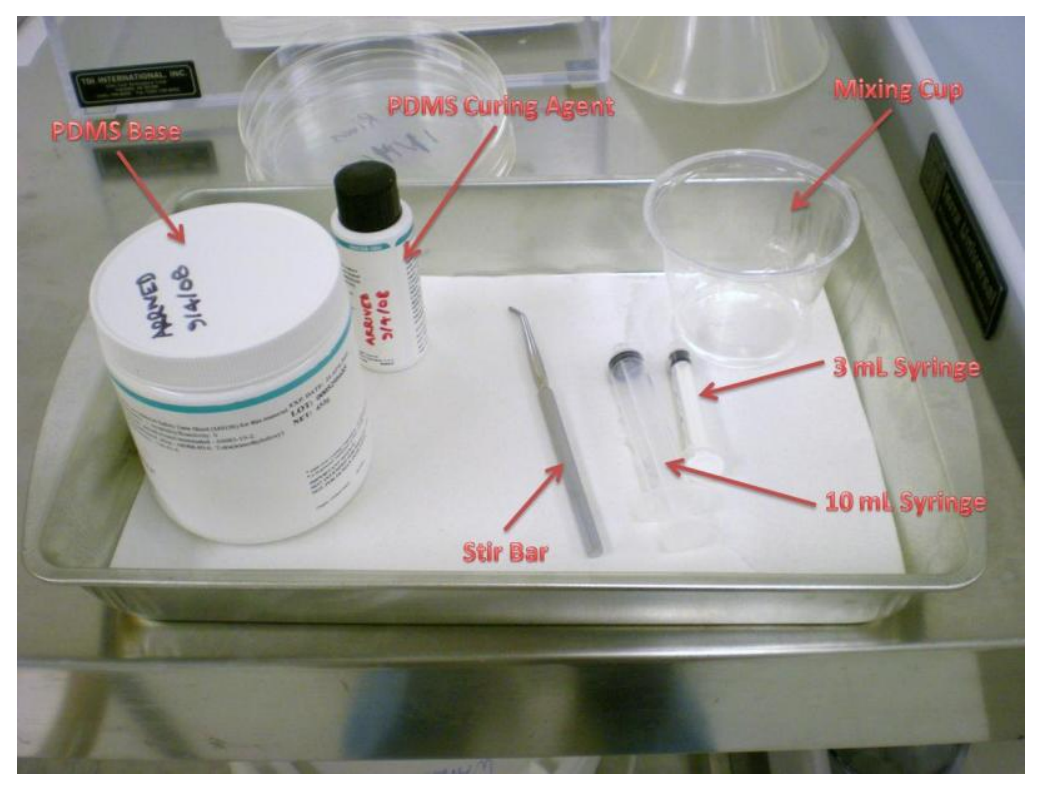

Figure 47 - PDMS Preparation Materials

\section{Procedures:}

1. Obtain your wafer and place it into a customized flat aluminum foil dish.

This can be achieved by laying a Petri dish of the same approximate diameter of your silicon wafer on top two layers of aluminum and wrapping the foil along the edges to create a circular tub-shape. Remove the Petri dish and place the wafer on top of the foil dish. 


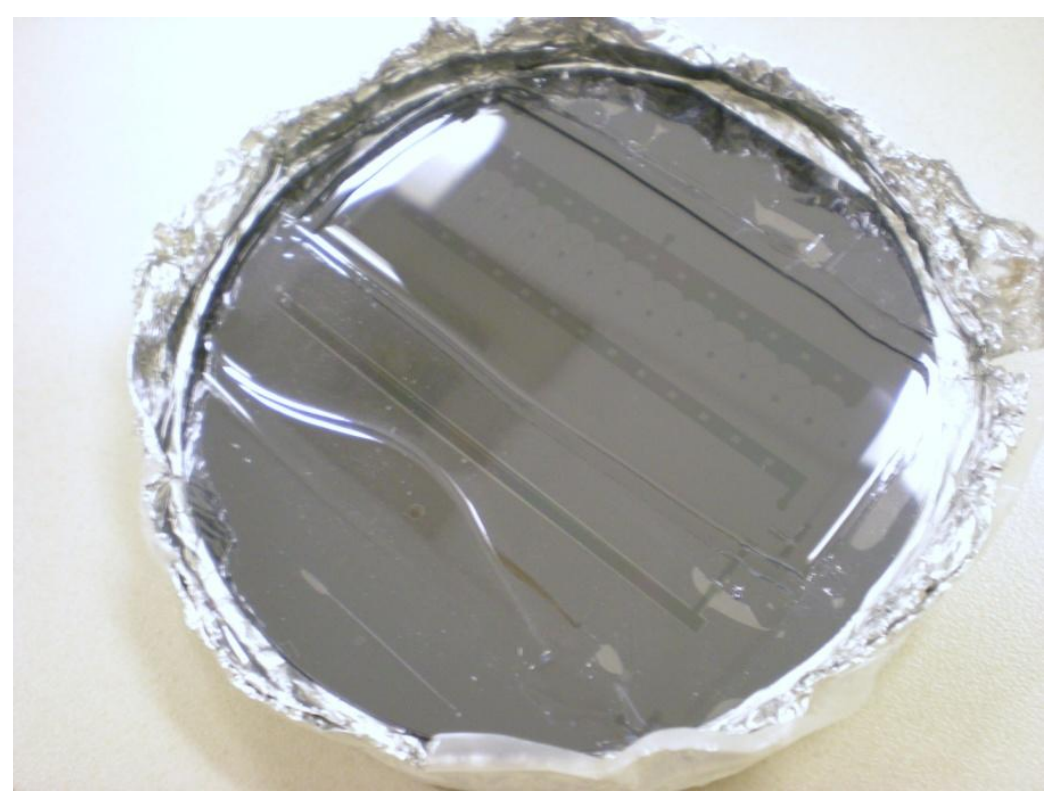

Figure 48 - SU-8 Wafer in an Aluminum Foil Dish for PDMS Pouring

2. Measure the area of the dish and convert the measurement to a volume depending on the desired device thickness.

a. Example: A 4" $(10.16 \mathrm{~cm})$ diameter wafer in a $4.5 "(11.43 \mathrm{~cm})$ foil dish will be used to obtain a $1 / 4 "(0.635 \mathrm{~cm})$ thick device.

b. The volume will be calculated in $\mathrm{mL}$ :

$$
\begin{gathered}
\text { Area }=\frac{\pi D^{2}}{4}=\frac{\pi(11.43 \mathrm{~cm})^{2}}{4}=102.6 \mathrm{~cm}^{2} \\
\text { Volume }=\left(102.6 \mathrm{~cm}^{2}\right)(0.635 \mathrm{~cm})=65.2 \mathrm{~cm}^{3}=\sim 65 \mathrm{~mL}
\end{gathered}
$$

3. Obtain the PDMS package (Sylgard 184) containing the "base" (larger cylinder) and "curing agent" (thin cylinder).

4. Using a 10:1 ratio mixture rule of base and curing agent, use the $10 \mathrm{~mL}$ syringe to extract the base, the $3 \mathrm{~mL}$ syringe for the curing agent, and pour into the mixing cup. Do not mix up the syringes. 
a. From the example, extract 6 sets from the $10 \mathrm{~mL}$ syringe (total of $60 \mathrm{~mL}$ ) of the base liquid. Then extract a set of $3 \mathrm{~mL}$ then a set 2 $\mathrm{mL}$ from the $3 \mathrm{~mL}$ syringe (total of $5 \mathrm{~mL}$ ).

b. Note: An increase in the curing agent of the mixture will create a stiffer PDMS material after hardening while a decrease will yield the reverse effect.

5. Using the stir bar, mix the PDMS mixture in a circular fashion for approximately 100 wicks. The mixture will contain many bubbles.

6. The bubbles must be removed or the PDMS will yield a different opacity. This can be done be degassing the mixture cup in a vacuum chamber. Insert the mixture cup into the vacuum chamber and seal the chamber by close the lid.

a. Turn on the vacuum chamber's power generator.

b. Turn the generator valve open to allow flow from the pipe to the chamber. 


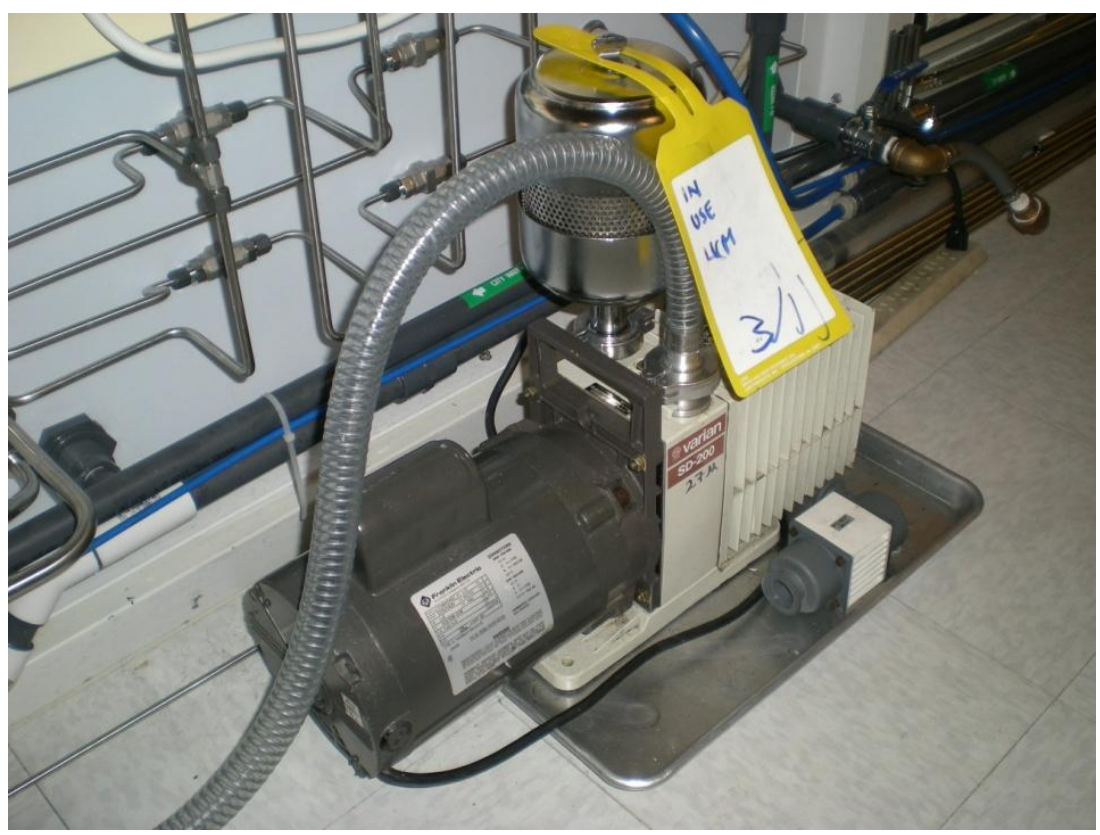

Figure 49 - Vacuum Chamber Power Generator

7. Turn the chamber valve on and wait till the gauge reads $-28 \mathrm{inHg}(-95$ $\mathrm{kPa}$ ). The mixture cup will begin to bubble and the level will rise. The vent knob should be closed, allowing the pressure to build in the chamber

8. Twist the vent knob counter-clockwise to release pressure in the chamber until the bubble level stabilizes. This bubble level should be almost twice the height of the mixture layer.

9. Allow the bubbles to vent for 20 minutes or until the mixture contains no bubbles. Turn the vent knob accordingly so that the bubble level continues to stabilize. 


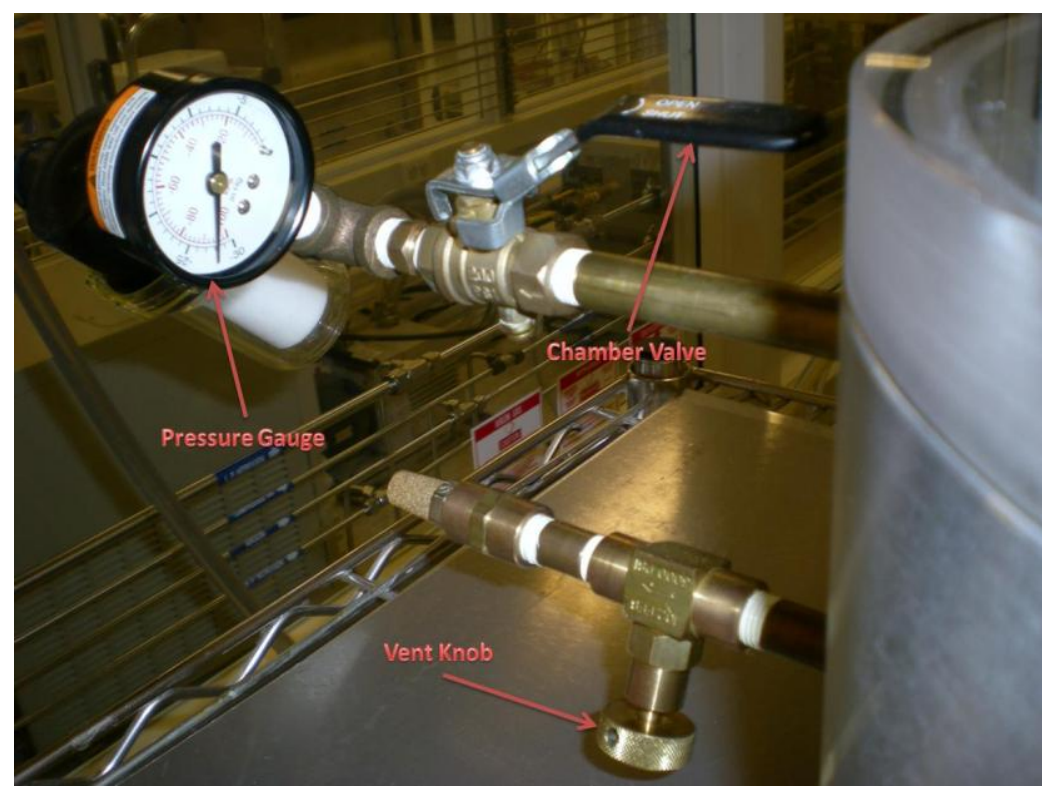

Figure 50 - Vacuum Chamber Controls

10. While waiting, turn on and preheat the heating oven to 65 degrees Celsius.

11. When all or most of the bubbles have vented from the mixture cup, turn off the chamber valve and twist the vent knob to allow excess pressure to escape. The lid should be easy to open if all the pressure has been released. Remove the mixture cup. 


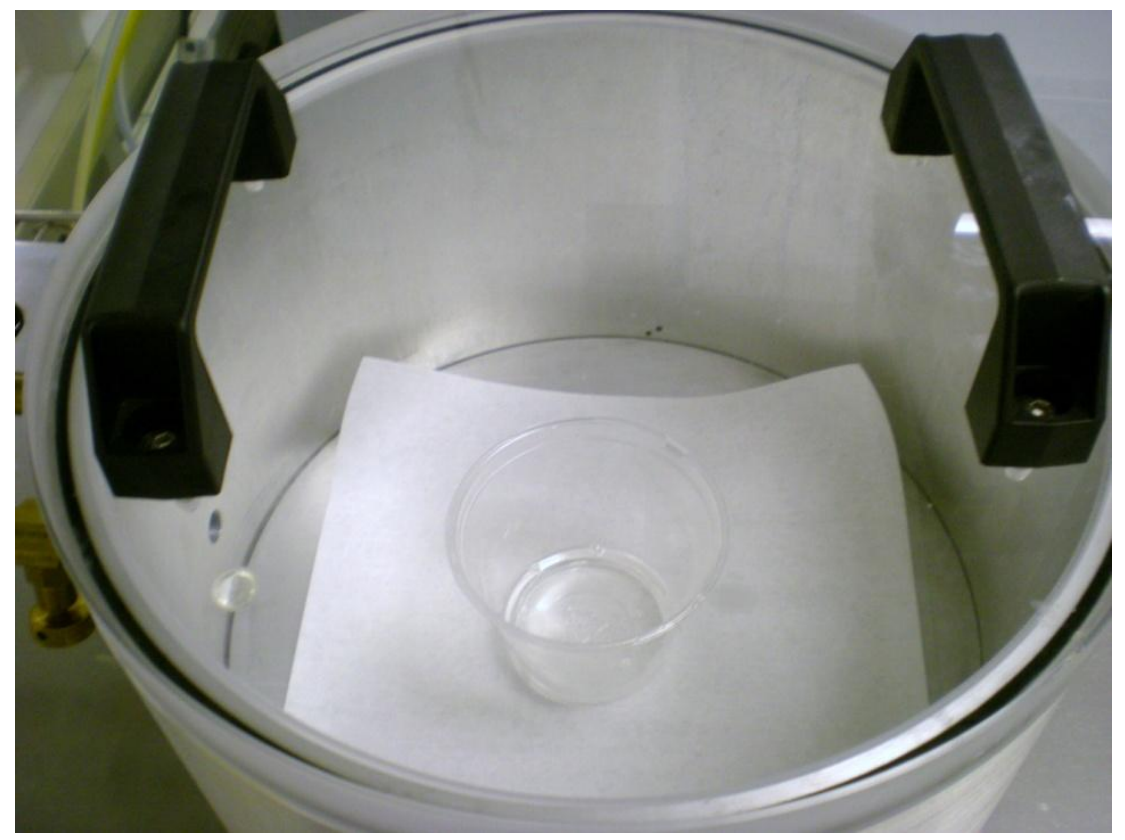

Figure 51 - Degassed Mixing Cup of PDMS in a Vacuum Chamber

12. Prepare the SU-8 master mold wafer. If the wafer had already been used to create PDMS, trim excess PDMS, rinse with DI water, and carefully dry with nitrogen gas.

13. Pour the PDMS mixture directly center to the SU-8 master mold and slowly allow the mixture to fill the edges by pouring within the PDMS paths. Do not pour PDMS beyond the expanding center or bubbles will form. 


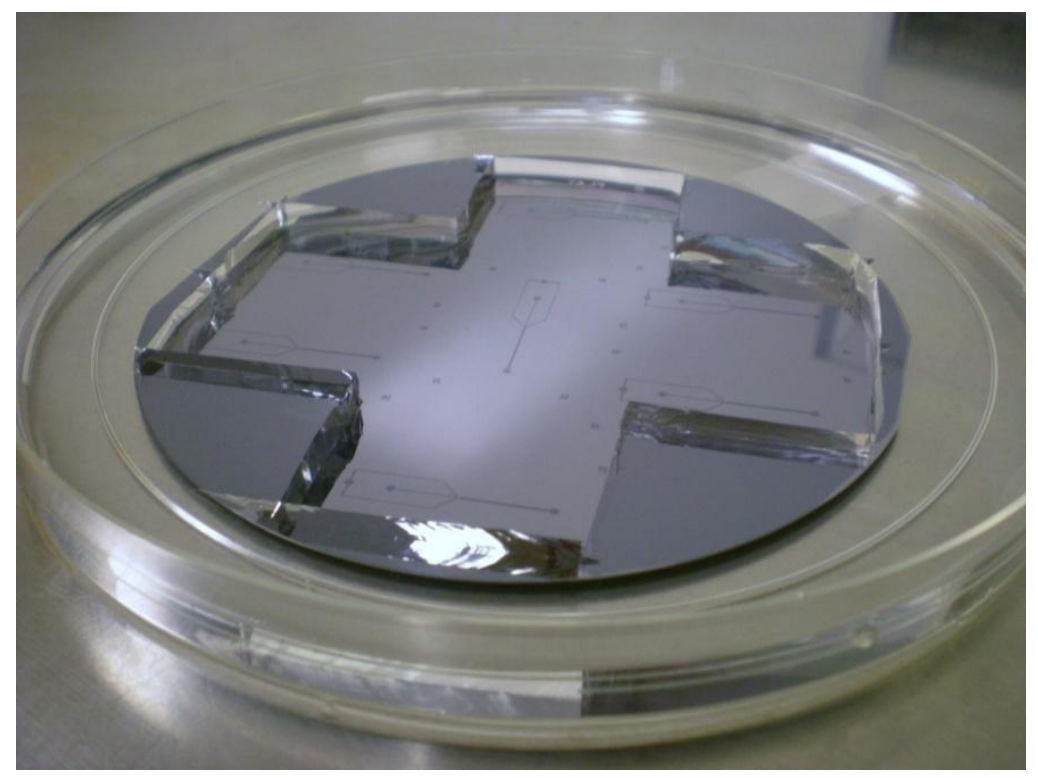

Figure 52 - Trimmed PDMS-Wafer Mold Prepped for PDMS Pouring

14. When the entire mixture is used and the edges are filled, inspect the wafer if any major bubbling has occurred. Small bubbles will eventually vent but if an excess of bubbles are present, repeat the venting chamber process with the PDMS on the SU-8 wafer. Vent for a short time until the remaining bubbles have dissipated.

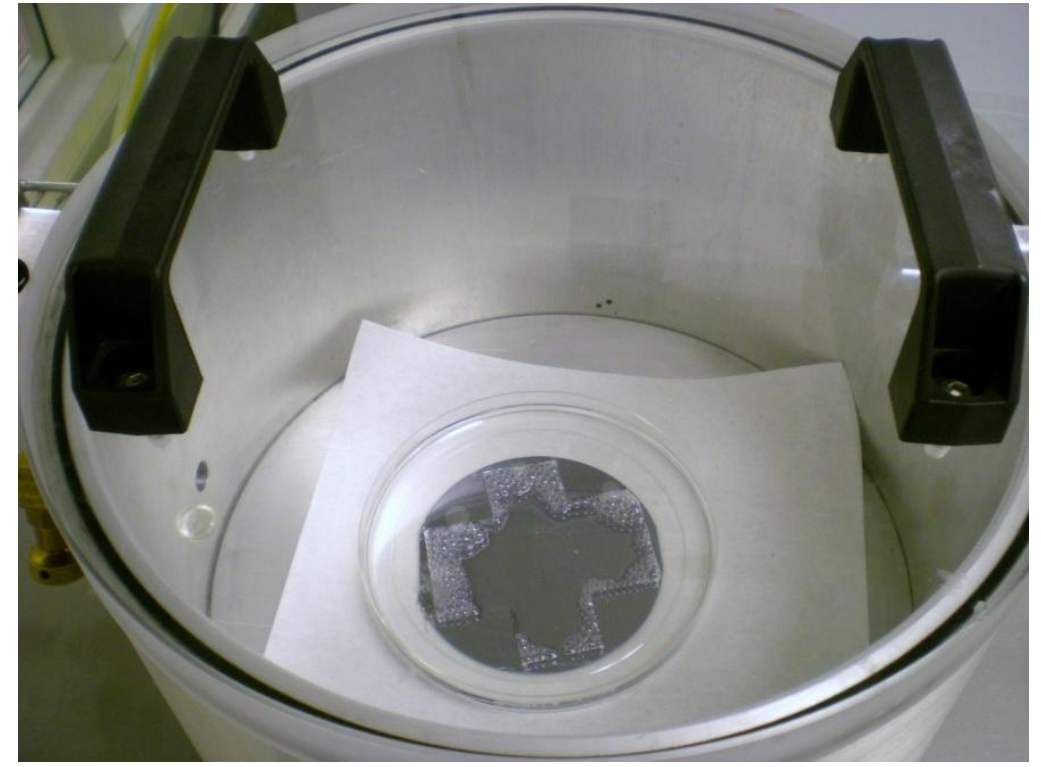

Figure 53 - Degassing the PDMS-Wafer 
15. Carefully take the PDMS-wafer to the heating oven of 65 degrees Celsius and allow the PDMS-wafer to bake for approximately one hour.

16. Remove the PDMS-wafer from the oven and ensure that the PDMS layer has hardened. Take the PDMS-wafer to a work bench.

17. Using a scalpel, identify the separate devices through the borderlines or alignment markers. Carefully insert the scalpel into the PDMS while avoiding contact with the wafer layer.

18. Hold the scalpel as vertical as possible and move in straight line to cut until you have reached the edge of the device. Do not attempt to reach the wafer layer or the layer may crack due to stress.

a. Note: To verify a through-cut, look for an internal spacing that appears while cutting. This spacing indicates a removal of the PDMS layer from the wafer layer. Do not touch the wafer layer while cutting.

19. Repeat the cuts until all sides of a device have been trimmed. Verify that each side has a complete through-cut.

20. Using the edge of the scalpel, push against the PDMS block and carefully grip the trimmed PDMS. Slowly peel off the PDMS, remove it from the PDMS-wafer dish, and place the PDMS device (features-side up) onto a Petri dish.

21. Continue to remove other PDMS device sections until the all the devices have been removed. Unused PDMS sections that do not contain device features can remain intact in the wafer dish. 
22. Repeat the PDMS process to create more sample devices.

\section{Assembling a Fluid Circuit using LabSmith MicrofluidicComponents}

A fluid circuit is a collection of pathways that combine the sample introduction, capture suction, flushing, ventilation, and rinsing controls. Using Tvalves and crosses, a circuit can be designed to integrate with our device and perform the necessary procedures to 1) introduce a cell sample, 2) create a suction pressure to trap the cell, 3) perform a flushing action to isolate the cell from excess stacking, 4) push the cell within a distance in the cell chamber to position the cell, 5) rinse away the sample solution in the device.

The fluid circuit was constructed by parts from the LabSmith Microfluidics

Component Starter Kit. The kit contains an Acrylic Breadboard, Capillary Tubing, T-Valves, Crosses, Bonded Port Connectors, One-Piece Ferrule Fittings, Ferrule Plugs, and Luer-lock Adapters. Using the parts provided in the kit, the procedures will document how to integrate the chip with the fluid circuit. Materials and Equipment:

- $3 m$ of Capillary Tubing

- Customized Acrylic Breadboard

- 3 T-Valves

- 6 Set Screws

- 3 Bonded Port Connectors

- 8 Ferrule Fitting 
- 1 Ferrule Fitting Plug

- 3 Luer-lock Adapters

- Epoxy Mixture and Toothpicks

- Precision Capillary Column Cutting Tool

\section{Procedures:}

1. In order to concurrently control the fluid circuit fixtures and image the device under test, the acrylic breadboard will be customized so that the device will be affixed in a spacing aimed center of the breadboard by a through-hole and ensures that the device is within the proper range of the microscopes focal distance. The breadboard is also helpful because it contains holes to screw in fixtures close to the device. The shape of this hole is a cross with 1" $\times 3$ " and 2" $\times 3$ " dimensions.

2. Screw in one T-Valve at the top of the cross and two T-Valves at the bottom left and right sides of the cross. The spacing between the device and valves should be enough that it will not over bend the tubing that will be attached.

3. Using the Capillary Column Cutter, trim six pieces of various lengths depending on the distances from a device inlet/outlet port to T-Valves and distances from the syringe pumps to T-valves.

4. The first tubing set will join the t-valves to the syringes (Tubing Set \#1 Syringe-to-Valve, Qty: 3). 
a. Insert the one-piece ferrule fittings on both sides of the capillary tube. The tubing should go through the entire ferrule if inserted correctly.

b. Attach one side of the ferrule to the Luer-lock adapter. Verify that the capillary tube is inside the Luer-lock adapter.

c. Attach the Luer-lock adapter to a syringe either through the Luerlock threading or by a press-fit, depending on the type of syringe used.

d. Insert the opposite ferrule to a T-valve by hand tightening the thread first and then using the torque wrench in a half-rotation.

NOTE: Do not over turn with the torque wrench or the ferrule will snap off.

e. Verification of a tight seal can be accomplished by gently pulling the capillary tube. The tube should not slip if tightened correctly.

5. The additional capillary tubing set (Tubing Set \#2 - Valve-to-Device, Qty: 3) will be attached from the device to one of the pathways of the T-valve.

a. Ensure that the additional tubing is long enough and has two ferrules attached on both sides, similar to Step 4.a.

b. Prepare the epoxy mixture by mixing a 2:1 ratio of the white base and yellow agent, respectively. Use a tooth pick for mixing and application.

c. Screw in the ferrule to the bonded port connector and verify that a small length of tubing sticks out from the bottom of the connector. 
Verify that the tubing is pressure locked in by gently pulling the tube.

d. Insert this end directly into an inlet/outlet port of the PDMS device. Verify that the bonded port connector is level with the PDMS layer and that a short length of tubing goes directly into the device.

e. Apply a small amount of mixed epoxy around the bonded port connector. The epoxy should be as concentric with the connector as possible.

f. Verify that there is contact between the connector, epoxy and PDMS layer by looking at the device from the glass bottom. The epoxy should surround the components and be "leak-free".

g. Allow the epoxy to fully dry by placing the device and tube components (device/tubing/connectors/ferrules only) in an oven set to $65^{\circ} \mathrm{C}$ and let dry for one hour. Alternatively, you may apply epoxy and allow drying for one day at room temperature.

h. Once dried, the opposite end of the tube can now be attached to the opposite pathway of the t-valve using the same method in Step

\section{4.d.}




\section{E. Cell Introduction Protocol}

Cell Introduction is a critical step in microfluidic testing and must be followed accordingly.

1. The following syringes should be filled with the respective amounts:

a. Syringe \#1 - 3cc syringe $-0.1 \mathrm{~mL}$ of $1: 10$ cell solution and buffer

i. Used to inject cell sample into the device

b. Syringe \#2 - 10cc syringe $-5 \mathrm{~mL}$ of buffer solution

i. Used to inject buffer solution for cell flushing

c. Syringe \#3 - 10cc syringe - empty

i. Used to create a suction for cell trapping

2. The T-valves should be set to their following positions

a. T-Valve \#1 - (ON - routes to device) / (OFF - routes to waste)

b. T-Valve \#2 - NOT USED

c. T-Valve \#3 - (ON - routes to device) / (OFF - routes to vent)

3. Attach the syringes to the respective valves as shown in Figure 45 and mount the syringe to a syringe pump

4. Set Syringe Pump \#1 (Inlet) to $1.0 \mu \mathrm{L} / \mathrm{min} \mathrm{PUSH}$, Syringe Pump \#2 (Flush) to $1.5 \mu \mathrm{L} / \mathrm{min} \mathrm{PUSH}$, and Syringe Pump \#3 (Suction) to 1.0 $\mu \mathrm{L} / \mathrm{min}$ PULL.

5. Turn Syringe Pump \#2 ON and allow the device to completely fill with buffer solution. The Inlet T-valve \#1 should be OFF, routing fluid away 
from the device; and the Suction T-valve should be ON, which acts as a plug. Turn OFF when fluid appears to be exiting the waste tube.

6. Set the T-Valve \#3 OFF and turn T-Valve \#1 ON. Set Syringe Pump \#1 $\mathrm{ON}$ and wait until cells are injected into the chamber.

7. When cells appear to stack in the chamber assay, turn Syringe Pump \#1 OFF and set T-valve \#1 OFF.

8. Turn T-Valve \#3 and Syringe Pump \#3 ON to create suction in the cell chamber. Turn Syringe Pump \#2 ON to create the flush. Excess fluid should be exiting T-Valve \#1 to waste. Leave this action ON until a single-cell isolated and analyzed.

9. To release the cell, set Syringe Pump \#3 to PUSH and wait until the single-cell is released. Turn Syringe Pump \#3 back to PULL and set OFF.

10. Repeat Steps 6 through 9 to capture another cell.

11. To rinse the device. Set Syringe Pump \#2 ON and set Syringe Pump \#3 to PUSH and turn Valve \#3 ON. T-Valve \#1 should still be ON to allow waste to exit the device. Continue until device is approximately free of particles. 


\section{F. Statistical Results of Cell Samples}

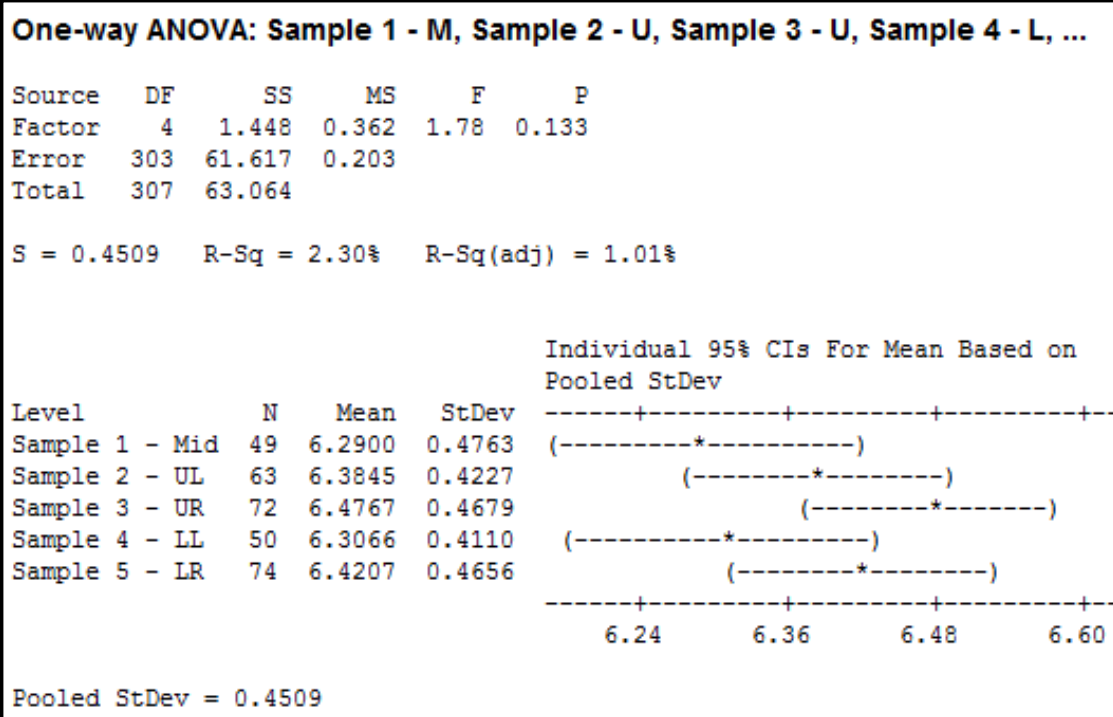

\section{Boxplot of Sample 1 - M, Sample 2 - U, Sample 3 - U, Sample 4 - L, ...}

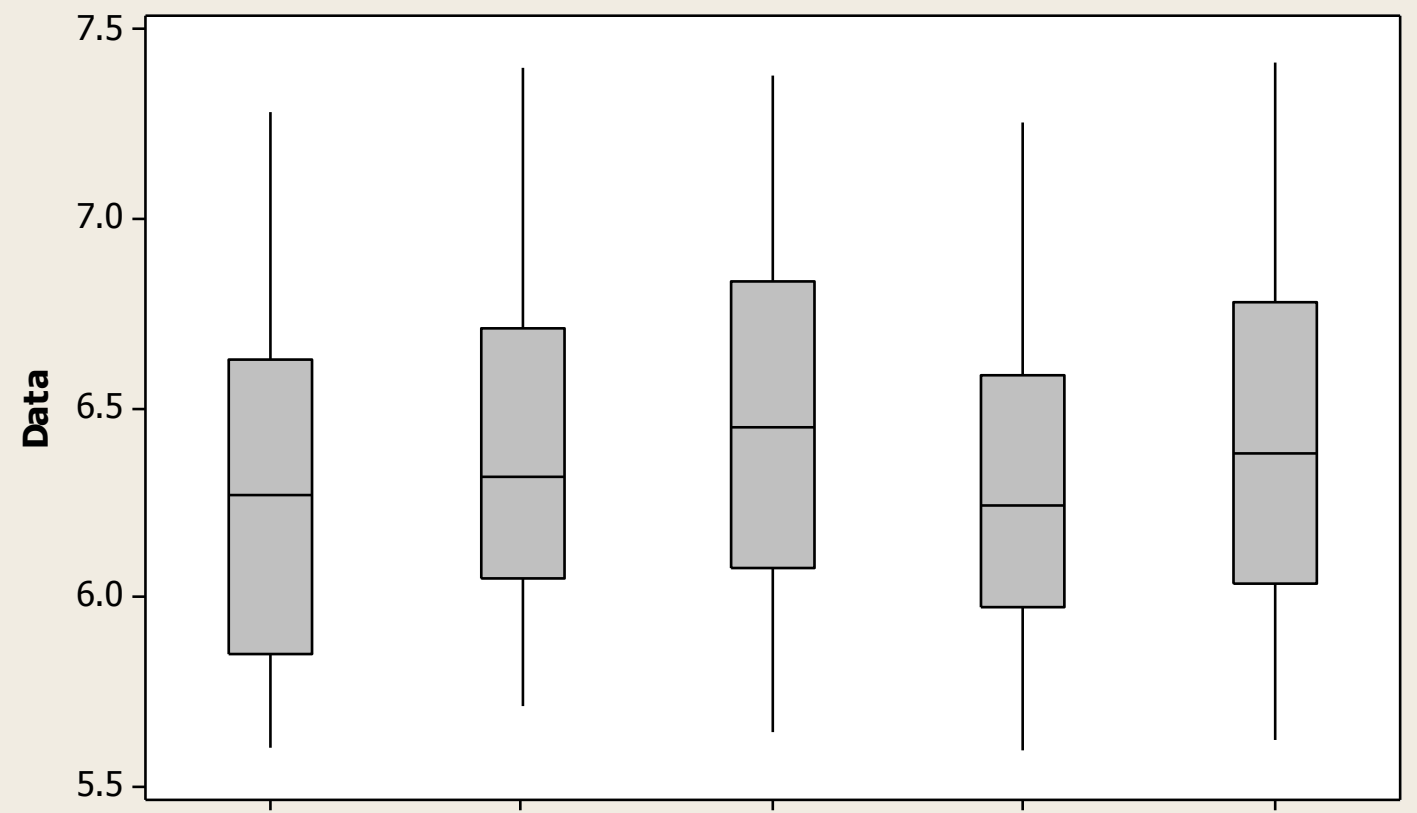

Sample 1 - Mid Sample 2 - UL Sample 3 - UR Sample 4- LL Sample 5 - LR 

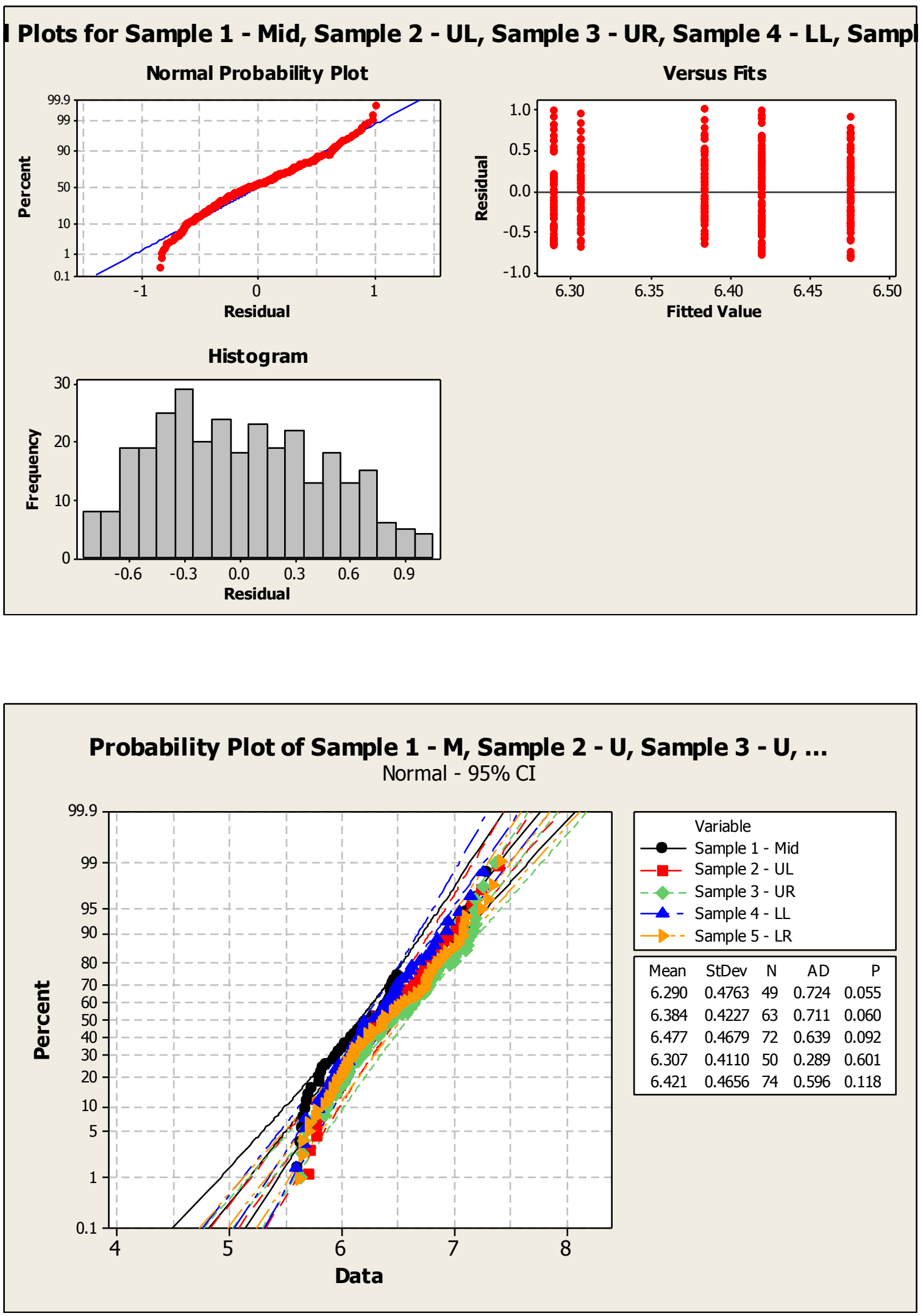


\section{References}

1. Chao, T.C. and A. Ros, Microfluidic single-cell analysis of intracellular compounds. J R Soc Interface, 2008. 5 Suppl 2: p. S139-50.

2. Chen, C.S., et al., Micropatterned surfaces for control of cell shape, position, and function. Biotechnol Prog, 1998. 14(3): p. 356-63.

3. Endo, T., et al., Design and fabrication of cell alignment device based on electrolytically-generated air bubbles, and its practical realization using polystyrene microbeads. Microchimica Acta, 2008. 164(3-4): p. 263-268.

4. Choi, J.W., et al., Electrochemical detection of pathogen infection using cell chip. Environ Monit Assess, 2007. 129(1-3): p. 37-42.

5. Ionescu-Zanetti, C., et al., Mammalian electrophysiology on a microfluidic platform. Proc Natl Acad Sci U S A, 2005. 102(26): p. 9112-7.

6. Khine, M., et al., A single cell electroporation chip. Lab Chip, 2005. 5(1): p. 38-43.

7. Medoro, G., et al., A Lab-on-a-Chip for Cell Detection and Manipulation. IEEE Sensors Journal, 2003. 3(3): p. 317-325.

8. Voldman, J., et al., A microfabrication-based dynamic array cytometer. Anal Chem, 2002. 74(16): p. 3984-90.

9. Tang, H. and Y. Gao, An Impedance Microsensor With Coplanar Electrodes and Vertical Sensing Apertures. IEEE Sensors Journal, 2005. 5(6): p. 1346-1352.

10. Iliescu, A., et al., A microfluidic device for impedance spectroscopy analysis of biological samples. Sensors and Actuators B, 2007. 123: $p$. 168-176.

11. Gawad, S., L. Schild, and P.H. Renaud, Micromachined impedance spectroscopy flow cytometer for cell analysis and particle sizing. Lab Chip, 2001. 1(1): p. 76-82.

12. Wise, K.D. and K. Najafi, Microfabrication techniques for integrated sensors and microsystems. Science, 1991. 254(5036): p. 1335-42.

13. Ayliffe, H. and A. Frazier, Electric Impedance Spectroscopy Using Microchannels with Integrated Metal Electrodes. IEEE Journal of Microelectromechanical Systems, 1999. 8(1): p. 50-57.

14. Cheung, K., S. Gawad, and P. Renaud, Impedance spectroscopy flow cytometry: on-chip label-free cell differentiation. Cytometry A, 2005. 65(2): p. 124-32.

15. Kijlstra, J., R. Wegh, and H. van Leeuwen, Impedance spectroscopy of colloids. Journal of Electroanalytical Chemistry, 1994. 366: p. 37-42.

16. Lennon, E., et al., Integration of three-dimensional microelectrodes in microfluidic biochip for electric field based processing of biological species: application to electrical impedance spectroscopy, in The 13th International Conference on Solid-State Sensors, Actuators, and Microsystems. 2005: Seoul, Korea. p. 1724-1727. 
17. Senez, V., et al., Evaluation of Electric Impedance Spectra for Single BioCells in Microfluidic Devices using Combined FEMLAB/HSPICE Simulated Models. Seisan Kenkyu, 2004. 56(1): p. 97-100.

18. Wu, J. and H. Chang. Micro-electrical impedance spectroscopy for particle detection. in Proc ASME 2nd Int Conf Micro Mini. 2004. Rochester, New York, USA.

19. Jang, L.S. and M.H. Wang, Microfluidic device for cell capture and impedance measurement. Biomed Microdevices, 2007. 9(5): p. 737-43.

20. Xia, Y. and G.M. Whitesides, Soft Lithography. Angew Chem Int Ed Engl, 1998. 37(5): p. 55-575.

21. Wang, W. and S. Soper, Bio-MEMS: Technologies and Applications, ed. W. Wang and S. Soper. 2007, Boca Raton: CRC Press.

22. Liou, W.W. and Y. Fang, Microfluid Mechanics: Principles and Modeling. Nanoscience and Technology Series. 2006, New York: McGraw-Hill.

23. Oddy, M.H., J.G. Santiago, and J.C. Mikkelsen, Electrokinetic instability micromixing. Anal Chem, 2001. 73(24): p. 5822-32.

24. Abidin, Z. and G.H. Markx, High-gradient electric field system for the dielectrophoretic seperation of cells. Journal of Electrostatics, 2005. 63: p. 823-830.

25. Chovan, T. and A. Guttman, Microfabricated devices in biotechnology and biochemical processing. Trends Biotechnol, 2002. 20(3): p. 116-22.

26. Park, J. and R. Lakes, Biomaterials: An Introduction. 2007, New York: Springer.

27. Bashir, R., BioMEMS: state-of-the-art in detection, opportunities and prospects. Adv Drug Deliv Rev, 2004. 56(11): p. 1565-86.

28. McDonald, J.C. and G.M. Whitesides, Poly(dimethylsiloxane) as a material for fabricating microfluidic devices. Acc Chem Res, 2002. 35(7): p. 491-9.

29. Melin, J. and S.R. Quake, Microfluidic large-scale integration: the evolution of design rules for biological automation. Annu Rev Biophys Biomol Struct, 2007. 36: p. 213-31.

30. Linder, V., et al., Rapid prototyping of 2D structures with feature sizes larger than 8 microm. Anal Chem, 2003. 75(10): p. 2522-7.

31. McDonald, J.C., et al., Fabrication of microfluidic systems in poly(dimethylsiloxane). Electrophoresis, 2000. 21(1): p. 27-40.

32. Weibel, D.B., W.R. Diluzio, and G.M. Whitesides, Microfabrication meets microbiology. Nat Rev Microbiol, 2007. 5(3): p. 209-18.

33. Squires, T.M. and S.R. Quake, Microfluidics: Fluid physics at the nanoliter scale. Reviews of Modern Physics, 2005. 77(3): p. 977-1026.

34. Stone, H.A., A.D. Stroock, and A. Ajdari, Engineering Flows in Small Devices: . Annu Rev Fluid Mech, 2004. 36: p. 381-411.

35. Beebe, D.J., G.A. Mensing, and G.M. Walker, Physics and applications of microfluidics in biology. Annu Rev Biomed Eng, 2002. 4: p. 261-86.

36. Hsu, T., MEMS \& Microsystems: Design, Manufacture, and Nanoscale Engineering. 2008, Hoboken, New Jersey: John Wiley \& Sons, Inc.

37. Waite, L. and J. Fine, Applied Biofluid Mechanics. 2007, New York: McGraw-Hill. 
38. Happel, J. and H. Brenner, Low Reynolds Number Hydrodynamics: with Special Applications to Particulate Media. 1965, Englewood Cliffs:

Prentice-Hall.

39. Schmukler, R., et al. Electrical impedance of living cells: a modified four electrode approach. in Proceedings of the Annual International Conference of the IEEE. 1988.

40. Maswiwat, K., D. Wachner, and J. Gimsa, Effects of cell orientation and electric field frequency on the transmembrane potential induced in ellipsoidal cells. Bioelectrochemistry, 2008. 74(1): p. 130-41.

41. Patel, P., A. Bhat, and G.H. Markx, A comparative study of cell death using electrical capacitance measurements and dielectrophoresis.

Enzyme and Microbial Technology, 2008. 43(7): p. 523-530.

42. Yang, L., C. Ruan, and Y. Li, Detection of viable Salmonella typhimurium by impedance measurement of electrode capacitance and medium resistance. Biosens Bioelectron, 2003. 19(5): p. 495-502.

43. Probstein, R.F., Physicochemical Hydrodynamics: An Introduction. 2nd ed. 2003, Hoboken: John Wiley \& Sons.

44. Gawad, S., et al., Dielectric spectroscopy in a micromachined flow cytometer: theoretical and practical considerations. Lab Chip, 2004. 4(3): p. 241-51.

45. Tuite, M.F. and S.G. Oliver, Saccharomyces. Biotechnology Handbooks, ed. T. Atkinson and R.F. Sherwood. Vol. 4. 1991, New York: Plenum Press.

46. Verpoorte, E., Beads and chips: new recipes for analysis. Lab Chip, 2003. 3(4): p. $60 \mathrm{~N}-68 \mathrm{~N}$.

47. Cabrera, C.R., B. Finlayson, and P. Yager, Formation of natural pH gradients in a microfluidic device under flow conditions: model and experimental validation. Anal Chem, 2001. 73(3): p. 658-66.

48. Dougherty, G.M., et al., The zeta potential of surface-functionalized metallic nanorod particles in aqueous solution. Electrophoresis, 2008. 29(5): p. 1131-9.

49. Macounova, K., et al., Generation of natural $\mathrm{pH}$ gradients in microfluidic channels for use in isoelectric focusing. Anal Chem, 2000. 72(16): $p$. 3745-51.

50. Borzani, W. and M.L. Vairo, Quantitative adsorption of methylene blue by dead yeast cells. J Bacteriol, 1958. 76(3): p. 251-5.

51. Sami, M., M. Ikeda, and S. Yabuuchi, Evaluation of the alkaline methylene blue staining method for yeast activity determination. Journal of Fermentation and Bioengineering, 1994. 78(3): p. 212-216.

52. Johnston, G.C., et al., Regulation of cell size in the yeast Saccharomyces cerevisiae. J Bacteriol, 1979. 137(1): p. 1-5.

53. Schulte, T.H., R.L. Bardell, and B.H. Weigl, Microfluidic technologies in clinical diagnostics. Clin Chim Acta, 2002. 321(1-2): p. 1-10.

54. de Mello, A.J. and N. Beard, Dealing with real samples: sample pretreatment in microfluidic systems. Lab Chip, 2003. 3(1): p. 11N-19N. 
55. Lim, D.V., et al., Current and developing technologies for monitoring agents of bioterrorism and biowarfare. Clin Microbiol Rev, 2005. 18(4): $p$. 583-607.

56. Clague, D.S. and E.K. Wheeler, Dielectrophoretic manipulation of macromolecules: the electric field. Phys Rev E Stat Nonlin Soft Matter Phys, 2001. 64(2 Pt 2): p. 026605.

57. Liang, E., R.L. Smith, and D.S. Clague, Dielectrophoretic manipulation of finite sized species and the importance of the quadrupolar contribution. Phys Rev E Stat Nonlin Soft Matter Phys, 2004. 70(6 Pt 2): p. 066617.

58. Jones, T.B., Electromechanics of Particles. 1995, New York: Cambridge University Press. 